\title{
OPTIMALITY AND EQUILIBRIUM IN A COMPETITIVE INSURANCE MARKET UNDER ADVERSE SELECTION AND MORAL HAZARD
}

\author{
Joseph Stiglitz \\ Jungyoll Yun \\ Working Paper 19317 \\ http://www.nber.org/papers/w19317
NATIONAL BUREAU OF ECONOMIC RESEARCH
1050 Massachusetts Avenue
Cambridge, MA 02138

August 2013

Financial support from the Institute for New Economic Thinking (INET) is gratefully acknowledged. The views expressed herein are those of the authors and do not necessarily reflect the views of the National Bureau of Economic Research.

NBER working papers are circulated for discussion and comment purposes. They have not been peerreviewed or been subject to the review by the NBER Board of Directors that accompanies official NBER publications.

(C) 2013 by Joseph Stiglitz and Jungyoll Yun. All rights reserved. Short sections of text, not to exceed two paragraphs, may be quoted without explicit permission provided that full credit, including $\odot$ notice, is given to the source. 
Optimality and Equilibrium In a Competitive Insurance Market Under Adverse Selection and Moral Hazard

Joseph Stiglitz and Jungyoll Yun

NBER Working Paper No. 19317

August 2013

JEL No. D86

\begin{abstract}
This paper analyzes optimal and equilibrium insurance contracts under adverse selection and moral hazard, comparing them with those under a single informational asymmetry. The complex interactions of self-selection and moral hazard constraints have important consequences. We develop an analytic approach that allows a characterization of equilibrium and optimal (Pareto Optimal (PO), and Utilitarian optimal (UO)) allocations. Among the results : (i) a PO allocation may involve "shirking" (not only less care in accident avoidance than is possible, but less care compared to the case of pure moral hazard) either by high risk individuals in the case of single-crossing preference or by one or both types in the case of multi-crossing preference (as may naturally be the case under the double informational asymmetry); and (ii) while an equilibrium, which is unique (even under multi-crossing preferences) if it exists, is more likely to exist as the non-shirking constraint for low-risk type gets more stringent (i.e. when low risk individuals shirk with lower levels of insurance). We also show that a pooling equilibrium, which is not feasible under pure adverse selection, may exist when individuals differ in risk aversion (as well as in accident probability) or when the provision of insurance is non-exclusive (i.e. individuals can purchase insurance from more than one firm). Furthermore, while with pure adverse selection, UO always entails pooling with complete insurance (in the standard model), with adverse selection and moral hazard, all PO allocations may entail separation and the UO may entail incomplete insurance. We show further that, in general, any PO allocation can be implemented by a basic pooling insurance provided by the government and a supplemental separating contracts that can be offered by the market, although, in the presence of moral hazard, a tax needs to be imposed upon the market provision.
\end{abstract}

The analysis suggests that two commonly observed features of many countries' public insurance schemes are consistent with PO: (a) Some individuals (type H) shirk - contrary to widespread views, it is not a sign of a poorly designed system that some individuals shirk; and (b) there exists a hybrid provision of insurance by the government and the market.

Joseph Stiglitz

Uris Hall, Columbia University

3022 Broadway, Room 212

New York, NY 10027

and NBER

jes322@ columbia.edu

Jungyoll Yun

Department of Economics,

Ewha University,

Seoul

Korea

jyyun@ewha.ac.kr 


\section{Introduction}

Risk and improvements in the way that it can be managed has been a central theme in economic theory and policy in recent decades. Individuals are risk averse, so the insecurity posed by the risk of unemployment, accident, disease, etc. has major adverse effects on welfare. ${ }^{2}$ Partially because of perceptions that private markets have not adequately responded, governments throughout the world have designed social insurance systems to help mitigate the economic effects of these untoward events. ${ }^{3}$ Yet controversies rage over the best design of insurance schemes, including the extent to which reliance can be placed on markets.

It has long been known that insurance can attenuate incentives to avoid the insured against event. Optimal insurance balances out the benefits of improved risk mitigation with the costs of weakened incentives. Practical policies are bedeviled by the further complications of individual heterogeneity and the complexities posed by the interaction of public insurance and private provision. A currently fashionable approach has it that government should provide some level of "basic coverage," but that people should be free to purchase additional coverage from private carriers. There has, to date, been little theoretical work establishing contexts in which such a mixed system (which we refer to below as a "hybrid" system) would satisfy optimality properties. The argument for the base coverage is often related to the fear that private markets will focus on "cream skimming" - providing insurance to those of the lowest risk-- so that basic coverage at affordable prices to high risk individuals can only be obtained through some version of an enforced pooling equilibrium, in which low risk individuals subsidize high risk individuals. The US Medicare program, for instance, works this way, with those wishing to buy supplemental insurance being encouraged to do so.

Over the past thirty years, a large literature has developed considering market equilibrium with adverse selection and moral hazard. The original results of, say, Rothschild-Stiglitz [1976] in the context of adverse selection or Arnott-Stiglitz [1991] in the context of moral hazard, have proven robust. Take the canonical insurance model, where an equilibrium is defined as a set of contracts, each of which break even when chosen by those who prefer the contract to any other offered in the market, and such that there does not exist another contract which, given the existing set of contracts, would make a profit were it to be offered. In adverse selection models where the single crossing property holds, ${ }^{4}$ if there is an equilibrium, it is a separating equilibrium characterized by full insurance of the high risk individual, and incomplete insurance of the low risk individual.

Remarkably, in the ensuing thirty years since the canonical models were first developed, there has been little literature devoted to the question of what happens when there is both moral hazard and adverse selection, as is almost always the case in the real world. Such situations pose difficult policy dilemmas.

Consider the on-going debate over health care reform. Those focusing on moral hazard

\footnotetext{
2 See the recent report of the Sarkozy commission (Stiglitz, et al (2010))

${ }^{3}$ Research over the past four decades has helped explain why markets may not respond adequately-there may not exist a competitive equilibrium, and when it does exist, it may provide only limited insurance and attempts to differentiate among individuals with different risks may be very costly.

4 That is, the indifference curves of high and low risk individuals (in say \{benefit, premium space) cross only once.
} 
argue that we should encourage people to self-insure, through health insurance savings accounts. But critics say that that will result in a breaking down of existing insurance pools: the least risky will self-insure, leaving the worse risks in the insurance pool. That in turn will lead to higher insurance premiums, leading more to be uninsured. Clearly, it is not a Pareto improvement: those that chose not to avail themselves of the tax subsidized accounts are worse off, essentially because they lose the implicit cross subsidy from low risk individuals in the earlier pooling equilibrium. Worries about adverse selection effects of the reforms introduced to mitigate moral hazard have hampered health care reform.

Similarly, in financial loan markets, requiring more collateral might mitigate the moral hazard problem - those with more collateral will be less induced to engage in excessively risky behavior. But it is possible that wealthier people with more collateral will be more risk prone (either because of the higher level of wealth, or because those with wealth include disproportionately large numbers who have gambled and "won.") Again, the interaction of adverse selection and moral hazard effects are at the center of the analysis of how to address problems posed by information asymmetries.

To date, however, there has been neither a full analysis of the market equilibrium nor of the Pareto optimal (PO) or utilitarian optimum (UO) set of insurance contracts (nor does such an analysis exist in other simple market contexts) in which there is the double informational asymmetry problem of both moral hazard and adverse selection. ${ }^{5}$ This paper provides such an analysis, with results that are strikingly simple, though even in the simplest model the analytics turn out to be remarkably complex. We combine the Rothschild-Stiglitz insurance model with two groups with the Arnott-Stiglitz model with two activity levels, providing an analysis of the full set of Pareto efficient contracts, characterizing the utilitarian optimum, describing the market equilibrium, and ascertaining how the government might be able to implement the optimal allocations.

This paper identifies several distinctive features of optimal and equilibrium allocations that are not present under pure adverse selection or under pure moral hazard; these distinctive features are the results of self-selection and moral hazard constraints interacting with each other: (i) a PO allocation may involve "shirking" (less care in accident avoidance compared to the case of pure moral hazard) either by high risk individuals in the case of single-crossing preference or by one or both types in the case of multi-crossing preference (as may naturally be the case under the double informational asymmetry) ${ }^{6}$; and (ii) while an equilibrium, which is unique (even under multi-crossing preferences) if it exists, is more likely to exist as the non-shirking constraint for low-risk type gets more stringent (i.e. when low risk individuals shirk with lower levels of insurance). We also show that a pooling equilibrium, which is not feasible under pure adverse selection, may exist when individuals differ in risk aversion (as

\footnotetext{
5 Three exceptions are the study of Whinston [1983], who uses the Diamond/Mirrlees social insurance/retirement model, and shows that the utilitarian optimum involves pooling; Stiglitz-Weiss [1987], who look at moral hazard and adverse selection in a credit market with collateral, where individuals differ in both their collateral and the probability of default; and Chassagnon-Chiappori (1997), who examined the properties of equilibrium in a model of adverse selection and moral hazard, which is characterized by multiplecrossing preferences. This paper makes clear how each employs assumptions that are special cases of the model analyzed here. There have been some works (Laffont-Tirole(1986), Piscard(1987)) that integrate both moral hazard and adverse selection problems into a single model where all the parties of contracts are riskneutral. But they do not explain the insurance arrangements for risk-averse parties.
}

6 This result can be contrasted with the previous arguments (Stewart(1994)) that adverse selection and moral hazard may partially offset the welfare loss associated with each other. 
well as in accident probability) or when the provision of insurance is non-exclusive (i.e. individuals can purchase insurance from more than one firm). Furthermore, while with pure adverse selection, UO always entails pooling with complete insurance (in the standard model), with adverse selection and moral hazard, all PO allocations may entail separation and the UO may entail incomplete insurance. Also we show that there exists a "hybrid" way of providing insurance combining both the government and the market that can achieve a Pareto optimal allocation under the double informational asymmetry, supporting a fashionable approach that is currently adopted by health and retirement insurance systems in the US (though our results imply further that a tax needs to be imposed upon the market provision.)

This paper is organized as follows: Based upon a model presented in Section 2, we characterize the optimal allocations under single and double informational asymmetries in Section 3 and Section 4, respectively. In Section 5, we also characterize the equilibrium allocations under the double informational asymmetry and compare the results to those under the single asymmetry; in particular, we analyze conditions for the existence of equilibrium and explore the possibility of a pooling equilibrium. The role of the market or the government in implementing an optimal allocation is discussed in Section 6, followed by concluding remarks in Section 7.

\section{Model}

Consider an individual who is faced with the risk of an accident with some probability, $\mathrm{P}_{\mathrm{i}}(\mathrm{e})$, which depends upon the type $\mathrm{i}$ of the individual and the level e of care he takes. It is assumed for simplicity that there are two possible levels of care that an individual can take, $\mathrm{e}=0$ (shirking) or $\mathrm{e}=\overline{\mathrm{e}}$ (non-shirking), and that there are two types of individuals - high risk (H-type) and low-risk (L-type) individuals-- who differ from each other only in the probability of accident for a given level of care. The type is privately known to the individual, while the portion $\theta$ of $\mathrm{H}$-type is common knowledge.

$$
\text { Letting } \mathrm{P}_{\mathrm{i}}(\mathrm{e}=\overline{\mathrm{e}})=\mathrm{P}_{\mathrm{i}}, \quad \mathrm{P}_{\mathrm{i}}(\mathrm{e}=0)=\mathrm{P}_{\mathrm{i}}^{\mathrm{S}}
$$

for $\mathrm{i}=\mathrm{H}, \mathrm{L}$, we assume that $\mathrm{P}_{\mathrm{H}}>\mathrm{P}_{\mathrm{L}}, \mathrm{P}_{\mathrm{i}}^{\mathrm{S}}>\mathrm{P}_{\mathrm{i}}(\mathrm{i}=\mathrm{H}, \mathrm{L}) . \quad \Delta \mathrm{P}_{\mathrm{i}} \equiv \mathrm{P}_{\mathrm{i}}^{\mathrm{S}}-\mathrm{P}_{\mathrm{i}}$, , measures the sensitivity of the accident probability to the care level an individual of i-type chooses. This can vary depending upon the type, i.e., it could be the case that either $\Delta \mathrm{P}_{\mathrm{L}} \geq \Delta \mathrm{P}_{\mathrm{H}}$ or that $\Delta \mathrm{P}_{\mathrm{L}}<\Delta \mathrm{P}_{\mathrm{H}}$. The former (latter) case can be interpreted as one in which effort and type are complements (substitutes) to each other in the determination of the accident probability. That is, when they are complements, being a "good" type not only lowers the accident probability, it also increases the reduction in accident probabilities from greater effort.

The expected utility of an i-type individual $(\mathrm{i}=\mathrm{H}, \mathrm{L})$ with wealth $\mathrm{w}$, who purchases the amount $\alpha_{i}$ of insurance by paying premium $\beta_{i}$ and takes the care level e, is ${ }^{7}$

$$
V_{i}\left(\alpha_{i}, \beta_{i}\right)=\operatorname{Max}_{e} P_{i}(e) U\left(w-d+\alpha_{i}\right)+\left(1-P_{i}(e)\right) U\left(w-\beta_{i}\right)-e,
$$

\footnotetext{
7 In this formulation, we assume the two types of individuals have the same utility of consumption in each state of nature. It is easy to generalize our results to the case where their utility of consumption differs. Similarly, the cost of effort devoted to accident avoidance can differ. The assumptions of separability and linearity are also made for convenience.
} 
where $\mathrm{d}$ is the amount of loss in the event of an accident.

The No-shirking (NS) constraints: $\mathrm{e}_{\mathrm{i}}\left(\alpha_{\mathrm{i}}, \beta_{\mathrm{i}}\right)$ is determined as follows: The individual chooses to shirk (or not to shirk) when

$$
\Delta \mathrm{P}_{\mathrm{i}}\left\{\mathrm{U}\left(\mathrm{w}-\beta_{\mathrm{i}}\right)-\mathrm{U}\left(\mathrm{w}-\mathrm{d}+\alpha_{\mathrm{i}}\right)\right\} \leq(\text { or }>) \overline{\mathrm{e}},
$$

which can be rewritten as

$$
\beta_{\mathrm{i}} \leq(\text { or }>) \mathrm{f}_{\mathrm{i}}\left(\alpha_{\mathrm{i}}\right) \equiv \mathrm{w}-\mathrm{U}^{-1}\left\{\frac{\overline{\mathrm{e}}}{\Delta \mathrm{P}_{\mathrm{i}}}+\mathrm{U}\left(\mathrm{w}-\mathrm{d}+\alpha_{\mathrm{i}}\right)\right\}, \mathrm{i}=\mathrm{H}, \mathrm{L}
$$

where $\mathrm{f}_{\mathrm{i}}^{\prime}<0$. We call condition (2) for i-type the no-shirking constraint for i-type, denoted by NS(i) constraint; the locus $\beta_{i}=f_{i}\left(\alpha_{i}\right)$ is called the NS(i) locus, and is negatively sloped: (2) implies that if individuals are to take care, there must be less-than-full insurance, that is, $\beta_{\mathrm{i}}<d-\alpha_{\mathrm{i}}$, i.e., $\alpha_{\mathrm{i}}+\beta_{\mathrm{i}}<d$.

Diagrammatically, we can see what is entailed in Figure 1. For a fixed effort level, an individual indifference curve in the $\{\alpha, \beta\}$ space is upward sloping and concave, as depicted in Figure 1. The slope of the indifference curve is $\frac{d \beta}{d \alpha}=\frac{P}{1-P} \frac{U^{\prime}(w-d+\alpha)}{U^{\prime}(w-\beta)}$. Higher benefits and lower premia increase utility, so a movement down and to the right increases expected utility. Indifference curves with shirking (no effort) are steeper in general than those without. The overall indifference curve, with e endogenous, would then be scalloped shaped. An interesting point is that the indifference curves for the two types may cross each other more than once (multi-crossing property); even though at any given level of care, the high risk individual's indifference curve is steeper than the low risk individual's, there may be some levels of insurance such that the low risk individual shirks and the high risk individual does not, and it can be the case that $\mathrm{P}_{\mathrm{L}}{ }^{\mathrm{S}}>\mathrm{P}_{\mathrm{H}}$. This can be contrasted with the single-crossing property that has been typically assumed in the literature, and arises naturally in simple specifications where there is only adverse selection.

We can easily identify necessary conditions for multiple crossing: the no-shirking locus of the $\mathrm{L}$ type must lie below that of the H-type, which from (2) means that $\Delta \mathrm{P}_{\mathrm{L}}<\Delta \mathrm{P}_{\mathrm{H}}$. We require, in addition, that $\mathrm{P}_{\mathrm{L}}{ }^{\mathrm{S}}>\mathrm{P}_{\mathrm{H}}$, which can be written as

$$
\Delta \mathrm{P}_{\mathrm{L}} \equiv \mathrm{P}_{\mathrm{L}}^{\mathrm{S}}-\mathrm{P}_{\mathrm{L}}>\mathrm{P}_{\mathrm{H}}-\mathrm{P}_{\mathrm{L}} \equiv \mathrm{T} \text {. }
$$

In short, multiple crossing requires

$$
\Delta \mathrm{P}_{\mathrm{H}}>\Delta \mathrm{P}_{\mathrm{L}}>T
$$

i.e., type and effort are substitutes to each other and, in some sense, individual heterogeneity is less important than effort in determining the accident probability of an individual. ${ }^{8}$ This case is illustrated by Figure 2. In Figure 2 the NS constraints divide the $(\alpha, \beta)$ space into three regions, that where neither shirks, that where both shirk, and the intermediate region, where the low risk individual shirks and the high risk does not. The low risk individual's indifference curves are flatter than the high risk individual's in the first and third region, but

8 This would be the case when $\mathrm{T}<\operatorname{Min}\left\{\Delta \mathrm{P}_{\mathrm{L}}, \Delta \mathrm{P}_{\mathrm{H}}\right\}$. 
they are steeper in the second region.

The profit for an insurance contract $(\alpha, \beta)$ purchased by an i-type individual, $\pi_{i}(\alpha, \beta)$, is

$$
\pi_{i}(\alpha, \beta)=\left(1-P_{i}\left(e_{i}(\alpha, \beta)\right)\right) \beta-P_{i}\left(e_{i}(\alpha, \beta)\right) \alpha, \quad i=H, L
$$

The profit for a contract depends upon the choice of care level by an individual. The care level switches at the NS locus; hence, taking e as endogenous, the zero profit line for a particular type of individual appears as in Figure 1.

The self-selection (SS) constraints. We focus on situations where the insurance provider(s) know that there are two types of individuals, but cannot ascertain who is of which type. Earlier literature (Stiglitz [1975], Rothschild-Stiglitz (1976)] identified two possible kinds of allocations: a pooling allocation, in which the two types buy the same insurance contract, and a separating allocation, in which they buy different contracts. In a separating allocation, the contracts $\left\{\left(\alpha_{\mathrm{H}}, \beta_{\mathrm{H}}\right),\left(\alpha_{\mathrm{L}}, \beta_{\mathrm{L}}\right)\right\}$ offered the two groups have to satisfy the SS constraints for each i, denoted by SS(i) constraints:

$$
V_{i}\left(\alpha_{i}, \beta_{i}\right) \geq V_{i}\left(\alpha_{j}, \beta_{j}\right), \quad \quad i, j=H, L,
$$

Type i (weakly) prefers its contract to the other contract.

We employ two different optimality concepts: Pareto Optimality (PO) and Utilitarian Optimality (UO). A set of contracts is PO if together they yield non-negative profits and there does not exist any other set of contracts which yields non-negative profits and which makes at least some individuals better off without making others worse off. A set of contracts is $\mathrm{UO}$ if it yields non-negative profits and it maximizes utilitarian social welfare, $\mathrm{V}$, where

$$
\mathrm{V}=\theta \mathrm{V}_{\mathrm{H}}+(1-\theta) \mathrm{V}_{\mathrm{L}}
$$

Note that a contract is $\mathrm{PO}$ if it is UO, while it is not necessarily UO if it is PO.

An equilibrium or an RS equilibrium, as defined by Rothschild-Stiglitz (1976), is defined as a set of contracts that yields zero profit such that there does not exist any other contract which yields positive profits by attracting some individuals.

Before analyzing optimal allocations and market equilibrium under the double informational asymmetry (DIA) (with both moral hazard and adverse selection), we will first outline the results under a single informational asymmetry (SIA), where there is either only adverse selection or only moral hazard.

\section{Optimality Under Single Informational Asymmetry (SIA)}

\section{3-1. Optimality under Pure Adverse Selection (PAS)}

Suppose that an individual has no choice of effort. For simplicity, we assume the accident probabilities are those associated with the non-shirking care level. The PO set of contracts $\left\{\left(\alpha_{H}, \beta_{H}\right),\left(\alpha_{L}, \beta_{L}\right)\right\}$ must solve the following problem:

$\operatorname{Max} V_{L}\left(\alpha_{L}, \beta_{L}\right)$

s.t.

$$
\begin{aligned}
& V_{H}\left(\alpha_{H}, \beta_{H}\right) \geq V_{H}\left(\alpha_{L}, \beta_{L}\right) \\
& V_{L}\left(\alpha_{L}, \beta_{L}\right) \geq V_{L}\left(\alpha_{H}, \beta_{H}\right)
\end{aligned}
$$




$$
\begin{aligned}
& \theta \pi_{\mathrm{H}}\left(\alpha_{\mathrm{H}}, \beta_{\mathrm{H}}\right)+(1-\theta) \pi_{\mathrm{L}}\left(\alpha_{\mathrm{L}}, \beta_{\mathrm{L}}\right) \geq 0 \\
& \mathrm{~V}_{\mathrm{H}}\left(\alpha_{\mathrm{H}}, \beta_{\mathrm{H}}\right) \geq \mathrm{K}
\end{aligned}
$$

where $\pi_{i}\left(\alpha_{i}, \beta_{i}\right)=\left(1-P_{i}\right) \beta_{i}-P_{i} \alpha_{i}(i=H, L)$, i.e. it must maximize the utility of L-type, subject to SS constraints, the non-negative profit constraint, and to H-type attaining at least a given level of utility, $\mathrm{K}$. We denote by $\left(\alpha_{\mathrm{H}}^{*}, \beta_{\mathrm{H}}^{*}\right)$ and $\left(\alpha_{\mathrm{L}}^{*}, \beta_{\mathrm{L}}^{*}\right)$ the full-insurance contract for H-type and the incomplete-insurance contract for L-type, respectively, such that each contract yields the zero profit, i.e., $\pi_{i}\left(\alpha_{i}^{*}, \beta_{i}^{*}\right)=\left(1-P_{i}\right) \beta_{i}^{*}-P_{i} \alpha_{i}^{*}=0$ for $i=H, L$, and that the two contracts strictly satisfy the SSH constraint. $\left\{\left(\alpha_{\mathrm{H}}^{*}, \beta_{\mathrm{H}}^{*}\right),\left(\alpha_{\mathrm{L}}^{*}, \beta_{\mathrm{L}}^{*}\right)\right\}$ is the RothschildStiglitz equilibrium, when it exists, but as we shall shortly show, this allocation may not be PO. Theorem 1 characterizes the PO and UO allocation under pure adverse selection (PAS) (the proof is relegated to the Appendix.):

Theorem 1. (Optimality under Pure Adverse Selection (PAS))

(i) There always exists a PO separating contract entailing some subsidy between $\mathrm{H}$ and L types of individuals.

(ii) There exists $\theta_{1}(>0)$ such that for $\theta<\theta_{1}$, all PO contracts entail some subsidy between $\mathrm{H}$ and $\mathrm{L}$ types of individuals.

(iii) Any PO separating contract entails full-insurance from the H-type and incomplete insurance for the L-type

(iv) The full insurance pooling contract $(\widetilde{\alpha}, \widetilde{\beta})$ achieves the UO outcome, where

$$
\tilde{\beta}=\frac{\overline{\mathrm{P}}}{1-\overline{\mathrm{P}}} \widetilde{\alpha} \text { and } \overline{\mathrm{P}} \equiv \theta \mathrm{P}_{\mathrm{H}}+(1-\theta) \mathrm{P}_{\mathrm{L}} \text {. }
$$

Only the first part of Theorem 1 may not be familiar. To see this result, we examine the utility frontier, represented by $\mathrm{V}\left(\mathrm{v}_{\mathrm{H}}\right)$, which shows the maximum amount of utility that can be attained by $\mathrm{L}$ type for any given level of utility attained by H-type. ${ }^{9}$ We do this by parametrically considering a subsidy from L-type to H-type. The zero subsidy point is the $\mathrm{R}-\mathrm{S}$ separating allocation (that is, the competitive equilibrium if it exists).

Theorem 1 (iv) suggests that the utilitarian optimum is achieved through the maximum subsidy that can be transferred to H-type from L-type given the zero-profit and self-selection constraints. Theorem 1 (i) and (iv) imply that while the UO is PO, it is not Pareto-superior to other allocations (even for a small $\theta$ ).

Letting $\mathrm{V}_{\mathrm{H}}^{*} \equiv \mathrm{V}_{\mathrm{H}}\left(\alpha_{\mathrm{H}}^{*}, \beta_{\mathrm{H}}^{*}\right)$ and $\mathrm{V}_{\mathrm{L}}^{*} \equiv \mathrm{V}_{\mathrm{L}}\left(\alpha_{\mathrm{L}}^{*}, \beta_{\mathrm{L}}^{*}\right)$, we can establish that for $\theta<\theta_{1}$, $\frac{\partial \mathrm{V}}{\partial \mathrm{v}_{\mathrm{H}}}>0$ at $\mathrm{V}_{\mathrm{H}}=\mathrm{V}_{\mathrm{H}}^{*}$, i.e., by the L-type transferring money to the $\mathrm{H}$ type, the loosening of the self-selection constraint dominates the loss of welfare that arises from the income transfer. The implication of Theorem 1 (ii) is that the separating contract involving no subsidy is not necessarily PO. Indeed, it will be shown later in this paper that $\left\{\left(\alpha_{\mathrm{H}}^{*}, \beta_{\mathrm{H}}^{*}\right),\left(\alpha_{\mathrm{L}}^{*}, \beta_{\mathrm{L}}^{*}\right)\right\}$ is an R-S equilibrium (in the sense of Rothschild-Stiglitz) if and only if $\theta \geq \theta_{1}$. This result provides a necessary and sufficient condition for the existence of an RS equilibrium and provides new insights into the Rothschild-Stiglitz equilibrium theorem:

\footnotetext{
9 It is natural that we focus on the utility curve, because it provides the complete characterization of the set of Pareto optimal allocations.
} 


\section{$\left\{\left(\alpha_{H}^{*}, \beta_{H}^{*}\right),\left(\alpha_{L}^{*}, \beta_{L}^{*}\right)\right\}$ is the competitive equilibrium if and only if it is $P O$.}

Figure 3 provides an intuitive explanation for Theorem 1. Figure 3 shows a variant of the familiar adverse selection model, with the zero profit locus for the $\mathrm{L}$ and $\mathrm{H}$ type labeled in the obvious way. As we increase $\alpha_{\mathrm{H}}$ from $\alpha_{\mathrm{H}}^{*}$ along the full-insurance line ${ }^{10}$, i.e., as we increase the subsidy from L-type to H-type, the amount $\alpha_{L}$ of insurance for L-type will increase. There are two conflicting factors that affect the utility $V_{L}$ of L-type in response to the change in $\alpha_{\mathrm{H}}$ : the self selection constraint becomes less binding as the utility of H-type increases, but the profit constraint becomes more binding. The former effect is illustrated by the shift of $\mathrm{V}_{\mathrm{H}}$ to $\mathrm{V}_{\mathrm{H}}{ }^{\prime}$ in Figure 3, while the latter effect is shown by the shift of the zeroprofit line for $\mathrm{L}$ (indicated by upward arrow) in Figure 3. The result $\left(\alpha_{\mathrm{L}}^{\prime}, \beta_{\mathrm{L}}^{\prime}\right)$ may imply that the utility of L-type could increase as in Figure 3.

Whether or not the utility of L-type increases in $\alpha_{\mathrm{H}}$ depends upon the distribution of types. If $\theta$ is high, then the profit effect dominates, and as we increase the expected utility of $\mathrm{H}$ type, that of L-type decreases. Eventually, as we transfer more money from L to H-type, we reach the pooling contract $(\widetilde{\alpha}, \tilde{\beta})$ as shown in Figure 3. It is not feasible to increase the well being of H-type beyond that point. When, on the other hand, $\theta$ is negligible, the effect on the profit constraint is negligible, and hence as we increase the subsidy to H-type, we relax the self selection constraint, and, at least initially, the well being of L-type as well. Eventually, however, it decreases, as the contract for L-type approaches the full-insurance one. It pays the low risk individuals to subsidize the high risk individuals, so long as the marginal benefit in increased insurance consistent with separating exceeds the marginal cost of the subsidy. If there are essentially no high risk indivdiuals, the marginal cost is negligible. Such allocations cannot, of course, be sustained within a standard competitive RothschildStiglitz equilibrium.

\section{3-2. Optimality and equilibrium under Pure Moral Hazard (PMH) alone}

Figure 4 depicts the pure moral hazard $(\mathrm{PMH})$ case. The critical curve is the zero profit locus, which is the line OB (with slope $\frac{\mathrm{P}}{1-\mathrm{P}}$ ) below the NS locus, and the line OA with slope $\frac{\mathrm{P}^{\mathrm{S}}}{1-\mathrm{P}^{\mathrm{S}}}$ above the NS locus. Assume now we have only one type (say type L), but subject to the NS constraint. UO and PO then coincide: we simply maximize the well-being of the representative agent subject to the zero profit locus. There are two possibilities, illustrated in Figure 4. The first is that the optimum occurs with shirking (' $A$ ' in Figure 4); the second, at the no-shirking constraint (' $\mathrm{B}$ ' in Figure 4). Either can occur; it simply depends upon the shape of the indifference curve. Note that in the second case individuals would like to get more insurance - they are not fully insured; but they cannot commit themselves not to shirk. And if they are given any more insurance they will. It is easy to show that the market equilibrium coincides with the UO and PO. ${ }^{11}$

We will consider one of the following two assumptions for each type.

\footnotetext{
10 There is full insurance if $d-\beta=\alpha$. Hence the line marked $\alpha+\beta=d$ is the full insurance line.

11 See Arnott and Stiglitz [1991]. But note that this result is in part an artifact of the fact that there is only one good. See Greenwald and Stiglitz [1986].
} 
A1: For any $\left(\alpha_{i}^{\prime}, \beta_{i}^{\prime}\right)$ and $\left(\alpha_{i}, \beta_{i}\right)$ such that $\beta_{i}=f_{i}\left(\alpha_{i}\right), \beta_{i}^{\prime}=d-\alpha_{i}{ }^{\prime}$ and $V_{i}\left(\alpha_{i}, \beta_{i}\right)=$ $V_{i}\left(\alpha_{i}{ }^{\prime}, \beta_{i}{ }^{\prime}\right)$, it is the case that $\pi_{i}\left(\alpha_{i}, \beta_{i}\right)>\pi_{i}\left(\alpha_{i}{ }^{\prime}, \beta_{i}{ }^{\prime}\right)$ (alternatively, if $\pi_{i}\left(\alpha_{i}, \beta_{i}\right)=$ $\left.\pi_{i}\left(\alpha_{i}{ }^{\prime}, \beta_{i}{ }^{\prime}\right)\right)$, then $\left.V_{i}\left(\alpha_{i}, \beta_{i}\right)>V_{i}\left(\alpha_{i}{ }^{\prime}, \beta_{i}{ }^{\prime}\right)\right)$.

A2: For any $\left(\alpha_{i}^{\prime}, \beta_{i}^{\prime}\right)$ and $\left(\alpha_{i}, \beta_{i}\right)$ such that $\beta_{i}=f_{i}\left(\alpha_{i}\right), \beta_{i}^{\prime}=d-\alpha_{i}{ }^{\prime}$ and $V_{i}\left(\alpha_{i}, \beta_{i}\right)=$ $V_{i}\left(\alpha_{i}{ }^{\prime}, \beta_{i}{ }^{\prime}\right)$, it is the case that $\pi_{i}\left(\alpha_{i}, \beta_{i}\right)<\pi_{i}\left(\alpha_{i}{ }^{\prime}, \beta_{i}{ }^{\prime}\right)$ (alternatively, if $\pi_{i}\left(\alpha_{i}, \beta_{i}\right)=$ $\left.\left.\pi_{i}\left(\alpha_{i}^{\prime}, \beta_{i}^{\prime}\right)\right), \quad V_{i}\left(\alpha_{i}, \beta_{i}\right)<\left(\alpha_{i}^{\prime}, \beta_{i}{ }^{\prime}\right)\right)$.

What the assumption A1 (or A2) says is that a contract offering an individual the maximum amount of insurance without inducing him to shirk (or a contract inducing shirking) dominates a full-insurance contract inducing shirking that offers the same level of utility. Under assumption A1 (or A2), the optimal insurance contract under PMH coincides with the one that strictly satisfies the NS condition (or with the one offering full insurance). ${ }^{12}$ The indifference curve shown in Figure 4 satisfies the assumption A1. If A1 holds for a particular type of individual, a PO contract for that type will be constrained by the NS condition. (Similarly, if A2 holds for a type, then a PO contract for that type will not be constrained by the NS condition.)

Let us define a contract $\left(\alpha_{\mathrm{i}}^{\mathrm{o}}, \beta_{\mathrm{i}}^{\mathrm{o}}\right)$ for $\mathrm{i}$-type $(\mathrm{i}=\mathrm{H}, \mathrm{L})$, such that it yields zero profit for the type, i.e., $\pi_{\mathrm{i}}\left(\alpha_{\mathrm{i}}^{\mathrm{o}}, \beta_{\mathrm{i}}^{\mathrm{o}}\right)=\left(1-\mathrm{P}_{\mathrm{i}}\right) \beta_{\mathrm{i}}^{\mathrm{o}}-\mathrm{P}_{\mathrm{i}} \alpha_{\mathrm{i}}^{\mathrm{o}}=0$, and it satisfies either $\beta_{\mathrm{i}}^{\mathrm{o}}=\mathrm{f}_{\mathrm{i}}\left(\alpha_{\mathrm{i}}^{\mathrm{o}}\right)$ or $\beta_{\mathrm{i}}^{\mathrm{o}}=\mathrm{d}-\alpha_{\mathrm{i}}^{\mathrm{o}}$. We can then state the following Theorem.

Theorem 2 (Optimality and Equilibrium under PMH)

A PO and equilibrium set of contracts is $\left\{\left(\alpha_{\mathrm{L}}^{\mathrm{o}}, \beta_{\mathrm{L}}^{\mathrm{o}}\right),\left(\alpha_{\mathrm{H}}^{\mathrm{o}}, \beta_{\mathrm{H}}^{\mathrm{o}}\right)\right\}$, where $\beta_{\mathrm{i}}^{\mathrm{o}}=\mathrm{f}_{\mathrm{i}}\left(\alpha_{\mathrm{i}}^{\mathrm{o}}\right)$ or $\beta_{\mathrm{i}}^{\mathrm{o}}=\mathrm{d}-\alpha_{\mathrm{i}}^{\mathrm{o}}$ under $\mathrm{A} 1$ or $\mathrm{A} 2$, respectively.

Note that the contract $\left(\alpha_{i}^{o}, \beta_{i}^{o}\right)$ is uniquely determined by the parameters $P_{i}$ and $\Delta P_{i}$.

For most of the analysis in this paper we will focus upon the case when A1 holds for each type. Although the assumption A2 implies that the NS constraint is not binding, however, it could affect a PO allocation when adverse selection is also present. We will not thus ignore the possibility that A2 holds for one or the two types. That is, we will mention, whenever relevant, how the results could change as A2 (rather than A1) holds. As we shall show, it may be optimal for one of the two groups to shirk. Shirking itself is not necessarily evidence of a poorly designed incentive scheme.

\section{Optimality under the Double Informational Asymmetry (DIA)}

The analysis of optimality with both moral hazard and self-selection (DIA) involves considering the consequences of having both NS and SS constraints. The heart of the analysis entails a detailed examination of the interaction between these constraints, which turns out to be a matter of considerable complexity. The introduction of moral hazard imposes additional restrictions upon the set of PO contracts for both $\mathrm{H}$ and L-types through

\footnotetext{
12 The assumption $A 1$ implies that the probability $\mathrm{P}_{\mathrm{i}}^{\mathrm{S}}$ of accident in the event of shirking is higher than $\mathrm{P}_{\mathrm{i}}$ by more than a certain level. The assumption A2 will hold, on the other hand, if effort had little effect on accident probabilities and/or the indifference curve above the non-shirking constraint were initially very steep.
} 
the NS constraints, and these additional restrictions bring about important differences between the optimal allocation under DIA and that under PAS or that under PMH.

The characterization of PO under DIA is further complicated by the possibility of multicrossing preferences, which arises naturally when $\mathrm{f}_{\mathrm{H}}(\alpha)>\mathrm{f}_{\mathrm{L}}(\alpha)$. In analyzing the optimality under DIA we will first confine ourselves to the case of single-crossing preference before turning to the case of multi-crossing preference.

\section{4-1. Single-crossing Preference}

In characterizing the optimal allocations under DIA, we will first prove the following proposition which provides necessary conditions that must be satisfied if a contract is to be $\mathrm{PO}$ in the case of single-crossing preferences.

\section{Proposition 1}

Suppose that the single-crossing property is not violated, and suppose that A1 holds for both of the two types. Then, a contract $\left(\alpha_{\mathrm{H}}, \beta_{\mathrm{H}}\right)$ of for H-type can be PO only if the following conditions hold: $\beta_{\mathrm{H}}=\mathrm{f}_{\mathrm{H}}\left(\alpha_{\mathrm{H}}\right)$ when $\Delta \mathrm{P}_{\mathrm{L}}<\Delta \mathrm{P}_{\mathrm{H}}$, and $\alpha_{\mathrm{H}}+\beta_{\mathrm{H}}=\mathrm{d}$ or $\beta_{\mathrm{H}}=\mathrm{f}_{\mathrm{H}}\left(\alpha_{\mathrm{H}}\right)$ when $\Delta \mathrm{P}_{\mathrm{L}} \geq \Delta \mathrm{P}_{\mathrm{H}}$. A contract $\left(\alpha_{\mathrm{L}}, \beta_{\mathrm{L}}\right)$ for L-type is PO only if $\beta_{\mathrm{L}} \leq \mathrm{f}_{\mathrm{L}}\left(\alpha_{\mathrm{L}}\right)$.

The proof can be found in the Appendix. (Similar conditions for the optimality under multi-crossing preferences will be presented later.) Proposition 1 shows that a PO contract with single-crossing preferences should satisfy the following conditions: a $\mathrm{PO}$ contract for $\mathrm{H}$ type may entail full-insurance even when A1 holds under certain conditions, while that for Ltype should satisfy its NS constraint. We can use this result to characterize PO allocations, as it allows us to narrow down the relevant set of constraints, dividing the analysis of the optimality into two cases, that where the H-type's NS constraint is strictly satisfied, and that where the H-type gets full insurance.

Let us consider the following problem to examine the optimal allocation in the case when A1 holds for both of the two types :

$\operatorname{Max} \mathrm{V}_{\mathrm{L}}\left(\alpha_{\mathrm{L}}, \beta_{\mathrm{L}}\right)=\mathrm{P}_{\mathrm{L}} \mathrm{U}\left(\mathrm{w}-\mathrm{d}+\alpha_{\mathrm{L}}\right)+\left(1-\mathrm{P}_{\mathrm{L}}\right) \mathrm{U}\left(\mathrm{w}-\beta_{\mathrm{L}}\right)$

s.t.

$$
\begin{array}{lc}
\mathrm{V}_{\mathrm{H}}\left(\alpha_{\mathrm{H}}, \beta_{\mathrm{H}}\right) \geq \mathrm{V}_{\mathrm{H}}\left(\alpha_{\mathrm{L}}, \beta_{\mathrm{L}}\right) & (\mathrm{SSH}) \\
\mathrm{V}_{\mathrm{L}}\left(\alpha_{\mathrm{H}}, \beta_{\mathrm{H}}\right) \leq \mathrm{V}_{\mathrm{L}}\left(\alpha_{\mathrm{L}}, \beta_{\mathrm{L}}\right) & (5 \mathrm{~A}) \\
\beta_{\mathrm{L}} \leq \mathrm{f}_{\mathrm{L}}\left(\alpha_{\mathrm{L}}\right) & (\mathrm{SSL}) \quad(5 \mathrm{~B}) \\
\theta\left\{\left(1-\mathrm{P}_{\mathrm{H}}\left(\alpha_{\mathrm{H}}, \beta_{\mathrm{H}}\right)\right) \beta_{\mathrm{H}}-\mathrm{P}_{\mathrm{H}}\left(\alpha_{\mathrm{H}}, \beta_{\mathrm{H}}\right) \alpha_{\mathrm{H}}\right\}+(1-\theta)\left\{\left(1-\mathrm{P}_{\mathrm{L}}\right) \beta_{\mathrm{L}}-\mathrm{P}_{\mathrm{L}} \alpha_{\mathrm{L}}\right\}=0 \\
& \text { (Zero Profit Constraint) }
\end{array}
$$

where $\beta_{H}=f_{H}\left(\alpha_{H}\right)$ or $d-\alpha_{H}$, and $V_{i}\left(\alpha_{H}, \beta_{H}\right)$ is the (expected) utility of i-type choosing $\left(\alpha_{\mathrm{H}}, \beta_{\mathrm{H}}\right)$.

In the discussion below, we refer to SSH and SSL as the self-selection constraint for the high and low risk type of individuals, respectively (5B and 5C). Similarly, we refer to the no 
shirking constraint for the high and low risk individuals as NSH and NSL. In characterizing the solutions to (5), we will adopt the following strategy of analysis: we will first use the zero profit constraint 5(D) and the condition that $\beta_{\mathrm{H}}=\mathrm{f}_{\mathrm{H}}\left(\alpha_{\mathrm{H}}\right)$ or that $\beta_{\mathrm{H}}=\mathrm{d}-\alpha_{\mathrm{H}}$ to represent $\beta_{\mathrm{L}}$ and $\beta_{\mathrm{H}}$ as functions of $\left(\alpha_{\mathrm{L}}, \alpha_{\mathrm{H}}\right)$, and to rewrite $\mathrm{V}_{\mathrm{L}}$ and all the other constraints (i.e., $\mathrm{SS}$ constraints for $\mathrm{H}$ and L and NS constraint for L) in terms of $\left(\alpha_{\mathrm{L}}, \alpha_{\mathrm{H}}\right)$. The solution to the problem (5) will then be $\alpha_{L}\left(\alpha_{H}\right)$ as a function of $\alpha_{H}$, which will enable us to see how the optimal $\alpha_{\mathrm{L}}$, or the optimal $\mathrm{V}_{\mathrm{L}}$, will vary with $\alpha_{\mathrm{H}}$ (indicating the amount of subsidy from Ltype to H-type).

Let us first rewrite $\beta_{\mathrm{L}}$ as a function of $\alpha_{\mathrm{L}}$ and $\alpha_{\mathrm{H}}$ as follows:

$$
\mathrm{B}\left(\alpha_{\mathrm{L}}, \alpha_{\mathrm{H}}\right) \equiv \frac{\mathrm{P}_{\mathrm{L}}}{1-\mathrm{P}_{\mathrm{L}}} \alpha_{\mathrm{L}}+\frac{\theta}{1-\theta} \frac{1}{1-\mathrm{P}_{\mathrm{L}}}\left(\mathrm{P}_{\mathrm{H}} \alpha_{\mathrm{H}}-\left(1-\mathrm{P}_{\mathrm{H}}\right) \mathrm{f}_{\mathrm{H}}\left(\alpha_{\mathrm{H}}\right)\right)
$$

or

$$
\mathrm{BB}\left(\alpha_{\mathrm{L}}, \alpha_{\mathrm{H}}\right) \equiv \frac{\mathrm{P}_{\mathrm{L}^{\prime}}}{1-\mathrm{P}_{\mathrm{L}^{\prime}}} \alpha_{\mathrm{L}}+\frac{\theta}{1-\theta} \frac{1}{1-\mathrm{P}_{\mathrm{L}^{\prime}}}\left(\mathrm{P}_{\mathrm{H}}^{\mathrm{S}} \alpha_{\mathrm{H}}-\left(1-\mathrm{P}_{\mathrm{H}}^{\mathrm{S}}\right)\left(\mathrm{d}-\alpha_{\mathrm{H}}\right)\right)
$$

where $\mathrm{P}_{\mathrm{L}}^{\prime}$ could be either $\mathrm{P}_{\mathrm{L}}$ or $\mathrm{P}_{\mathrm{L}}^{\mathrm{S}}$ depending upon $\left(\alpha_{\mathrm{L}}, \beta_{\mathrm{L}}\right)$. Note that, so long as $\mathrm{L}$ type subsidizes H-type, $\left(1-\mathrm{P}_{\mathrm{L}}\right) \beta_{\mathrm{L}}>\mathrm{P}_{\mathrm{L}} \alpha_{\mathrm{L}}$ and $\mathrm{P}_{\mathrm{H}} \alpha_{\mathrm{H}}>\left(1-\mathrm{P}_{\mathrm{H}}\right) \mathrm{f}_{\mathrm{H}}\left(\alpha_{\mathrm{H}}\right)$ (or $\mathrm{P}_{\mathrm{H}}^{\mathrm{S}} \alpha_{\mathrm{H}}>$ $\left.\left(1-\mathrm{P}_{\mathrm{H}}^{\mathrm{S}}\right)\left(\mathrm{d}-\alpha_{\mathrm{H}}\right)\right)$.

Substituting (6) or (6') and $\beta_{\mathrm{H}}=\mathrm{f}_{\mathrm{H}}\left(\alpha_{\mathrm{H}}\right)$ or $\beta_{\mathrm{H}}=\mathrm{d}-\alpha_{\mathrm{H}}$ into (5A), (5B) and (5C), we have

$$
\begin{aligned}
& V_{H}\left(\alpha_{H}, f_{H}\left(\alpha_{H}\right)\right) \geq V_{H}\left(\alpha_{L}, B\left(\alpha_{L}, \alpha_{H}\right)\right) \\
& \left.V_{L}\left(\alpha_{H}, f_{H}\left(\alpha_{H}\right)\right) \leq V_{L}\left(\alpha_{L}, B\left(\alpha_{L}, \alpha_{H}\right)\right)\right) \\
& B\left(\alpha_{L}, \alpha_{H}\right) \leq f_{L}\left(\alpha_{L}\right)
\end{aligned}
$$

or

$$
\begin{aligned}
& V_{H}\left(\alpha_{H}, d-\alpha_{H}\right) \geq V_{H}\left(\alpha_{L}, B B\left(\alpha_{L}, \alpha_{H}\right)\right) \\
& \left.V_{L}\left(\alpha_{H}, d-\alpha_{H}\right) \leq \leq V_{L}\left(\alpha_{L}, B B\left(\alpha_{L}, \alpha_{H}\right)\right)\right) \\
& \operatorname{BB}\left(\alpha_{L}, \alpha_{H}\right) \leq f_{L}\left(\alpha_{L}\right)
\end{aligned}
$$

respectively.

Solving for $\alpha_{L}$ as a function of $\alpha_{H}$ in (7A) or (7B) or (7C) ((7A') or (7B') or (7C')) with the inequality being replaced by equality, we will denote the solution for (7A) or (7B) or (7C) $\left(\left(7 \mathrm{~A}^{\prime}\right)\right.$ or $\left(7 \mathrm{~B}^{\prime}\right)$ or $\left.\left(7 \mathrm{C}^{\prime}\right)\right)$ by $\operatorname{MXSH}\left(\alpha_{H}\right)$ or $\operatorname{MNSL}\left(\alpha_{H}\right)$ or $\operatorname{MXNL}\left(\alpha_{H}\right)\left(\operatorname{sMXSH}\left(\alpha_{H}\right)\right.$ or $\operatorname{sMNSL}\left(\alpha_{H}\right)$ or $\left.\operatorname{SMXNL}\left(\alpha_{H}\right)\right)$, respectively, with each representing the following: $\operatorname{MXSH}\left(\alpha_{H}\right)$ (or $\operatorname{sMXSH}\left(\alpha_{\mathrm{H}}\right)$ ) is a maximum value of $\alpha_{\mathrm{L}}$ (for a given $\alpha_{\mathrm{H}}$ ) that satisfies SSH when $\beta_{\mathrm{H}}=\mathrm{f}_{\mathrm{H}}\left(\alpha_{\mathrm{H}}\right)$ (or when $\beta_{\mathrm{H}}=\mathrm{d}-\alpha_{\mathrm{H}}$ ); $\operatorname{MNSL}\left(\alpha_{\mathrm{H}}\right)$ (or $\operatorname{sMNSL}\left(\alpha_{\mathrm{H}}\right)$ ) is a minimum level of $\alpha_{\mathrm{L}}$ (for a given $\alpha_{\mathrm{H}}$ ) that satisfies the SSL when $\beta_{\mathrm{H}}=\mathrm{f}_{\mathrm{H}}\left(\alpha_{\mathrm{H}}\right)$ (or when $\beta_{\mathrm{H}}=\mathrm{d}-\alpha_{\mathrm{H}}$ ); while $\operatorname{MXNL}\left(\alpha_{H}\right)$ is a maximum level of $\alpha_{L}$ (for a given $\alpha_{H}$ ) that satisfies NSL when $\beta_{\mathrm{H}}=\mathrm{f}_{\mathrm{H}}\left(\alpha_{\mathrm{H}}\right)$ (or when $\left.\beta_{\mathrm{H}}=\mathrm{d}-\alpha_{\mathrm{H}}\right)^{13}$

\footnotetext{
13 The mneumonic for remembering these constraints is MX is the maximium value of $\alpha_{\mathrm{L}}$ consistent with a set of constraints, MN the minimum; SH and SL denote the self-selection constaint for the high and low types
} 
Taking these into consideration, we can rewrite the maximization problem (5) as follows:

$$
\begin{aligned}
& \operatorname{Max}_{\alpha_{L}} V_{L}\left(\alpha_{L}, B\left(\alpha_{L}, \alpha_{H}\right)\right)=\left\{P_{L} U\left(w-d+\alpha_{L}\right)+\left(1-P_{L}\right) U\left(w-B\left(\alpha_{L}, \alpha_{H}\right)\right\}\right. \\
& \quad\left(\text { or } V_{L}\left(\alpha_{L}, B B\left(\alpha_{L}, \alpha_{H}\right)\right)=\left\{P_{L} U\left(w-d+\alpha_{L}\right)+\left(1-P_{L}\right) U\left(w-B B\left(\alpha_{L}, \alpha_{H}\right)\right\}\right)\right.
\end{aligned}
$$

s.t.

$$
\begin{array}{lc}
\alpha_{L} \leq \operatorname{MXSH}\left(\alpha_{H}\right)\left(\text { or } \operatorname{sMXSH}\left(\alpha_{H}\right)\right) & \text { (8A) }\left(\text { or }\left(8 \mathrm{~A}^{\prime}\right)\right) \\
\alpha_{\mathrm{L}} \geq \operatorname{MNSL}\left(\alpha_{\mathrm{H}}\right)\left(\text { or } \operatorname{sMNSL}\left(\alpha_{\mathrm{H}}\right)\right) & \text { (8B) } \left.\text { or }\left(8 \mathrm{~B}^{\prime}\right)\right) \\
\alpha_{\mathrm{L}} \leq \operatorname{MXNL}\left(\alpha_{\mathrm{H}}\right)\left(\text { or } \operatorname{sMXNL}\left(\alpha_{\mathrm{H}}\right)\right) & \text { (8C) } \left.\text { or }\left(8 \mathrm{C}^{\prime}\right)\right)
\end{array}
$$

In characterizing the solutions to the problem (8), we will first consider several critical contracts just as references for the analysis. Let $(\bar{\alpha}, \bar{\beta})$ or $(\overline{\bar{\alpha}}, \overline{\bar{\beta}})$ be a zero profit pooling contract under no moral hazard but with the amount of insurance set by the NS constraint for the H-type, or the one which provides full insurance and so leads to shirking for both types, respectively. That is,

$$
\bar{\beta}=\frac{\overline{\mathrm{P}}}{1-\overline{\mathrm{P}}} \bar{\alpha}=\mathrm{f}_{\mathrm{H}}(\bar{\alpha}) \quad \text { or } \quad \overline{\bar{\beta}}=\frac{\overline{\mathrm{P}}^{\mathrm{S}}}{1-\overline{\mathrm{P}}^{\mathrm{S}}} \overline{\bar{\alpha}}=\mathrm{d}-\overline{\bar{\alpha}},
$$

and

$$
\operatorname{MXSH}(\bar{\alpha})=\bar{\alpha}=\operatorname{MNSL}(\bar{\alpha}) \quad \text { and } \quad \operatorname{sMXSH}(\overline{\bar{\alpha}})=\overline{\bar{\alpha}}=\operatorname{sMNSL}(\overline{\bar{\alpha}}),
$$

since it is a zero-profit pooling contracts. We can then prove the following Lemma on the properties of the constraints:

Lemma 1

i) $\overline{\bar{\alpha}}>\bar{\alpha}>\alpha_{\mathrm{H}}^{\mathrm{o}}$.

ii) $\operatorname{MNSL}^{\prime}\left(\alpha_{\mathrm{H}}\right)>\operatorname{MXSL}^{\prime}\left(\alpha_{\mathrm{H}}\right)>1$ and $\operatorname{MXNL}^{\prime}\left(\alpha_{\mathrm{H}}\right)<0$,

while $\operatorname{sMNSL}^{\prime}\left(\alpha_{\mathrm{H}}\right)>\operatorname{sMXSH}\left(\alpha_{\mathrm{H}}\right)>1$ and $\operatorname{sMXNL}^{\prime}\left(\alpha_{\mathrm{H}}\right)<0$.

iii) $\operatorname{MXNL}(\bar{\alpha})>\bar{\alpha}$ when $\Delta \mathrm{P}_{\mathrm{L}}>\Delta \mathrm{P}_{\mathrm{H}}$, and $\operatorname{MXNL}(\bar{\alpha})<\bar{\alpha}$ when $\Delta \mathrm{P}_{\mathrm{L}}<\Delta \mathrm{P}_{\mathrm{H}}$, while $\operatorname{sMXNL}(\overline{\bar{\alpha}})<\overline{\bar{\alpha}}$.

The proof can be found in the Appendix, while the properties of the constraints are depicted in Figure $5 \mathrm{a}$ and $5 \mathrm{~b}$. The pooling contract $(\bar{\alpha}, \bar{\beta})$ is shown by Lemma 1 iii) to satisfy or fail to satisfy NSL condition when $\Delta \mathrm{P}_{\mathrm{L}}>\Delta \mathrm{P}_{\mathrm{H}}$ or when $\Delta \mathrm{P}_{\mathrm{L}}<\Delta \mathrm{P}_{\mathrm{H}}$, as depicted in Figure $5 \mathrm{a}$ or in Figure 5b, respectively.

The set of $\left(\alpha_{\mathrm{L}}, \alpha_{\mathrm{H}}\right)$ 's that satisfy all the constraints (8A)-(8C) or (8A')-(8C') is illustrated by the shaded area in Figure $5 \mathrm{~b}$ when $\Delta \mathrm{P}_{\mathrm{L}}<\Delta \mathrm{P}_{\mathrm{H}}$, while it is illustrated by the shaded area (left one) or by the sum of the two shaded areas (depending upon parameter values as will be discussed later) in Figure 5a when $\Delta \mathrm{P}_{\mathrm{L}} \geq \Delta \mathrm{P}_{\mathrm{H}}$. In characterizing PO contracts with single- 
crossing preferences under DIA, we will first denote by $\alpha_{\mathrm{L}}\left(\alpha_{\mathrm{H}}\right)$ the maximum value of $\alpha_{\mathrm{L}}$ 's that satisfy all the constraints $(8 \mathrm{~A})-(8 \mathrm{C})$ or $\left(8 \mathrm{~A}^{\prime}\right)-\left(8 \mathrm{C}^{\prime}\right)$ for a given $\alpha_{\mathrm{H}}$, and will define $\mathrm{G}$ and $G^{\prime}$ as follows:

$$
\begin{aligned}
& \mathrm{G}=\left\{\alpha_{\mathrm{H}} \mid \alpha_{\mathrm{L}}\left(\alpha_{\mathrm{H}}\right) \neq \varnothing, \beta_{\mathrm{H}}=\mathrm{f}_{\mathrm{H}}\left(\alpha_{\mathrm{H}}\right)\right\} \\
& \mathrm{G}^{\prime}=\left\{\alpha_{\mathrm{H}} \mid \alpha_{\mathrm{L}}\left(\alpha_{\mathrm{H}}\right) \neq \varnothing, \beta_{\mathrm{H}}=\mathrm{d}-\alpha_{\mathrm{H}}\right\}
\end{aligned}
$$

Denoting the supremum of the set $G$ (or $G^{\prime}$ ) by $\operatorname{Sup}(G)$ (or by $\operatorname{Sup}\left(G^{\prime}\right)$ ), we can then prove the following Lemma:

Lemma 2

i) $\operatorname{Sup}(\mathrm{G})<\bar{\alpha}$ when $\Delta \mathrm{P}_{\mathrm{L}}<\Delta \mathrm{P}_{\mathrm{H}}$ while $\operatorname{Sup}(\mathrm{G})=\bar{\alpha}$ when $\Delta \mathrm{P}_{\mathrm{L}} \geq \Delta \mathrm{P}_{\mathrm{H}}$.

ii) When $\Delta \mathrm{P}_{\mathrm{L}} \geq \Delta \mathrm{P}_{\mathrm{H}}$, Sup $\left(\mathrm{G}^{\prime}\right)<\overline{\bar{\alpha}}$. Also, there exists $\theta^{\prime}(>0)$ such that for $\theta<\theta^{\prime}$ $\operatorname{Sup}\left(\mathrm{G}^{\prime}\right)>\bar{\alpha}$.

The proof can be found in the Appendix. Lemma 2 suggests that a PO contract with single-crossing preferences under DIA may involve shirking for $\mathrm{H}$-type when $\Delta \mathrm{P}_{\mathrm{L}} \geq \Delta \mathrm{P}_{\mathrm{H}}$ while it is never the case when $\Delta \mathrm{P}_{\mathrm{L}}<\Delta \mathrm{P}_{\mathrm{H}}$.

Our analysis of characterizing PO contracts is parallel to that of Section 3.1. Note that a bench-mark contract $\left(\alpha_{\mathrm{H}}^{\mathrm{o}}, \beta_{\mathrm{H}}^{\mathrm{o}}\right)$ for H-type is the one that yields zero profit for H-type, i.e., $\pi_{\mathrm{H}}\left(\alpha_{\mathrm{H}}^{\mathrm{o}}, \beta_{\mathrm{H}}^{\mathrm{o}}\right)=\left(1-\mathrm{p}_{\mathrm{H}}\right) \beta_{\mathrm{H}}^{\mathrm{o}}-\mathrm{p}_{\mathrm{H}} \alpha_{\mathrm{H}}^{\mathrm{o}}=0$ while satisfying $\beta_{\mathrm{H}}^{\mathrm{o}}=\mathrm{f}_{\mathrm{H}}\left(\alpha_{\mathrm{H}}^{\mathrm{o}}\right)$, i.e., a PO contract for H-type under PMH when A1 holds. Starting from the contract $\left(\alpha_{\mathrm{H}}^{\mathrm{o}}, \beta_{\mathrm{H}}^{\mathrm{o}}\right)$ for H-type that involves no subsidy from L-type, we will increase $\alpha_{H}$ so as to increase (or decrease) the amount of subsidy from L-type and thereby increase utility of H-type in order to figure out the changes in utilities for both types of individuals.

To characterize a set of PO contracts that corresponds to the change in $\alpha_{H}$ or in $\alpha_{L}\left(\alpha_{H}\right)$, we need to analyze the relationship between $\alpha_{\mathrm{L}}$ and $\mathrm{V}_{\mathrm{L}}$, which is not straightforward. As the subsidy increases, i.e., as $\alpha_{\mathrm{H}}$ increases under the strict NS or the full-insurance condition for H-type, there are, as in the case of PAS, two conflicting effects upon the amount of insurance for L-type or upon their welfare: the positive effect caused by the relaxed self-selection constraint and the negative effect caused by the more-binding profit constraint. What is critically different in this case from the case of PAS is that the positive effect is limited by the NS constraints. When the NS constraint is tighter for L-type than for H-type (i.e., when $\Delta \mathrm{P}_{\mathrm{L}}<\Delta \mathrm{P}_{\mathrm{H}}$ ), the increase in the amount of insurance for L-type that results from the relaxed SSH constraint may be limited by the NSL constraint. When H-type is faced with tighter NS constraint than L-type (i.e., when $\Delta \mathrm{P}_{\mathrm{L}} \geq \Delta \mathrm{P}_{\mathrm{H}}$ ), on the other hand, the amount of insurance for L-type may be constrained by NSH constraint; under certain circumstances, interestingly, the subsidy may involve so much insurance for the H-type that they shirk (i.e., Sup (G) $>\bar{\alpha}$ as shown by the shaded area on the right hand side of Figure 5a), despite the fact that the subsidy (satisfying the SSH constraint) entailing shirking is more costly than the subsidy that does not entail shirking. This will be discussed in detail below.

When $\alpha_{\mathrm{L}}$ is decreasing in $\alpha_{\mathrm{H}}$, so is the utility $V_{\mathrm{L}}$ of L-type. If $\alpha_{\mathrm{L}}$ is increasing in $\alpha_{\mathrm{H}}$, on the other hand, $V_{L}$ could be increasing or decreasing in $\alpha_{H}$, depending upon whether or not 
the effect of the relaxed SS constraint outweighs that of the more-binding profit constraint. ${ }^{14}$ Note, however, that the utilitarian social welfare is increasing in $\alpha_{\mathrm{H}}$ so long as $\alpha_{\mathrm{L}}$ is increasing in $\alpha_{\mathrm{H}}$.

Taking these into account, we will characterize $\mathrm{PO}$ allocations with single-crossing preferences under DIA in Case I $\left(\Delta \mathrm{P}_{\mathrm{L}} \geq \Delta \mathrm{P}_{\mathrm{H}}\right)$ and in Case II $\left(\Delta \mathrm{P}_{\mathrm{L}}<\Delta \mathrm{P}_{\mathrm{H}}\right)$

\section{4-1-1. Case I : $\Delta \mathrm{P}_{\mathrm{L}} \geq \Delta \mathrm{P}_{\mathrm{H}}$ or $\mathrm{f}_{\mathrm{L}}(\alpha) \geq \mathrm{f}_{\mathrm{H}}(\alpha)$}

When the NSH constraint has to be satisfied, we cannot increase the subsidy further beyond that associated with the pooling allocation on the NSH locus, which is $\mathrm{A}(\bar{\alpha}, \bar{\beta})$ as shown in Figure 6a. If we allow for shirking on the part of H-type, however, we may be able to give $\mathrm{H}$-type a utility higher than $\mathrm{V}_{\mathrm{H}}(\bar{\alpha}, \bar{\beta}) \equiv \overline{\mathrm{v}}_{\mathrm{H}}$. In other words, we could start to increase $\alpha_{H}$ from a contract $\left(\bar{\alpha}_{H}, \bar{\beta}_{H}\right)$ on the full-insurance line such that $V_{H}\left(\bar{\alpha}_{H}, \bar{\beta}_{H}\right)=\bar{v}_{H}$. (See Figure $6 \mathrm{~b}$, where a contract $\left(\bar{\alpha}_{\mathrm{H}}, \bar{\beta}_{\mathrm{H}}\right)$ is illustrated by B). The feasibility of this option would depend upon whether or not there exists a contract for L-type that satisfies the SSL and zero-profit constraints given $\left(\bar{\alpha}_{H}, \bar{\beta}_{H}\right)$. Alternatively, in terms of Figure 5a, it will depend upon whether or not $\operatorname{Sup}\left(G^{\prime}\right)>\bar{\alpha}$. As Lemma 2 ii) indicates, if $\theta$ is small so that the required amount of subsidy that each L-type has to pay is small, the subsidy inducing H-type to shirk would be feasible. Figure $6 \mathrm{~b}$ shows that the subsidy is feasible as the iso-profit line $\mathrm{Z}$ ' for L-type yielding zero-profit given the full-insurance contract B for H-type is located lower than C, which strictly satisfies both SSL and NSL given B for H-type.

Furthermore, we can consider a case when a PO contract always involves shirking for $\mathrm{H}$ type. Suppose that $\operatorname{Sup}\left(\mathrm{G}^{\prime}\right)>\bar{\alpha}$. As the subsidy increases from $\bar{\alpha}$, L-type may initially suffer from utility loss because B will yield lower profit for H-type than A under A1. As the subsidy continues to increase, however, the utility of L-type could increase when $\theta$ is small. That is, this pareto-improving arrangement is feasible because the additional subsidy is negligible when $\theta$ is small. Consider the case where there are a negligible number of high types. Then the cost of subsidization is negligible. As we increase insurance for H-type from $\mathrm{B}$ to $\mathrm{E}$ as in Figure 6c, the corresponding additional cost of subsidization is so small (as is indicated by the line Z" in Figure $6 \mathrm{c}$ ) that the resulting utility for L-type may increase (from $\bar{V}_{L}$ to $\widehat{V}_{L}$ in Figure 6c). Ultimately, we only want to weaken the SSH constraint to the point where it does not violate the SSL constraint, i.e. it must be on the optimal PMH contract

for the L type. The resulting utility possibility curve (for small $\theta$ ) is depicted as in Figure 7 , which suggests that any contract involve non-shirking for H-type is not PO.

More formally we can establish the following Theorem on PO in Case I:

\section{Theorem 3 (PO in Case I)}

Suppose that A1 holds for each type. Then, the followings are true:

1) There exists $\bar{\theta}(>0)$ such that for $\theta>\bar{\theta}$, the followings are true: i) a PO does not entail shirking; ii) a pooling contract on the NSH locus achieves the UO outcome.

2) There exists $\hat{\theta}(\in(0, \bar{\theta}))$ such that for $\theta<\hat{\theta}$, all the PO allocations are separating ones

\footnotetext{
14 Obviously, the more insurance that the L type receives, the better off he is, but going on in the backgroundto satisfy the zero profit locus - there are changes to the premium he has to pay, and the premium reflects not just the cost of his own insurance, but the subsidy he is providing to the H-type.
} 
and entail shirking by H-type.

The proof can be found in the Appendix. So long as A1 holds for H-type, a PO contract for $\mathrm{H}$ strictly satisfies NSH constraint (even when NSH is more stringent than NSL) unless $\theta$ is low. These suggest that when $\theta$ is high, a pooling contract with incomplete insurance is PO and thus UO. This contrasts with the situation where there is no moral hazard, where UO entails pooling, but full insurance. Recall that under PAS, any pooling allocation with less than full insurance could be improved upon with a set of separating contrasts. Now, the NS constraint keeps any other contract offering more insurance to H-type from being Paretosuperior to the original pooling one. ${ }^{15}$

Theorem 3 also demonstrates that a PO allocation should entail shirking on the part of $\mathrm{H}$ type when the portion of H-type is small. Note that, for a small $\theta$, any separating contract entailing no shirking will be Pareto-dominated by a pooling contract A in Figure 6a, which is in turn, as shown by Figure 6c, Pareto-dominated by a separating contract (F, E) that entails shirking for H-type. The amount of insurance for L-type, which would be severely limited by the stringent NSH constraint, can be considerably increased by allowing H-type to shirk, making both types better off when the portion of H-type is small. Note that in a PMH model without AS there cannot exist shirking in the optimal outcome, ${ }^{16}$ and in the PAS model the H-type always gets full insurance. Under DIA, however, the SS constraints interact with NS constraints so that a PO outcome may entail efficiency loss even for H-type relative to the one $\left(\alpha_{\mathrm{H}}^{\mathrm{o}}, \beta_{\mathrm{H}}^{\mathrm{o}}\right)$ that is optimal under PMH under A1. In other words, when the optimal contract for $\mathrm{H}$-type under PMH entails non-shirking under $\mathrm{A} 1$, the presence of adverse selection as well as moral hazard may induce H-type to shirk.

\section{4-1-2. Case II: $: \Delta \mathrm{P}_{\mathrm{L}}<\Delta \mathrm{P}_{\mathrm{H}}$ or $\mathrm{f}_{\mathrm{L}}(\alpha)<\mathrm{f}_{\mathrm{H}}(\alpha)$}

The problem for a PO contract in Case II (with single-crossing preferences) will be the same as (5) when $\beta_{\mathrm{H}}=\mathrm{f}_{\mathrm{H}}\left(\alpha_{\mathrm{H}}\right)$. Figures 5b shows that as the subsidy or $\alpha_{\mathrm{H}}$ increases, $\alpha_{\mathrm{L}}\left(\alpha_{\mathrm{H}}\right)$ increases initially (as the SSH constraint is binding) until $\alpha_{\mathrm{H}}$ reaches a certain point at which the NSL constraint becomes binding; $\alpha_{L}\left(\alpha_{H}\right)$ decreases thereafter (as the NSL constraint continues to be binding) until $\alpha_{\mathrm{H}}$ reaches a point where the SSL constraint has to be binding. Further increases in $\alpha_{H}$ satisfying the constraints are not possible. We can then establish the following theorem on the optimality in Case II.

Theorem 4 (Optimality in Case II with single-crossing preferences)

A pooling contract is not PO. Under A1, a PO contract strictly satisfies NSH constraint and it does not entail shirking for any type.

The result is driven by the restriction upon the amount of insurance for L-type that is

\footnotetext{
15 The optimality of a pooling contract under the double informational asymmetry is also shown by Whinston (1983), who analyzed the optimal provision of retirement insurance under the double informational asymmetry in a special case when $\Delta \mathrm{P}_{\mathrm{H}}=\Delta \mathrm{P}_{\mathrm{L}}$, while confining his analysis to the contracts that do not allow individuals to shirk.

${ }^{16}$ In particular, when a full-insurance contract is just barely dominated by a contract at the non-shirking constraint, the $\mathrm{UO}$ allocation is supported by a separating contract involving a full-insurance contract for H-type for almost every $\theta$.
} 
imposed by their NS constraint. As a consequence,. The benefit of the subsidy from L-type to H-type from the relaxation of SSH constraint is limited by the relatively severe NSL constraint. In particular, the L-type individuals would not be able to avail themselves of the maximum amount of insurance consistent with the SS constraints (which is the amount of insurance offered by a pooling contract), because of the NSL constraint. This is shown by Figure $5 \mathrm{~b}$ where $\operatorname{Sup}(\mathrm{G})<\bar{\alpha}$, and this is why a pooling contract is never PO. ${ }^{17}$ The result on the non-optimality of a pooling contract in this case can be compared to the case of PAS, in which the utilitarian optimum always requires pooling at full insurance. ${ }^{18}$ Note also that, so long as A1 holds for each type, it would not pay H-type to shirk in this case as the amount of insurance for L-type is not further constrained by the NSH constraint as in Case I. In Case II with single-crossing preferences, therefore, the introduction of moral hazard would not affect the efficiency of a PO allocation under adverse selection: a PO contract for H-type under DIA can preserve its efficiency relative to $\mathrm{PMH}$.

\section{4-2. Multiple-Crossing Preferences}

The single-crossing property of preferences may be violated in Case II when $f_{H}(\alpha)>$ $\mathrm{f}_{\mathrm{L}}(\alpha)$. In this case the SS constraint is in a sense tighter than it would be the case under the single-crossing preferences, so that the chance for the optimality of a pooling contract may increase. ${ }^{19}$ The tighter SS constraint also keeps a PO contract from being on the NS locus, which may lead to a PO contract that entails shirking even when A1 holds for each type. In figuring out these properties of a PO allocation we will assume in this analysis that A1 holds for both types.

This paper does not provide a complete characterization of the set of PO contracts under multi-crossing preferences, but rather highlights an important feature of a PO contract with multi-crossing preferences that can be compared to those under single-crossing preferences: a PO contract under DIA may entail efficiency loss for one or both types relative to PMH. For our purposes, it suffices to confine our analysis to a set of separating PO allocations that yield zero profit for each type as well as to pooling PO allocations. ${ }^{20} 21$

In examining PO's of these types we will divide $(\alpha, \beta)$ space into the four different regions $\mathrm{R}(1, \mathrm{~h})(\mathrm{l}=\mathrm{L}, 0, \mathrm{~h}=\mathrm{H}, 0)$, where 1-type and h-type shirk: $\mathrm{R}(0,0)$ or $\mathrm{R}(\mathrm{L}, \mathrm{H})$ is a region

\footnotetext{
17 Alternatively: We know from proposition 1 that if there is a pooling equilibrium, it must be at the intersection of the zero profit-pooling line and the NS(L) constraint (point $\mathrm{C}$ in figure 6-1). But a separating set of contracts entailing $\{\mathrm{C}, \mathrm{X})$, where $\mathrm{X}^{*}$ is any point along $\mathrm{H}$-indifference curve through $\mathrm{C}$ above $\mathrm{C}$ entails a lower subsidy, and therefore there can exist a set of contracts that Pareto-dominates a pooling contract $\mathrm{C}$.

18 Remember that a PO is not PO for small $\theta$ in Case I, as is shown in Theorem 3.

19 The way to think about this is the following: if the H type are very risk averse, then the self-selection constraint is not very binding, since even mild reductions in insurance are viewed as very costly. But with the single crossing property violated, the H-type's indifference curve may be even flatter than the L-types.

20 Note that neither a separating contract yielding zero profit for each type nor a pooling contract may be PO. We just concentrate in this paper, however, on the cases when at least one of the above contracts is PO, in order to show that a PO may have the peculiar property mentioned above under multi-crossing preferences.

21 Under pure adverse selection there is a possibility that a separating contract yielding positive profits is an RS equilibrium in the presence of multi-crossing preferences (caused by difference in risk aversion, for example) as there may not exist a contract that can profitably attract low-risk type only given the putative equilibrium contracts. Under moral hazard as well as adverse selection, however, a separating contract yielding positive profits cannot be sustained as an equilibrium, because we can always think of a contract that can profitably attract non-shirking H-type, given the putative equilibrium contracts which should entail shirking for $\mathrm{H}$-type.
} 
where no type shirks or a region where both types shirk, respectively, whereas $\mathrm{R}(\mathrm{L}, 0)$ or $\mathrm{R}(0, \mathrm{H})$ is a region where only L-type shirks or a region where only H-type shirks, respectively. We can then first consider the four different regional PO's, denoted by PO$\mathrm{R}(1, \mathrm{~h})$, each of which is $\mathrm{PO}$ within a region $\mathrm{R}(1, \mathrm{~h})$. After figuring out a regional $\mathrm{PO}$ contract PO-R $(1, h)$, we will compare each regional PO contract PO-R $(1, \mathrm{~h})$ with the others to determine a global PO contract, which is denoted by PO-G.

In particular, let $\mathrm{k}$ be the type $\mathrm{H}$ or $\mathrm{L}$ of an individual whose accident probability is higher than that of the other type under a contract PO-R(1,h). For example, $\mathrm{k}=\mathrm{L}$ for a contract PO-R(L,0) while $\mathrm{k}=\mathrm{H}$ for the other regional PO contracts. Also, let us first denote by $\mathrm{S}(1, \mathrm{~h})$ a set $\left\{\left(\alpha_{\mathrm{L}}, \beta_{\mathrm{L}}\right),\left(\alpha_{\mathrm{H}}, \beta_{\mathrm{H}}\right)\right\}$ of separating contracts that satisfies strictly both SSL and SSH:

$$
V_{i}\left(\alpha_{L}, \beta_{L}\right)=V_{i}\left(\alpha_{H}, \beta_{H}\right) \quad \text { for } i=H, L
$$

We can then prove the following Lemma on the properties of $S(1, h)\left(\equiv\left\{\left(\alpha_{L}, \beta_{L}\right),\left(\alpha_{H}, \beta_{H}\right)\right\}\right)$.

Lemma 3

i) There exists no $\mathrm{S}(1, \mathrm{H})$ that is $\mathrm{PO}-\mathrm{R}(1, \mathrm{H})($ for $\mathrm{l}=\mathrm{L}, 0)$.

ii) For $\mathrm{S}(0,0),\left.\frac{\partial \pi_{\mathrm{H}}\left(\alpha_{\mathrm{H}}, \beta_{\mathrm{H}}\right)}{\partial \alpha_{\mathrm{L}}}\right|_{\pi_{\mathrm{L}}\left(\alpha_{\mathrm{L}}, \beta_{\mathrm{L}}\right)=0}<0 ;$ for $\mathrm{S}(\mathrm{L}, 0),\left.\frac{\partial \pi_{\mathrm{L}}\left(\alpha_{\mathrm{L}}, \beta_{\mathrm{L}}\right)}{\partial \alpha_{\mathrm{H}}}\right|_{\pi_{\mathrm{H}}\left(\alpha_{\mathrm{H}}, \beta_{\mathrm{H}}\right)=0}<0$

iii) There always exists $\mathrm{S}(0,0)\left(\equiv\left\{\left(\alpha_{\mathrm{L}}, \beta_{\mathrm{L}}\right),\left(\alpha_{\mathrm{H}}, \beta_{\mathrm{H}}\right)\right\}\right)$ such that $\pi_{\mathrm{H}}\left(\alpha_{H}, \beta_{H}\right)>0$ and $\pi_{\mathrm{L}}\left(\alpha_{\mathrm{L}}, \beta_{\mathrm{L}}\right)=0$.

The proof can be found in the Appendix. Now we can then establish the necessary conditions for a regional PO to satisfy as follows:

Proposition 2

Suppose that preferences exhibit multi-crossing property and that A1 holds for both types. A necessary condition for PO-R $(1, \mathrm{~h})$ is as follows:

(1) A set $\left\{\left(\alpha_{L}, \beta_{L}\right),\left(\alpha_{H}, \beta_{H}\right)\right\}$ of separating contracts yielding zero profit for each type is PO$\mathrm{R}(1, \mathrm{~h})$ only if it is $\mathrm{S}(1, \mathrm{~h})$ when it exists, or, otherwise,

$$
\mathrm{V}_{\mathrm{k}}\left(\alpha_{\mathrm{k}}, \beta_{\mathrm{k}}\right)=\mathrm{V}_{\mathrm{k}}\left(\alpha_{\mathrm{k}}, \beta_{\mathrm{k} \prime}\right) \text { \& } \beta_{\mathrm{k}}=d-\alpha_{\mathrm{k}} \text { or } \beta_{\mathrm{k}}=\mathrm{f}_{\mathrm{k}}\left(\alpha_{\mathrm{k}}\right) \quad \text { where } \mathrm{k}, \mathrm{k}^{\prime}=\mathrm{L}, \mathrm{H}
$$

Also, there always exists a set of separating contracts that yields zero profit for each type and satisfies the necessary condition (1).

(2) A pooling contract $(\alpha, \beta)$ is PO-R(1,h) only if (a) $\alpha+\beta=d$ or (b) if $\beta=\mathrm{f}_{\mathrm{i}}(\alpha)$ for $\mathrm{i}=\mathrm{L}, \mathrm{H}$.

The proof can be found in the Appendix. Proposition 2 presents necessary conditions for an allocation to be PO-R(i,j) under multi-crossing preferences and shows that a separating contract satisfying (1) exists. As shown by (A,B), (C,D), (E,F) in Figure 9a, a separating PO$\mathrm{R}(1, \mathrm{~h})$ involving no subsidy should strictly satisfy both of the SS constraints whenever possible. A pooling PO-R $(1, \mathrm{~h})$ contract has to be either on the NS locus of one type or on the full-insurance line because, otherwise, a pareto-improving arrangement will be made possible. Take, for example, a pooling contract Z' as in Figure 9b. We can offer H-type more insurance along his indifference curve, satisfying SSH constraint and making higher profits for H-type 
while maintaining the same level of utility for each type.

Now let us turn to a global PO contract, PO-G. Concentrating ourselves on the set of separating PO-G contracts, we can establish the following Proposition:

Proposition 3

A separating PO-G that yields zero profit for each type is unique if it exists.

The proof can be found in the Appendix. Proposition 3 can be used to characterize an RS equilibrium under the double informational asymmetry (DIA), as will be shown in the next section.

Which of these PO-R(1,h)'s is PO-G would depend upon various factors, including (a) the curvature of the indifference curve (the degree of risk aversion); (b) the position of the $\mathrm{H}$ non-shirking constraint (the "tighter" it is, the greater the benefit from allowing H-type to shirk; (c) the change in accident probability from crossing the NS locus (which is one of the factors determining the tightness of the NS constraint, i.e. when $\Delta \mathrm{p}$ is small, then the NS constraint is tight, but the cost of shirking is low).

The fact that one of the four PO-R(1,h)'s is PO-G suggests that a PO contract under multicrossing preferences has some features different from those under single-crossing preferences. First, it may strictly satisfy both of the SS constraints, in which case no PO contract is on the NS or full-insurance locus. Second, more importantly, a separating PO contract may involve inefficiency compared to the case of single-crossing preferences. It may entail shirking for one or both types of individuals (even under A1) or insufficient amount of insurance (relative to NS constraint) even if it does not entail shirking. Also, a pooling contract either involves full insurance or strictly satisfies one of the two NS constraints, so that the allocation may involve shirking for one or both of the two types even under A1. A pooling contract $\mathrm{Z}$ in Figure 9b, for example, could be PO-G, while it induces both types to shirk.

A candidate for a separating PO-G contract, however, may be dominated by a pooling contract, depending upon distributions of types. Unless contracts both for $\mathrm{H}$ and for L-type strictly satisfy their respective NS constraints, a separating contract involving no crosssubsidy may be pareto-dominated by a pooling contract that is on NSH or NSL locus when $\theta \approx 1$ or $\theta \approx 0$, respectively. This suggests that, as is shown in Figure $9 \mathrm{a}$, a separating contract could be dominated by a pooling contract $\mathrm{X}$ or $\mathrm{Y}$ in Figure $9 \mathrm{a}$ when $\theta \approx 0$ or when $\theta \approx 1$, respectively. This implies that in the presence of multi-crossing preferences, which is due to the double informational asymmetry, a separating contract with no subsidy may not be supported as a PO unless $\theta$ is in the intermediate range between 1 and 0 , because it could be not only H-type but also L-type who suffers from the efficiency loss associated with selfselection. This will have an important consequence for the equilibrium existence, which will be dealt with in the next section.

Although we do not provide a complete characterization of PO with the preferences of multi-crossing property in this paper, we can establish the following Theorem on the optimality in Case II.

Theorem 5 (Optimality with multiple-crossing preference)

Suppose that A1 holds for both types.

i) A PO allocation under multi-crossing preferences, which is a pooling or a separating one that involves no subsidy, may entail shirking for one type or for both types of individuals. 
Also, it may involve less-than-full insurance when entailing shirking and it may not strictly satisfy NS constraint when entailing non-shirking.

ii) There exists $\tilde{\theta}(>0)$ such that, for $\theta<\tilde{\theta}$, a PO allocation cannot be achieved by a separating contract with no cross-subsidy while it can be achieved by a pooling contract that is on the NSL locus. There also exists $\tilde{\theta}^{\prime}(<1)$ such that, for $\theta>\tilde{\theta}^{\prime}$, a PO allocation may not be achieved not by a separating contract with no cross-subsidy but by a pooling contract that is on the NSH locus

The proof can be found in the Appendix. Theorem 5 suggests the two features of PO allocations with multi-crossing preferences, which are not true in the case of single-crossing preferences. First, in Case II, a PO can be achieved by a pooling contract as well in the presence of multi-crossing preferences, which is not the case under single-crossing preferences. Second, because of the interaction of self-selection constraint with moral hazard constraint the distinctive features of a PO allocation (compared to the case of pure moral hazard or of pure adverse selection) still hold - a PO allocation may involve shirking, which would not be optimal under PMH. In particular, the presence of multi-crossing preferences tends to reinforce this feature as a PO allocation may involve shirking even for both types of individuals. This result comes mainly from the fact that L-type individuals may have stronger preference for insurance than H-type in a certain region. This type of preference on the part of L-type would lead to peculiar features of a PO contract: a contract for H-type, as well as the one for L-type, may entail efficiency loss associated with selfselection in the form of insufficient amount of insurance well below the level that is dictated by NS(i) $(\mathrm{i}=\mathrm{H}, \mathrm{L})$ or of shirking (full insurance). This suggests that a separating contract with no cross-subsidy could be dominated by a pooling contract when $\theta$ is high as well as when $\theta$ is low. Note, however, that, when $\theta \approx 1$, a separating contract may not be dominated by any pooling contract, as is illustrated by a contract $(\mathrm{A}, \mathrm{Y})$ in Figure $9 \mathrm{~b}$, while, when $\theta \approx 0$, any separating contract will be dominated by a pooling contract X (in Figure 9a) on the NSL locus .

\section{Equilibrium under Adverse Selection and Moral Hazard (DIA)}

In this section we analyze the existence and nature of a Nash or Rothschild-Stiglitz (RS) equilibrium under adverse selection and moral hazard. In particular, we will first examine how the presence of moral hazard affects the conditions for the existence of equilibrium under adverse selection and the possibility of a pooling equilibrium. ${ }^{22}$

\section{5-1. Existence of RS Equilibrium}

We first recall the following theorem on equilibrium existence under PAS.

Theorem 6 (Equilibrium under PAS, Rothschild-Stiglitz (1976) )

\footnotetext{
22 Chassagnon and Chiappori (1997), who analyzed the issue of equilibrium existence under adverse selection and moral hazard when the single-crossing property is violated, demonstrated some non-standard (compared to Rothschild-Stiglitz) results on the equilibrium, such as multiple equilibria, existence or non-existence of equilibrium (regardless of distribution), etc..
} 
If the single crossing property holds,

i) A necessary and sufficient condition for the existence of an RS equilibrium is that there exists a Pareto optimal allocation with no subsidy.

ii) There exists $\theta_{1}(>0)$ for any given $\left(\mathrm{P}_{\mathrm{L}}, \mathrm{P}_{\mathrm{H}}\right)$ (and utility function), where $\theta_{1}$ is defined in Theorem 1, such that an RS equilibrium $\left\{\left(\alpha_{\mathrm{L}}^{*}, \beta_{\mathrm{L}}^{*}\right),\left(\alpha_{\mathrm{H}}^{*}, \beta_{\mathrm{H}}^{*}\right)\right\}$ does not exist under PAS for $\theta<\theta_{1}$ and does exist for $\theta \geq \theta_{1}$.

iii) If an equilibrium exists, it is a separating equilibrium

The proof is easy. The pair of contracts that maximizes $V_{L}$ subject to the SS(i) entails a subsidy if $\theta<\theta_{1}$.

Theorem 7 (Equilibrium with Adverse Selection and Moral Hazard)

i) If there exists a PO without any cross subsidization, it is an RS equilibrium

ii) A necessary condition for a pooling RS equilibrium is that there exists a pooling $\mathrm{PO}$ allocation. A necessary condition for a RS pooling equilibrium is that the indifference curve of the L-type be steeper than that of the H-type below the putative equilibrium, and this cannot occur if the single crossing property is satisfied.

iii) A pooling allocation may be an RS equilibrium if the single crossing property is not satisfied.

A PO without cross subsidization must be a separating equilibrium. There is no way that a separating equilibrium allocation for $\mathrm{V}_{\mathrm{L}}$ can be improved upon if it is a $\mathrm{PO}$ without cross subsidy. If a pooling allocation is not $\mathrm{PO}$, there always exists another allocation that would make everyone better off and break even. The discussion of the (iii) of Theorem 7 is postponed until the next subsection.

Now we can see from Proposition 3 that pareto optimality is a necessary condition for an allocation to be an RS equilibrium.

Proposition 4

A set $\left\{\left(\alpha_{L}, \beta_{L}\right),\left(\alpha_{H}, \beta_{H}\right)\right\}$ of separating contracts is an RS equilibrium under multicrossing preferences if and only if it is global PO and $\pi_{i}\left(\alpha_{i}, \beta_{i}\right)=0$ for each $i=H, L$.

The proof can be found in the Appendix. Using Proposition 3 and 4 we can characterize the RS equilibrium under the double informational asymmetry as follows:

Theorem 8 (Equilibrium under Moral Hazard and Adverse Selection)

Suppose that A1 holds for both types. An RS equilibrium, if it exists, is unique. Under single-crossing preferences, it entails incomplete insurance and non-shirking for H-type individuals, who bear no efficiency costs compared to PMH case. This may not be true in the case of multi-crossing preferences: an RS equilibrium may entail shirking or insufficient amount of insurance (relative to NS constraint) for H-type as well as for L-type.

The proof is delegated to the Appendix. Theorem 8 suggests that, unless preferences 
violate the single-crossing property, an RS equilibrium would not involve any efficiency loss (in terms of insufficient amount of insurance or of shirking) compared to PMH or to PAS. Under multi-crossing preferences, however, an equilibrium may entail shirking or insufficient amount of insurance (relative to NS constraints) for one or both types of individuals. This is because the multi-crossing property of preferences may keep a contract for a riskier individual from being on his NS locus or on the full-insurance locus. Also, the result on the uniqueness of an RS equilibrium can be compared to Chassagnon- Chiappori (1997), who argued that there may exist multiple RS equilibria which are pareto-ranked to each other in the presence of multi-crossing preferences under DIA.

\section{Conditions for existence}

Now we will discuss how the presence of moral hazard affects the likelihood of equilibrium non-existence under adverse selection given the assumption (A1). The NS constraint for each type affects the equilibrium existence differently, depending upon whether Case I or Case II holds and whether or not the preferences satisfy single-crossing property if Case II holds. The presence of NSH constraint, resulting in incomplete insurance for H-type, decreases the likelihood of equilibrium existence, compared to the case of PAD. This is because the lower amount of insurance for H-type associated with the moral hazard constraint leads to a lower amount of insurance for L-type, making a pooling contract relatively more attractive, and hence making equilibrium existence relatively less likely. ${ }^{23}$ Figure $10 \mathrm{~b}$ illustrates this point: as NSH constraint gets tighter (from $f_{H}$ to $f_{H}{ }^{\prime}$ ) the resulting utility $V_{L}$ for L-type becomes lower. The NSL constraint, on the other hand, may increase the likelihood of equilibrium existence. That is, the tighter moral hazard constraint for the Ltype reduces the scope of potential deviant contracts (against $\left.\left\{\left(\alpha_{\mathrm{L}}^{\mathrm{e}}, \beta_{\mathrm{L}}^{\mathrm{e}}\right),\left(\alpha_{\mathrm{H}}^{\mathrm{e}}, \beta_{\mathrm{H}}^{\mathrm{e}}\right)\right\}\right)$ in Case II and thereby may increase the likelihood of equilibrium existence. Figure 10a shows that as NHL constraint gets tighter (from $f_{L}$ to $f_{L}^{\prime}$ ) the scope for equilibrium non-existence becomes larger. $^{24}$

We will now analyze more specifically how the change in the NS constraint for each type affects the equilibrium existence under adverse selection. In particular, we will see how the threshold value of $\theta$ for the equilibrium non-existence, $\tilde{\theta}$, changes as $\Delta \mathrm{P}_{\mathrm{L}}$ (or $\Delta \mathrm{P}_{\mathrm{H}}$ ) changes. Although it is not certain in general whether or not $\tilde{\theta}>\theta_{1}\left(\theta_{1}\right.$ : the threshold value of $\theta$ for the non-existence under PAS), we can establish the following results.

\section{Theorem 9}

Suppose that A1 holds for both types.

i) There always exists $\tilde{\theta}(>0)$ such that an RS equilibrium does not exist for $\theta<\tilde{\theta}$. And, in Case II with single-crossing preferences, the lower threshold value $\tilde{\theta}$ for the nonexistence of an RS equilibrium has the following property: $\tilde{\theta}$ is increasing in $\Delta \mathrm{P}_{\mathrm{L}}$ while it is decreasing in $\Delta \mathrm{P}_{\mathrm{H}}$.

ii) In Case II with multi-crossing preferences there also exists $\tilde{\theta}^{\prime}(<1)$ as well such that an RS equilibrium may not exist for $\theta>\tilde{\theta}^{\prime}$.

\footnotetext{
23 When the multi-crossing property holds, the stricter incentive constraint for H-type would increase the likelihood of equilibrium existence as the amount of insurance for H-type remains the same as full-insurance. 24 The fact that NS constraint for each type affects equilibrium existence differently has also been pointed out by $\operatorname{Jack}(2002)$.
} 
The proof is delegated to the Appendix. In particular, Theorem 9 i) shows that as a PO contract for L-type does not strictly satisfy the NS constraint under A1, there always exists a small value of $\theta$ for which an RS equilibrium does not exist. Also, if the multi-crossing property holds for preferences, an RS equilibrium may not exist when the portion of one type is very high compared to the other type, because the probability of accident can be higher for a shirking L-type than for a non-shirking H-type. ${ }^{25}$

\section{5-2. Possibility of a Pooling Equilibrium}

Theorem 6 asserts that a pooling equilibrium never exists if the single crossing property holds, with the indifference curve of the low risk being flatter than for the high risk. As we noted, however, under plausible assumptions, the single crossing property may not hold in our model. Consider the point on the pooling zero profit line where the line hits the NSH locus. Any contract near the pooling contract below the $\mathrm{V}_{\mathrm{L}}$ indifference curve through that point is preferred by H-types, and cannot break the pooling contract. Whether the pooling contract is an equilibrium requires a global analysis, i.e. there must exist a point above the zero profit locus for the $\mathrm{L}$ type, above the $\mathrm{V}_{\mathrm{H}}$ indifference curve through the pooling contract, and below the $\mathrm{V}_{\mathrm{L}}$ indifference curve through the pooling contract. It can be shown that a "breaking contract" must lie below the NSL locus, and the tighter that is, the less likely that is to be.

We will identify in this subsection some cases in which a pooling equilibrium exists, which can arise when individuals are different in their risk-aversion as well as in their riskiness. (Recall that so far in the analysis, we have assumed that individuals differ only in their risk properties, not in their preferences.). Here we will consider the case when $\mathrm{f}_{\mathrm{L}}(\alpha)=\mathrm{f}_{\mathrm{H}}(\alpha) \equiv$ $\mathrm{f}(\alpha)$, while, as will be noted below, the same underlying arguments can be applied to the other cases when $\mathrm{f}_{\mathrm{L}}(\alpha) \neq \mathrm{f}_{\mathrm{H}}(\alpha)$. We will also focus upon the case when the assumption A1 is satisfied so that a PO contract under PMH may strictly satisfy the NS constraint. The pooling contract that we consider as a candidate for an equilibrium is the one $(\bar{\alpha}, \bar{\beta})$ on the NS locus, i.e., $\bar{\beta}=\mathrm{f}(\bar{\alpha})=\frac{\overline{\mathrm{P}}}{1-\overline{\mathrm{P}}} \bar{\alpha}$, which is illustrated by A in Figure 11 .

\section{Difference in Risk-Aversion}

Suppose that L-type individuals are more risk-averse than H-type individuals, i.e., that $-\frac{\mathrm{U}_{\mathrm{L}}^{\prime \prime}}{\mathrm{U}_{\mathrm{L}^{\prime}}}>-\frac{\mathrm{U}_{\mathrm{H}}^{\prime \prime}}{\mathrm{U}_{\mathrm{H}^{\prime}}}$, where $\mathrm{U}_{\mathrm{i}}(\mathrm{i}=\mathrm{H}, \mathrm{L})$ is the utility of i-type, so that $\frac{\mathrm{U}_{\mathrm{L}}^{\prime}(\mathrm{w}-\mathrm{d}+\alpha)}{\mathrm{U}_{\mathrm{L}}^{\prime}(\mathrm{w}-\beta)}>\frac{\mathrm{U}_{\mathrm{H}}^{\prime}(\mathrm{w}-\mathrm{d}+\alpha)}{\mathrm{U}_{\mathrm{H}}^{\prime}(\mathrm{w}-\beta)}$ whenever $\alpha+\beta<d$. We know by the assumption (A1) that $V_{L}\left(\alpha_{L}, \beta_{L}\right)>V_{L}\left(\alpha_{L}^{\prime}, \beta_{L}^{\prime}\right)$, where $\beta_{\mathrm{L}}=\mathrm{f}\left(\alpha_{\mathrm{L}}\right)=\frac{\mathrm{P}_{\mathrm{L}}}{1-\mathrm{P}_{\mathrm{L}}} \alpha_{\mathrm{L}}, \quad \beta_{\mathrm{L}}^{\prime}=\mathrm{d}-\alpha_{\mathrm{L}}^{\prime}=\frac{\mathrm{P}_{\mathrm{L}}^{\mathrm{S}}}{1-\mathrm{P}_{\mathrm{L}}^{\mathrm{S}}} \alpha_{\mathrm{L}}{ }^{\prime} \quad\left(\left(\alpha_{\mathrm{L}}, \beta_{\mathrm{L}}\right)\right.$ and $\left(\alpha_{\mathrm{L}}^{\prime}, \beta_{\mathrm{L}}^{\prime}\right)$, are illustrated by $\mathrm{E}$ and $\mathrm{D}$ in Figure 11, respectively). Let us define $\theta^{*}(\in(0,1])$ such that $\mathrm{V}_{\mathrm{L}}(\bar{\alpha}, \bar{\beta})=$ $\mathrm{V}_{\mathrm{L}}\left(\alpha_{\mathrm{L}}^{\prime}, \beta_{\mathrm{L}}^{\prime}\right)$, implying that $\mathrm{V}_{\mathrm{L}}(\bar{\alpha}, \bar{\beta})>\mathrm{V}_{\mathrm{L}}\left(\alpha_{\mathrm{L}}^{\prime}, \beta_{\mathrm{L}}^{\prime}\right)$ for $\theta<\theta^{*}$. Note that $\theta^{*}=1$ for some $\mathrm{P}_{\mathrm{L}}^{\mathrm{S}}$ such that $\mathrm{P}_{\mathrm{L}}^{\mathrm{S}}>\mathrm{P}_{\mathrm{H}}$. We can then identify circumstances under which a pooling equilibrium exists:

\footnotetext{
25 In this case we could say that a shirking L-type is riskier than a non-shirking H-type. Note, however, that when the portion of H-type is high, an equilibrium may exist as the pooling contract would be dominated by a separating contract $(\mathrm{A}, \mathrm{Y})$, if it is feasible as shown in Figure $9 \mathrm{~b}$.
} 
Theorem 10 (Pooling Equilibrium With Difference in Risk-Aversion)

Suppose that $-\frac{U_{\mathrm{L}}{ }^{\prime}}{\mathrm{U}_{\mathrm{L}^{\prime}}}>-\frac{\mathrm{U}_{\mathrm{H}}}{\mathrm{U}_{\mathrm{H}^{\prime}}}$, where $\mathrm{U}_{\mathrm{i}}(\mathrm{i}=\mathrm{H}, \mathrm{L})$ is the utility of i-type. Also, suppose that $\frac{\mathrm{P}_{\mathrm{L}}}{1-\mathrm{P}_{\mathrm{L}}} \frac{\mathrm{U}_{\mathrm{L}}^{\prime}(\mathrm{w}-\mathrm{d}+\bar{\alpha})}{\mathrm{U}_{\mathrm{L}}^{\prime}(\mathrm{w}-\bar{\beta})}>\frac{\mathrm{P}_{\mathrm{H}}}{1-\mathrm{P}_{\mathrm{H}}} \frac{\mathrm{U}_{\mathrm{H}}^{\prime}(\mathrm{w}-\mathrm{d}+\bar{\alpha})}{\mathrm{U}_{\mathrm{H}}^{\prime}(\mathrm{w}-\bar{\beta})}$ at $(\bar{\alpha}, \bar{\beta})$. Then, for $\theta<\theta^{*}$, a pooling equilibrium $(\bar{\alpha}, \bar{\beta})$ exists.

The proofs can be found in the Appendix. In the model we have analyzed, a pooling contract cannot be supported by a Nash equilibrium, because there exists a contract that will be purchased just by the low risk individual and does not change his behavior (i.e. satisfies the NS constraint. $)^{26}$. When we introduce heterogeneity in risk-aversion on the part of individuals, however, the presence of moral hazard may contribute to the sustainability of a pooling contract as an RS equilibrium.

Figure 11 illustrates the case when a pooling contract A can be sustained as an RS equilibrium unless $\theta$ is high. A contract $B$ would attract $H$-type individuals only to make losses, whereas a contract $\mathrm{C}$ would attract L-type individuals only to make losses because they would shirk under $\mathrm{C}$. Note that the contract $\mathrm{C}$ could yield positive profits without NS constraints.

There are two factors that lead a pooling equilibrium to be sustainable under the double informational asymmetry. First, the presence of moral hazard would dictate incomplete insurance for individuals, at which a L-type individual, who is more risk-averse than the other type, may have a stronger demand for insurance. ${ }^{27}$ This suggests that, given a pooling contract, any deviant contract that can attract L-type individuals needs to offer larger amounts of insurance than that offered by the pooling contract. Second, a deviant contract offering larger amounts of insurance is likely to induce individuals to shirk, so that it may fail to make positive profits.

These arguments can hold even when $\mathrm{f}_{\mathrm{L}}(\alpha)>\mathrm{f}_{\mathrm{H}}(\alpha)$ or when $\mathrm{f}_{\mathrm{L}}(\alpha)<\mathrm{f}_{\mathrm{H}}(\alpha)$, so long as the marginal rate of substitution at $(\bar{\alpha}, \bar{\beta})$ is higher for L-type than for H-type and so long as $\theta$ is low so that $\mathrm{V}_{\mathrm{L}}(\bar{\alpha}, \bar{\beta})>\mathrm{V}_{\mathrm{L}}\left(\alpha_{\mathrm{L}}^{\prime}, \beta_{\mathrm{L}}^{\prime}\right)$.

\section{Equilibrium with Non-exclusive Provision of Insurance}

Whenever insurance is incomplete due to moral hazard, private insurance providers have incentives to offer additional insurance, as the marginal rate of substitution of insurance is greater than its price. As Arnott and Stiglitz [1991a,1991b] show, the nature of equilibrium when there are multiple providers depends on whether or not an individual's total purchase of insurance can be observed.

Previous discussions have focused on three cases: (a) full revelation of quantity information; (b) no revelation and no firm knows how much it sells to any individual; (c) each firm knows its own sales to any individual but not that of any other firm. Here, we

\footnotetext{
26 Thus, the standard analysis for whether a contract can "break" an equilibrium is somewhat more complicated in the case of double informational asymmetry.

27 The stronger demand for insurance by more risk-averse individuals who also chooses greater effort in preventing accident may imply positive relationship between insurance and riskiness (Donder-Hindriks(2009)), which would act toward the sustainability of a pooling equilibrium.
} 
show that with a fourth plausible information structure it is more likely that an equilibrium may exist. It is based on the premise that the government may be able to identify all of an individual's purchases of insurance, although private insurance firms on their own cannot. ${ }^{28}$ Suppose that, when an individual purchases insurance in excess of a certain amount $\alpha^{*}$, the government lets insurance firms know about it; and that firms in response sell any amount of insurance at the fixed price $\frac{\overline{\mathrm{P}}}{1-\overline{\mathrm{P}}}$ (reflecting the market risk) so long as the individual does not purchase more than $\alpha^{*}$. We will see in this section if this pricing contract with the quantity limits can be used to sustain an equilibrium under DIA when insurance firms provide insurances non-exclusively given the partial revelation of information by the government.

If individuals purchase excessive insurance, they will shirk - the purchase of additional insurance imposes a negative externality on other providers. In this case the government may want to take some actions to discourage individuals from purchasing excessive insurance that can induce shirking. This will induce the market to provide the efficient allocation of insurance under moral hazard when the insurance provision is non-exclusive.

What we will show in this section is that this type of government action designed to secure the efficiency in the presence of non-exclusive insurance provision under moral hazard can play an important role in determining an equilibrium under adverse selection. To see this we will continue to assume that $\Delta \mathrm{P}_{\mathrm{L}}=\Delta \mathrm{P}_{\mathrm{H}} \equiv \Delta \mathrm{P}$, and consider an insurance contract $\left(\alpha^{*}, \beta^{*}\right)$ such that

$$
\begin{array}{r}
\left(\alpha^{*}, \beta^{*}\right)=\operatorname{Argmax} V_{L}(\alpha, \beta) \\
\text { s.t. } \quad \beta=\frac{\bar{P}}{1-\bar{P}} \alpha \\
\\
\beta \leq \mathrm{f}(\alpha),
\end{array}
$$

i.e., that it maximizes the utility of L-type given the NS constraint and the zero profit (associated with a pooling contract) constraint. The NS constraint may or may not be binding for the contract $\left(\alpha^{*}, \beta^{*}\right)$. In the former case, we will have

$$
\beta^{*}=f\left(\alpha^{*}\right)
$$

where $\left(\alpha^{*}, \beta^{*}\right)$ is a pooling contract on the NS locus that satisfies zero profit condition. We can first prove the following Lemma:

\section{Lemma 4}

There exists $\theta(\Delta \mathrm{P})(\in(0,1])$ such that $\beta^{*}=f\left(\alpha^{*}\right)$ for $\theta<\theta(\Delta \mathrm{P})$, where $\theta^{\prime}(\Delta \mathrm{P})<0$.

We can then establish the following Theorem.

Theorem 11 (Equilibrium with Non-exclusive Provision under DIA)

Suppose that $\Delta \mathrm{P}_{\mathrm{L}}=\Delta \mathrm{P}_{\mathrm{H}} \equiv \Delta \mathrm{P}$, and suppose that the government informs insurance firms of those who have purchased insurance in excess of $\alpha^{*}$. Then, $\left(\alpha^{*}, \beta^{*}\right)$ is an RS equilibrium for $\theta<\theta(\Delta \mathrm{P})$, where $\beta^{*}=f\left(\alpha^{*}\right)$. When an equilibrium exists, the equilibrium

\footnotetext{
28 For instance, the government could require that all insurance policies be registered, and any non-registered insurance policy would not be enforceable.
} 
strategy of a firm is to sell any amount of insurance at the fixed price $\frac{\overline{\mathrm{P}}}{1-\overline{\mathrm{P}}}$, so long as the individual does not purchase more than $\alpha^{*}$.

Consider the standard case where the indifference curve of L-type individuals is flatter than that of $\mathrm{H}$. The standard way in which a pooling contract is broken is to offer a contract, A in Figure 12, lying below $\mathrm{V}_{\mathrm{H}}$ and above $\mathrm{V}_{\mathrm{L}}$. Such a contract, entailing less insurance, will make a profit. But now, given that all insurance firms offer insurance at the price $\frac{\overline{\mathrm{P}}}{1-\overline{\mathrm{P}}}$ up to $\alpha^{*}$. A in Figure 12a must entail insurance at less than that price (otherwise it would not be purchased), and all individuals will purchase A, supplementing it with insurance from other providers. $^{29}$ As a result, the contract will lose money.

This argument may not hold for high $\theta$. As $\theta$ increases, the price $\frac{\overline{\mathrm{p}}}{1-\overline{\mathrm{p}}}$ becomes high, and at a high enough price, L-type individuals would like to reduce their insurance below the pooling contract $\left(\alpha^{*}, \beta^{*}\right)$ while H-type individuals would want to keep their insurance. This would make the pooling outcome $\left(\alpha^{*}, \beta^{*}\right)$ unsustainable, as each type would choose different amount of insurance. The differential choices of insurances between two types would affect the price of insurance, which would again induce each type to adjust his choice of insurance. This process might result in a price equilibrium in which the H-type chooses the maximum amount of insurance that induces non-shirking at the given price, while the Ltype chooses a smaller amount of insurance at the same price. ${ }^{30} 31$

There are two ways that the presence of moral hazard contributes to the sustainability of a pooling equilibrium. First, due to the moral hazard constraint, L-type individuals may be willing to purchase more insurance at the price $\frac{\overline{\mathrm{p}}}{1-\overline{\mathrm{p}}}$ at $\left(\alpha^{*}, \beta^{*}\right)$. As the non-shirking constraints get tighter, therefore, the chance for a pooling equilibrium becomes greater. In the absence of moral hazard, on the other hand, a pooling equilibrium never exists. Second, the non-exclusive nature of private provision of insurance induces H-type individuals, as well as L-type individuals, to choose any deviant contract involving a lower level of insurance with lower prices. In other words, the moral hazard constraint which makes L-type's preference for insurance stronger and the non-exclusive provision of additional insurance at the fixed price can work together to sustain a pooling equilibrium.

In particular, concerns about moral hazard make it natural to want to put constraints on the amount of insurance - there is an obvious externality, as we have noted. If firms have information about the quantity of insurance, they will use it to limit the amount of insurance. And this makes the pooling equilibrium they we have described particularly persuasive.

29 Arnott and Stiglitz [1991a, 1991b ] discussed the use of latent policies to discourage contracts which might break an equilibrium. Here, it is the actual policies offered in the market which serve to deter equilibrium breaking deviations. Note that if the government provided full information about coverage, then the equilibrium which would emerge would correspond to the exclusive contract equilibrium.

30 As will be analyzed later, this argument would apply to the case of pure adverse selection, in which the Htype chooses the full insurance at the equilibrium price while the L-type chooses less-than-full insurance.

31 Alternatively, there can also exist a pure pooling price equilibrium, at the level of insurance preferred by the low-type, in which the government announces any purchases in excess of that amount. The H-type would then know that if they purchase in excess of the pooling amount, it would signal that they are H-type, and they will be refused insurance by all insurance providers except at the price $\left(\frac{P_{H}}{1-P_{H}}\right)$ reflecting their market risk. 
Now let us consider a case of PAS when there is no moral hazard. To figure out an equilibrium in this case we will consider an insurance contract $\left(\alpha^{*}, \beta^{*}\right)$ such that

$$
\begin{aligned}
\left(\alpha^{*}, \beta^{*}\right)= & \operatorname{Argmax} V_{L}(\alpha, \beta) \\
\text { s.t. } & \beta=\frac{\bar{P}}{1-\bar{P}} \alpha,
\end{aligned}
$$

i.e., that it maximizes the utility of L-type given the zero profit (associated with a pooling contract) constraint. We can then establish the following Theorem with the proof being delegated to the Appendix.

Theorem 12 (Equilibrium with Non-exclusive Provision under PAS)

Suppose that the government informs insurance firms of those who have purchased insurance in excess of $\alpha^{*}$. Suppose that insurance firms provide insurances non-exclusively given the information revealed by the government, while individuals may choose insurance contracts sequentially. Under PAS an RS equilibrium strategy will be a pricing contract that offers insurances at the fixed price $\frac{P_{H}}{1-P_{H}}$ for those revealed to have purchased more than $\alpha^{*}$ and at the fixed price $\frac{\overline{\mathrm{P}}}{1-\overline{\mathrm{P}}}$ for the others.

As shown in Figure 12b, the resulting equilibrium allocation would then be a hybrid type allocation: a pooling allocation $\left(\alpha^{*}, \beta^{*}\right)$ for both types plus a supplemental insurance for $\mathrm{H}$ type, or, alternatively, $\left(\alpha^{*}, \beta^{*}\right)$ for both types (A in Figure 12b) and $\left(\alpha^{\prime}-\alpha^{*}, \beta^{\prime}-\beta^{*}\right)$ for H-type (C in Figure 12) such that $\beta^{\prime}-\beta^{*}=\frac{P_{H}}{1-P_{H}}\left(\alpha^{\prime}-\alpha^{*}\right)$ and $\alpha^{\prime}+\beta^{\prime}=d$. When the private provision of insurance is non-exclusive, a pooling contract $\left(\alpha^{*}, \beta^{*}\right)$ may be sustained as a part of an equilibrium, provided that the government identifies those who have excess amount of insurance.

The reason why the pure pooling allocation $\left(\alpha^{*}, \beta^{*}\right)$ cannot be sustained as an equilibrium under PAS is because, at that point, $\mathrm{H}$-type individuals have incentive to increase amount of insurances at the price $\frac{P_{H}}{1-P_{H}}$ reflecting their market risk. Note that, in the absence of moral hazard, additional insurances for H-type would not change their probability of accident, unlike the case of DIA where $\left(\alpha^{*}, \beta^{*}\right)$ can be sustained as an equilibrium. ${ }^{32}$

\section{The Role of the Market in Implementing PO and UO}

Although the market outcome, if it exists, is PO, every PO outcome cannot be implemented by private markets. What we argue in this section is that, with the minimum intervention of the government, the PO outcome can be achieved by the market under adverse selection whether or not moral hazard is present.

32 Note that this equilibrium is not PO because, given this equilibrium, L-type could also be offered some supplemental insurance at their market risk $\frac{P_{L}}{1-P_{L}}$ without affecting the contract $\left(\alpha^{\prime}, \beta\right)$ for H-type. This supplemental insurance for L-type, however, would not be able to be offered given the current information revelation of government. 
Suppose that the market is relatively more efficient in providing insurance compared to the government. We will assume, however, that the market is just slightly more efficient in the provision of insurance than the government to downplay the effect of the relative efficiency of the market upon the design of the implementation mechanism. ${ }^{33}$ We can then show that a hybrid provision of insurances by the government and the market is an optimal mechanism of insurance provision except for limiting cases.

\section{6-1. Pure Adverse Selection}

For a PO allocation $\left\{\left(\alpha_{\mathrm{H}}, \beta_{\mathrm{H}}\right),\left(\alpha_{\mathrm{L}}, \beta_{\mathrm{L}}\right)\right\}$ let $\mathrm{P}_{\mathrm{i}}$ be the probability of accident for an individual of type $i$ who chooses $\left(\alpha_{\mathrm{i}}, \beta_{\mathrm{i}}\right)$ and let $\overline{\mathrm{P}}=\theta \mathrm{P}_{\mathrm{H}}+(1-\theta) \mathrm{P}_{\mathrm{L}}$. We can then prove the following theorem.

\section{Theorem 13}

For any PO allocation $\left\{\left(\alpha_{H}, \beta_{H}\right),\left(\alpha_{L}, \beta_{L}\right)\right\}$ under adverse selection, there exists $(\bar{\alpha}, \bar{\beta})$ such that $\bar{\beta}=\frac{\bar{P}}{1-\bar{P}} \bar{\alpha}, \beta_{i}-\bar{\beta}=\frac{P_{i}}{1-P_{i}}\left(\alpha_{i}-\bar{\alpha}\right) \leq 0$, for $i=H, L$, and that $\left\{\left(\alpha_{i}-\bar{\alpha}\right),\left(\beta_{i}-\bar{\beta}\right)\right\}$ is an RS equilibrium given $(\bar{\alpha}, \bar{\beta})$ regardless of $\theta$. In particular, $\bar{\beta}=\bar{\alpha}=0$ when a PO allocation entails no subsidy, whereas $\beta_{\mathrm{i}}=\bar{\beta}$ and $\alpha_{\mathrm{i}}=\bar{\alpha}$ when a PO allocation is a pooling one.

The proof can be found in the Appendix. Theorem 13 demonstrates that any PO allocation can be decomposed into a pooling allocation $(\bar{\alpha}, \bar{\beta})$ entailing the subsidy embedded in the PO allocation and a separating allocation that does not involve any subsidy. This suggests that after offering the pooling contract $(\bar{\alpha}, \bar{\beta})$, the government can leave to the market the provision of the remaining separating contract in implementing the PO allocation, and if the market is relatively more efficient in the insurance provision than the government, it should do so.

The possible role of the market under adverse selection can be illustrated by Figure 13 . Figure 13 shows the case when the UO, which is a separating outcome (B,C), can be implemented by a hybrid provision of the government and the market: the government provision of A (pooling contract) and the market provision of the remaining separating contract involving no subsidy. In particular, the supplementary provision of insurance can always be sustained as an RS equilibrium, regardless of $\theta$, because the market provision is PO given the government provision and does not involve any subsidy.

We have thus established the following Corollary.

\section{Corollary 1}

The optimal mechanism of implementing any PO provision of insurance under adverse selection is a hybrid provision by the government and the market, except for the limiting cases where a PO involves no subsidy so that it is implemented only by the market or where a PO allocation is a pooling one so that it is implemented only by the government. In particular, the UO allocation, which is a pooling one, can only be attained by the government provision.

\footnotetext{
33 This assumption implies that, whenever indifferent between the government and private provisions in the model, the private provision is desirable or that the government provision needs to be minimized.
} 


\section{6-2. Moral Hazard and Adverse Selection}

In the presence of moral hazard as well as adverse selection, the market has to provide some insurance in implementing any PO especially when low-risk type individuals are subject to stricter non-shirking constraint than high-risk type ones (Case II). Focusing upon the utilitarian optimum in particular, we can present the following Corollary.

\section{Corollary 2}

With adverse selection and moral hazard, the market may play a role in the achieving the utilitarian optimum, whereas it can be attained only by the government under PAS.

Corollary 2 is clear from the discussions on the UO in Section 4, which demonstrates that the UO should be a pooling allocation with complete insurance under PAS, whereas it may be a separating allocation for a wide range of parameters under DIA. In this respect we can argue that, although the presence of adverse selection restricts the role of market in achieving the utilitarian optimum, the introduction of moral hazard may create room for the market to play an important role in implementing the utilitarian optimum. This argument is consistent with the practice of many current insurance systems, such as health insurance and retirement insurance, in which the government provides all the individuals with basic insurance and the market offers a variety of additional insurance that can match diverse preferences of individuals.

In delegating some provision of insurance to the market in this case, however, the government needs to regulate the market in general to achieve the PO allocation, for in the absence of such regulation, insurance firms will not take account of the externality that their provision of insurance has on other firms, and in particular, on the government, as the provider of the base insurance. We can establish the following: .

\section{Theorem 14}

Any PO separating contract $\left\{\left(\alpha_{\mathrm{H}}, \beta_{\mathrm{H}}\right),\left(\alpha_{\mathrm{L}}, \beta_{\mathrm{L}}\right)\right\}$ under moral hazard and adverse selection entailing incomplete insurance can be implemented by the government provision of a pooling contract $(\bar{\alpha}, \bar{\beta})$ and the market provision of a separating contract $\left\{\left(\alpha_{\mathrm{i}}-\bar{\alpha}\right),\left(\beta_{\mathrm{i}}-\bar{\beta}\right)\right\}_{\mathrm{i}=\mathrm{H}, \mathrm{L}}$, together with the schedule of government tax $t(\alpha)$ such that

$$
\begin{aligned}
t(\alpha) & =0 & & \text { for } \alpha<\alpha_{L} \\
& =\left.\frac{U^{\prime}(w-d+\alpha)}{U^{\prime}(w-\beta)}\right|_{V_{L}}-1 & & \text { for } \alpha \in\left[\alpha_{L}, \alpha_{H}\right) \\
& =\left.\frac{U^{\prime}(w-d+\alpha)}{U^{\prime}(w-\beta)}\right|_{V_{H}}-1 & & \text { for } \alpha \geq \alpha_{H},
\end{aligned}
$$

where $V_{i}=V\left(\alpha_{i}, \beta_{i}\right), i=H, L$.

Theorem 14 demonstrates that, while the optimal allocation can be achieved by a hybrid provision of the government and the market under adverse selection, the government needs to intervene further in the market after offering a pooling contract in the presence of moral hazard. The reason for this additional intervention is because the supplementary separating allocation by the market will exert an externality upon the pooling contract offered by the 
government in presence of moral hazard, which private firms would not take into account in offering contracts. In other words, without the government tax, the market would provide excessive amount of insurance (compared to the PO allocation) given the government provision of the basic pooling contracts under DIA.

\section{Conclusion}

This paper examines how the presence of moral hazard affects the optimal and equilibrium allocations under adverse selection and discusses the roles of the market and the government in implementing the optimal allocation. Moral hazard and self-selection constraints interact with each other and this changes optimal and equilibrium allocations in important ways from what emerges in cases where there is only moral hazard or only adverse selection. We show that the nature of the equilibrium depends critically upon how the accident probabilities differ across risk types and are affected by the level of care taken. At the center of our analysis is a focus on the impact of a subsidy from the low risk (L-type) to the high risk type. As in the case of the pure adverse selection, as the subsidy increases, there are two conflicting effects upon the amount of insurance for L-type or upon their welfare: the positive effect of the relaxed self-selection constraint and the negative effect of the more-binding profit constraint. So long as the net effect is positive, utilitarian welfare is increased, because the changes in the profit constraints are simply transfers, and are effectively cancelled out between the two types of individuals. ${ }^{34}$ With moral hazard, the non-shirking constraints, however, limit the magnitude of the positive effect.

On the nature of the optimal allocation, the main results are the followings. First, a Pareto optimal (PO) allocation may involve shirking for high-risk individuals, which would not be true under pure moral hazard. The fact that some individuals shirk (do not take adequate care) has often been raised as a criticism of public insurance programs. Our paper shows that such shirking may indeed characterize Pareto Optimal allocations. The cost of inducing them not to shirk exceeds the benefits. Perhaps more surprising is the result that in the case with multi-crossing preferences (which is often true under the double informational asymmetry) a PO allocation may entail shirking even for both types of individuals. Second, the utilitarian optimum (UO) may be achieved either by a pooling contract with incomplete insurance or by a separating contract that may entail full insurance (and shirking) for highrisk individuals. The reason for the utilitarian optimality of the pooling contract with partial insurance is that the more severe non-shirking constraint for high risk type makes infeasible a dominating separating contract. This result can be compared to the case of pure adverse selection where the UO is always achieved by a pooling contract with complete insurance.

Regarding equilibrium under moral hazard and adverse selection, as in the pure adverse selection model, if there exists a separating PO allocation with no subsidy, that allocation is a Rothschild-Stiglitz (RS) equilibrium. But there are several distinctive results under double information asymmetry: First, a RS equilibrium may entail shirking for one type or for both types of individuals in the presence of multi-crossing preferences. This property of an equilibrium is never present under pure moral hazard. Second, the presence of the moral hazard constraints affects the likelihood (e.g. the critical value of $\theta, \tilde{\theta}$ ) that a separating allocation with no subsidy is PO, and therefore the likelihood of equilibrium existence. A

\footnotetext{
34 This is a slight simplification, because the higher risk individual has a lower expected (net of accident) income, and hence a higher marginal utility of income.
} 
separating contract involving no subsidy is more likely to be pareto optimal as the nonshirking constraint for low-risk type individuals gets tighter, because the positive welfare effect from the loosening of the self-constraint, from providing a subsidy to the high risk individuals, is limited. Besides, we also showed that, in the presence of multi-crossing preferences, an RS equilibrium may not exist either for high $\theta$ or for low $\theta$.

Second, this paper also discusses the possibility of a pooling equilibrium under the double informational asymmetry. When the low risk type is more risk averse than the other type, the former may have stronger preference for insurance at a pooling allocation than the latter, which can keep a (potentially) deviant contract entailing smaller amount of insurances from attracting the low risk type. Furthermore, when the provision of insurance is non-exclusive, a pooling contract can be sustained as an equilibrium, provided that the government reveals information about the excessive purchase of insurances (by an individual) that can induce shirking, because a deviant contract (against a pooling contract) entailing a smaller amount of insurances with a lower price can attract H-types as well as L-types. In this respect, this paper also began the investigation of another important class of problems: that where there is some, but limited, revelation of information about individual's insurance purchases. When there is full revelation, if an equilibrium exists, it will consist of exclusive contracts, and has been well-described in the earlier literature. When there is no information, the only equilibrium is a price equilibrium, but such an equilibrium is very fragile and complex. ${ }^{35}$ Indeed, this was the context in which adverse selection was first studied, with one of the results being that the only equilibrium may entail no insurance. We show here that if the government reveals when any individual purchases more than a critical threshold of insurance, the market will limit purchases and a pooling equilibrium can be sustained.

Finally, this paper demonstrates that any Pareto optimal allocation can be implemented through the hybrid provision of insurance by the government and the market (except for the limiting cases when a PO allocation does not involve any subsidy so that it can be implemented only by the market and when a PO allocation is a pooling one so that it can be implemented only by the government.) This is a theoretical justification of what we often observe in reality, i.e., a system in which the government provides basic insurance to everyone (effectively a pooling contract) and leaves to the market the supplementary provision. However, when delegating some provision of insurance to the market in the presence of moral hazard, the government needs to intervene through taxes because of the externality the market exerts upon government provision.

The insurance market has proved a fertile context in which to examine the effects of adverse selection and moral hazard in isolation. Results and concepts developed in highly idealized models have proven useful in understanding many other markets. This paper has shown that while the interaction between adverse selection and moral hazard is complex, there are simple analytic tools which allow a tractable analysis with considerable generality, and with results that, in some cases, confirm those obtained when there is only one information asymmetry. More interestingly, in other cases we show those results to be of limited validity.

\footnotetext{
35 See Arnott and Stiglitz [ 1991a, 1991b ]. An insurance company may try to break the price equilibrium by offering a large policy, sufficiently large that individuals would not wish to supplement that policy with market insurance at the going price.
} 
References

Arnott, R., B. Greenwald, J. Stiglitz, 1994, "Information and Economic Efficiency," Information Economics and Policy, 6(1), pp. 77-82.

R. Arnott and J. E. Stiglitz, 1988, "The Basic Analytics of Moral Hazard,", Scandinavian Journal of Economics, 90(3), pp. 383-413.

— and — 1990, "The Welfare Economics of Moral Hazard," with R. Arnott, in Risk, Information and Insurance: Essays in the Memory of Karl H. Borch, H. Louberge (ed.), Norwell: Kluwer Academic Publishers, pp. 91-122

— and — 1991a, "Price Equilibrium, Efficiency, and Decentralizability in Insurance Markets”, NBER Working Paper 3642, 1991.

— and — 1991b, "Equilibrium in Competitive Insurance Markets with Moral Hazard," Princeton University Discussion Paper 4, 1987. Also NBER Working Paper 3588.

A. Chassagnon, P. Chiappori (1997), "Insurance under Moral Hazard and Adverse Selection: The Case of Pure Competition," mimeo

P. Donder, J. Hindriks (2009), "Adverse Selection, Moral Hazard, Propitious Selection," Journal of Risk and Uncertainty, Vo. 38(1), pp 73-86

W. Jack (2009), "Equilibrium in Competitive Insurance Market with ex ante Adverse Selection and ex post Moral Hazard," Journal of Public Economics, 84, pp. 251-278

J. Laffont, J. Tirole (1986), "Using Cost Observation to Regulate Firms," Journal of Political Economy, Vol. 94(3), pp. 614-641

Rothschild, M. and J.E Stiglitz, 1976, "Equilibrium in Competitive Insurance Markets: An Essay on the Economics of Imperfect Information", Quarterly Journal of Economics, 90(4), pp. 629-649.

Spence, M., 1978, "Product Differentiation and Performance in Insurance Markets," Journal of Public Economics, 10(3), pp. 427-447. 
Stiglitz, J.E, Sen, A., and J.P. Fitoussi, 2010, Mismeasuring Our Lives: Why GDP Doesn't Add Up, New York: The New Press. Previously published in 2009 as "Report by the Commission on the Measurement of Economic Performance and Social Progress", available at http://www.stiglitz-sen-fitoussi.fr/en/index.htm

—_ A. Weiss, 1987, “Macroeconomic Equilibrium and Credit Rationing,” NBER Working Paper, No. 2164.

Whinston, M., 1983, "Moral Hazard, Adverse Selection, and Optimal Provision of Social Insurance," Journal of Public Economics, 22(1), pp 49-71.

Appendix

$<$ proofs $>$

\section{Theorem 1}

Collecting the necessary conditions for $\left\{\left(\alpha_{\mathrm{L}}, \beta_{\mathrm{L}}\right),\left(\alpha_{\mathrm{H}}, \beta_{\mathrm{H}}\right)\right\}$ and rearranging them, we have

$$
\begin{aligned}
& \mathrm{U}^{\prime}\left(\mathrm{w}-\mathrm{d}+\alpha_{H}\right)>\mathrm{U}^{\prime}\left(\mathrm{w}-\beta_{\mathrm{H}}\right) \\
& \mathrm{U}^{\prime}\left(\mathrm{w}-\mathrm{d}+\alpha_{\mathrm{L}}\right)=\frac{\delta(1-\theta)}{1-\gamma \frac{\mathrm{P}_{\mathrm{H}}}{\mathrm{P}_{\mathrm{L}}}} \\
& \mathrm{U}^{\prime}\left(\mathrm{w}-\beta_{\mathrm{L}}\right)=\frac{\delta(1-\theta)}{1-\gamma \frac{1-\mathrm{P}_{\mathrm{H}}}{1-\mathrm{P}_{\mathrm{L}}}}
\end{aligned}
$$

where $\gamma, \delta(\geq 0)$ are lagrangean multipliers associated with the first and the second constraints, respectively. These imply that $\alpha_{\mathrm{H}}+\beta_{\mathrm{H}}=d$, and that $\alpha_{\mathrm{L}}+\beta_{\mathrm{L}}<d$ because $\mathrm{P}_{\mathrm{H}}>\mathrm{P}_{\mathrm{L}}$.

Substituting the condition that $\alpha_{\mathrm{H}}+\beta_{\mathrm{H}}=\mathrm{d}$ into the problem, we can then have the following by the envelope theorem:

where

$$
\frac{\partial V_{L}^{*}}{\partial \alpha_{H}}=-\delta^{-1} U^{\prime}\left(w-d+\alpha_{H}\right)-\gamma^{-1} \theta
$$

$$
\begin{aligned}
& \delta^{-1}=-\mathrm{P}_{\mathrm{L}} \frac{\mathrm{U}^{\prime}\left(\mathrm{w}-\mathrm{d}+\alpha_{\mathrm{L}}\right)-\mathrm{U}^{\prime}\left(\mathrm{w}-\beta_{\mathrm{L}}\right)}{\mathrm{U}^{\prime}\left(\mathrm{w}-\mathrm{d}+\alpha_{\mathrm{L}}\right)-\mathrm{PU}^{\prime}\left(\mathrm{w}-\beta_{\mathrm{L}}\right)} \in(-1,0) \text { and } \mathrm{P} \equiv \frac{\mathrm{P}_{\mathrm{L}}}{\mathrm{P}_{\mathrm{H}}} \frac{1-\mathrm{P}_{\mathrm{H}}}{1-\mathrm{P}_{\mathrm{L}}}<1, \\
& \gamma^{-1}=\frac{\mathrm{U}^{\prime}\left(\mathrm{w}-\mathrm{d}+\alpha_{\mathrm{L}}\right)}{1-\theta}(1+\delta)>0
\end{aligned}
$$

The sign of $\frac{\partial V_{\mathrm{L}}^{*}}{\partial \alpha_{\mathrm{H}}}$ is ambiguous in general. If $\theta \approx 1, \frac{\partial \mathrm{V}_{\mathrm{L}}^{*}}{\partial \alpha_{\mathrm{H}}}<0$. If $\theta \approx 0$, however, $\frac{\partial \mathrm{V}_{\mathrm{L}}^{*}}{\partial \alpha_{\mathrm{H}}}>0$ at $\alpha_{\mathrm{H}}=\alpha_{\mathrm{H}}^{*}$ where $\mathrm{U}^{\prime}\left(\mathrm{w}-\mathrm{d}+\alpha_{\mathrm{L}}\right)>\mathrm{U}^{\prime}\left(\mathrm{w}-\beta_{\mathrm{L}}\right)$. As $\alpha_{\mathrm{H}} \rightarrow \widetilde{\alpha}$, however, $\delta \rightarrow 0$ because $\mathrm{U}^{\prime}\left(\mathrm{w}-\mathrm{d}+\alpha_{\mathrm{L}}\right)-\mathrm{U}^{\prime}(\mathrm{w}-$ $\left.\beta_{\mathrm{L}}\right) \rightarrow 0$, suggesting that $\frac{\partial \mathrm{V}_{\mathrm{L}}^{*}}{\partial \alpha_{\mathrm{H}}}<0$. This suggests that there always exists a PO separating contract. Finally, when $\alpha_{\mathrm{H}}=\alpha_{\mathrm{L}}$, i.e., at a pooling contract with complete insurance, any further subsidy (or any further increase in $\alpha_{H}$ ) would not satisfy the self-selection constraint.

It is trivial to show that a pooling contract that involves full insurance and yields zero profit, maximizes the utilitarian social welfare function even with perfect information. ${ }^{36}$ Since such a contract can be implemented even with imperfect information about information types, it is clear that is also represents the UO under imperfect information.

\section{Proposition 1}

${ }^{36}$ It is also clear that any pooling contract other than $(\tilde{\alpha}, \tilde{\beta})$ is dominated by $(\tilde{\alpha}, \tilde{\beta})$ so such an allocation cannot be PO. 
Consider first the case of single-crossing preferences. Suppose that $\beta_{\mathrm{L}}>\mathrm{f}_{\mathrm{L}}\left(\alpha_{\mathrm{L}}\right)$. We can then offer another contract $\left(\alpha^{\prime}, \beta^{\prime}\right)$ such that $V_{L}\left(\alpha_{\mathrm{H}}, \beta_{\mathrm{H}}\right)=V_{L}\left(\alpha^{\prime}, \beta^{\prime}\right), \alpha^{\prime}<\alpha_{\mathrm{L}}, \beta^{\prime}<\beta_{\mathrm{L}}$ and that $\beta^{\prime}=\mathrm{f}_{\mathrm{L}}\left(\alpha^{\prime}\right)$, which is to be chosen by L-type and not to be chosen by H-type, given the single crossing assumption. The new contract can make more profits than the original one because of the assumption $A 1$, suggesting that $\left\{\left(\alpha_{L}, \beta_{L}\right),\left(\alpha_{H}, \beta_{H}\right)\right\}$ is not PO.

Suppose that $\beta_{H}<\mathrm{f}_{\mathrm{H}}\left(\alpha_{\mathrm{H}}\right)$. We can then find another contract $\left(\alpha^{\prime}, \beta^{\prime}\right)$ offering more insurance (i.e. $\alpha^{\prime}>$ $\left.\alpha_{H}, \beta^{\prime}>\beta_{\mathrm{H}}\right)$ such that $V_{H}\left(\alpha_{\mathrm{H}}, \beta_{\mathrm{H}}\right)=V_{H}\left(\alpha^{\prime}, \beta^{\prime}\right)$, and that $\beta^{\prime}=\mathrm{f}_{\mathrm{H}}\left(\alpha^{\prime}\right)$, which is to be chosen only by H-type and yields more profits (because of the incomplete insurance for H-type), suggesting that $\left\{\left(\alpha_{\mathrm{L}}, \beta_{\mathrm{L}}\right),\left(\alpha_{\mathrm{H}}, \beta_{\mathrm{H}}\right)\right\}$ is not PO. Suppose that $\beta_{H}>\mathrm{f}_{\mathrm{H}}\left(\alpha_{\mathrm{H}}\right)$ and that $\left\{\left(\alpha_{\mathrm{L}}, \beta_{\mathrm{L}}\right),\left(\alpha_{\mathrm{H}}, \beta_{\mathrm{H}}\right)\right\}$ is PO. If $\alpha_{\mathrm{H}}+\beta_{\mathrm{H}}<d$, we can always think of a contract for H-type, $\left(\alpha^{\prime}, \beta^{\prime}\right)$, such that $V_{H}\left(\alpha_{H}, \beta_{H}\right)=V_{H}\left(\alpha^{\prime}, \beta^{\prime}\right)$, and $\alpha^{\prime}+\beta^{\prime}=d$, which is to be chosen only by $H$-type and yields more profits than $\left(\alpha_{H}, \beta_{H}\right)$ (because $\left(\alpha_{H}, \beta_{H}\right)$ represents the incomplete insurance), suggesting that a PO separating contract entails full insurance for $\mathrm{H}$-type in this case

\section{Lemma 1}

i) Suppose that $\alpha_{\mathrm{H}}=\alpha_{\mathrm{L}}=\bar{\alpha}$. In order for both (7A) and (7B) to be binding, it should be the case that $\mathrm{P}_{\mathrm{i}}\left\{\mathrm{U}\left(\mathrm{w}-\mathrm{d}+\alpha_{\mathrm{H}}\right)-\mathrm{U}\left(\mathrm{w}-\mathrm{d}+\alpha_{\mathrm{L}}\right)\right\}=\left(1-\mathrm{P}_{\mathrm{i}}\right)\left\{\mathrm{U}(\mathrm{w}-\mathrm{B})-\mathrm{U}\left(\mathrm{w}-\mathrm{f}_{\mathrm{H}}\left(\alpha_{\mathrm{H}}\right)\right)\right\}$ for $\mathrm{i}=\mathrm{H}, \mathrm{L}$. Since $\mathrm{B}$ gets higher for $\mathrm{P}_{\mathrm{H}}$ than for $\mathrm{P}_{\mathrm{L}}$, we can see that this condition would not hold for $\mathrm{i}=\mathrm{H}, \mathrm{L}$ unless $\alpha_{\mathrm{H}}=\alpha_{\mathrm{L}}$ and $\mathrm{B}=\mathrm{f}_{\mathrm{H}}\left(\alpha_{\mathrm{H}}\right)$. When $\alpha_{\mathrm{H}}=\alpha_{\mathrm{L}}=\bar{\alpha}$, therefore, $\operatorname{MXSH}($.) and MNSL(.) curves intersect each other, i.e., $\operatorname{MXSH}(\bar{\alpha})=\operatorname{MNSL}(\bar{\alpha})=\bar{\alpha}$. The similar argument will hold when $\beta_{\mathrm{H}}=\mathrm{d}-\alpha_{\mathrm{H}}$. In this case $\alpha_{\mathrm{H}}=\alpha_{\mathrm{L}}=\overline{\bar{\alpha}}$ and $\beta_{\mathrm{H}}=\beta_{\mathrm{L}}=\overline{\bar{\beta}}$ while $\overline{\bar{\beta}}=\mathrm{d}-\overline{\bar{\alpha}}$, implying that $\overline{\bar{\alpha}}>\bar{\alpha}$.

ii) Taking derivatives of (7A)-(7B) (or of $\left(7 A^{\prime}\right)-\left(7 B^{\prime}\right)$ ) with the equality being in place in each of the conditions with respect to $\alpha_{\mathrm{L}}$ and $\alpha_{\mathrm{H}}$, we get the desired results.

iii) When $\Delta \mathrm{P}_{\mathrm{L}}<\Delta \mathrm{P}_{\mathrm{H}} \quad \beta_{\mathrm{H}}>\mathrm{f}_{\mathrm{L}}\left(\alpha_{\mathrm{H}}\right)$, because $\beta_{\mathrm{H}}=\mathrm{f}_{\mathrm{H}}\left(\alpha_{\mathrm{H}}\right)>\mathrm{f}_{\mathrm{L}}\left(\alpha_{\mathrm{H}}\right)$, implying that $\beta_{\mathrm{L}}>\mathrm{f}_{\mathrm{L}}\left(\alpha_{\mathrm{L}}\right)$ at $\alpha_{\mathrm{L}}=\alpha_{\mathrm{H}}$ and $\beta_{\mathrm{L}}=\beta_{\mathrm{H}}$. When $\Delta \mathrm{P}_{\mathrm{L}}>\Delta \mathrm{P}_{\mathrm{H}}, \beta_{\mathrm{H}}<\mathrm{f}_{\mathrm{L}}\left(\alpha_{\mathrm{H}}\right)$ because $\beta_{\mathrm{H}}=\mathrm{f}_{\mathrm{H}}\left(\alpha_{\mathrm{H}}\right)<\mathrm{f}_{\mathrm{L}}\left(\alpha_{\mathrm{H}}\right)$, implying that $\beta_{\mathrm{L}}<\mathrm{f}_{\mathrm{L}}\left(\alpha_{\mathrm{L}}\right)$ at $\alpha_{\mathrm{L}}=\alpha_{\mathrm{H}}$ and $\beta_{\mathrm{L}}=\beta_{\mathrm{H}}$. Note that a contract $(\overline{\bar{\alpha}}, \overline{\bar{\beta}})$ induces shirking for L-type, which implies that a contract that does not entail shirking for $\mathrm{L}$ should involve the amount of insurance smaller than $\overline{\bar{\alpha}}$ (given a contract $(\overline{\bar{\alpha}}, \overline{\bar{\beta}})$ for H), i.e., $\operatorname{sMXNL}((\overline{\bar{\alpha}})<\overline{\bar{\alpha}}$.

iii) First note that $P_{L}^{\prime}=P_{L}$ in (6'). Substituting (6) or (6') into (7C) or (7C') and taking derivatives of (7C) or (7C') with respect to $\alpha_{H}$, we get the first part of the desired results. Since $B B\left(\alpha_{L}, \alpha_{H}\right)<B\left(\alpha_{L}, \alpha_{H}\right)$ for given $\left(\alpha_{\mathrm{L}}, \alpha_{\mathrm{H}}\right)$ because $\mathrm{d}-\alpha_{\mathrm{H}}>\mathrm{f}_{\mathrm{H}}\left(\alpha_{\mathrm{H}}\right)$, we get the second part of the desired result by (7C) and (7C').

\section{Lemma 2}

i) Note that $\operatorname{MXNL}(\overline{\bar{\alpha}})<\overline{\bar{\alpha}}$ since a pooling contract $(\overline{\bar{\alpha}}, \overline{\bar{\beta}})$ is a full-insurance one that entails shirking for L. Note also that $\operatorname{sMXNL}\left((\alpha)<\overline{\bar{\alpha}}\right.$ by Lemma 1 iii). Considering that $\operatorname{sMNSL}^{\prime}\left(\alpha_{H}\right)>1$ and $\operatorname{sMNSH}^{\prime}\left(\alpha_{H}\right)>1$ by Lemma 1 ii), we can see that $\operatorname{Sup}(\mathrm{G})<\overline{\bar{\alpha}}$. As $\operatorname{MXNL}(\bar{\alpha})>\bar{\alpha}$ when $\Delta \mathrm{P}_{\mathrm{L}}<\Delta \mathrm{P}_{\mathrm{H}}$ by Lemma 1 iii), $\operatorname{Sup}(\mathrm{G})<\bar{\alpha}$.

ii) First note that $P_{L}^{\prime}=P_{L}$ in (6'). From (6') we can see that $\mathrm{BB}\left(\alpha_{\mathrm{L}}, \alpha_{H}\right) \approx B\left(\alpha_{\mathrm{L}}, \alpha_{H}\right)$ when $\theta \approx 0$. This suggests that $\operatorname{MXNL}\left(\alpha_{H}\right) \approx \operatorname{sMXNL}\left(\alpha_{H}\right)$ when $\theta \approx 0$, implying that $\operatorname{Sup}(\mathrm{G})>\bar{\alpha}$ when $\Delta \mathrm{P}_{\mathrm{L}} \geq \Delta \mathrm{P}_{\mathrm{H}}$ for small $\theta$

\section{Theorem 3}

1) As for the existence of $\bar{\theta}$ :

Given the contract $\mathrm{B}\left(\bar{\alpha}_{\mathrm{H}}, \bar{\beta}_{\mathrm{H}}\right)$ for H-type in Figure $6 \mathrm{~b}$, the most profitable contract for L-type that satisfies SSL and NSL constraints would be the one C $\left(\alpha_{\mathrm{L}}^{\prime}, \beta_{\mathrm{L}}^{\prime}\right)$ (Figure $6 \mathrm{~b}$ ) such that

$$
\begin{aligned}
& P_{\mathrm{L}} \mathrm{U}\left(\mathrm{w}-\mathrm{d}+\alpha_{\mathrm{L}}{ }^{\prime}\right)+\left(1-\mathrm{P}_{\mathrm{L}}\right) \mathrm{U}\left(\mathrm{w}-\beta_{\mathrm{L}}{ }^{\prime}\right)=\mathrm{U}\left(\mathrm{w}-\mathrm{d}+\bar{\alpha}_{\mathrm{H}}\right) \\
& \frac{\mathrm{e}}{\Delta \mathrm{P}_{\mathrm{L}}}=\left\{\mathrm{U}\left(\mathrm{w}-\beta_{\mathrm{L}}{ }^{\prime}\right)-\mathrm{U}\left(\mathrm{w}-\mathrm{d}+\alpha_{\mathrm{L}}{ }^{\prime}\right)\right\} .
\end{aligned}
$$

Let us check how the profit would change as the contract moves from the pooling contract $(\bar{\alpha}, \bar{\beta})$ to a set of 
separating contracts .(B, C). Since $\mathrm{V}_{\mathrm{L}}(\bar{\alpha}, \bar{\beta})>\mathrm{V}_{\mathrm{L}}\left(\bar{\alpha}_{\mathrm{H}}, \bar{\beta}_{\mathrm{H}}\right), \mathrm{V}_{\mathrm{L}}(\bar{\alpha}, \bar{\beta})>\mathrm{V}_{\mathrm{L}}\left(\alpha_{\mathrm{L}}^{\prime}, \beta_{\mathrm{L}}^{\prime}\right)$. Also, $\beta_{\mathrm{L}}^{\prime}>\bar{\beta}$. This implies that $\pi_{\mathrm{L}}(\bar{\alpha}, \bar{\beta})<\pi_{\mathrm{L}}\left(\alpha_{\mathrm{L}}^{\prime}, \beta_{\mathrm{L}}^{\prime}\right)$. Thus, the change in profit, $\Delta$, would be

$$
\Delta=\theta\left\{\pi_{\mathrm{H}}(\bar{\alpha}, \bar{\beta})-\pi_{\mathrm{H}}\left(\bar{\alpha}_{\mathrm{H}}, \bar{\beta}_{\mathrm{H}}\right)\right\}+(1-\theta)\left\{\pi_{\mathrm{L}}(\bar{\alpha}, \bar{\beta})-\pi_{\mathrm{L}}\left(\alpha_{\mathrm{L}}^{\prime}, \beta_{\mathrm{L}}^{\prime}\right)\right\} .
$$

Since $\pi_{H}(\bar{\alpha}, \bar{\beta})-\pi_{H}\left(\bar{\alpha}_{H}, \bar{\beta}_{H}\right)<0$ by the assumption A1, there exists $\bar{\theta}(>0)$ such that for $\theta>\bar{\theta}, \Delta<0$, implying that $V_{\mathrm{H}}$ cannot be greater than $\overline{\mathrm{v}}_{\mathrm{H}}$.

As for the UO outcome:

The utilitarian optimum (when $\beta_{\mathrm{H}}=\mathrm{f}_{\mathrm{H}}\left(\alpha_{\mathrm{H}}\right)$ ) can be found by solving the following problem:

$$
\begin{aligned}
\operatorname{Max}_{\alpha_{\mathrm{H}} \mathrm{V}=\theta} & \left\{\mathrm{P}_{\mathrm{H}} \mathrm{U}\left(\mathrm{w}-\mathrm{d}+\alpha_{\mathrm{H}}\right)+\left(1-\mathrm{P}_{\mathrm{H}}\right) \mathrm{U}\left(\mathrm{w}-\mathrm{f}_{\mathrm{H}}\left(\alpha_{\mathrm{H}}\right)\right)\right\} \\
& +(1-\theta)\left\{\mathrm{P}_{\mathrm{L}} \mathrm{U}\left(\mathrm{w}-\mathrm{d}+\alpha_{\mathrm{L}}\left(\alpha_{\mathrm{H}}\right)\right)+\left(1-\mathrm{P}_{\mathrm{L}}\right) \mathrm{U}\left(\mathrm{w}-\mathrm{B}\left(\alpha_{\mathrm{L}}\left(\alpha_{\mathrm{H}}\right), \alpha_{\mathrm{H}}\right)\right)\right\}
\end{aligned}
$$

where $\mathrm{B}\left(\alpha_{\mathrm{L}}, \alpha_{\mathrm{H}}\right) \equiv \frac{\mathrm{P}_{\mathrm{L}}}{1-\mathrm{P}_{\mathrm{L}}} \alpha_{\mathrm{L}}+\frac{\theta}{1-\theta} \frac{1}{1-\mathrm{P}_{\mathrm{L}}}\left(\mathrm{P}_{\mathrm{H}} \alpha_{\mathrm{H}}-\left(1-\mathrm{P}_{\mathrm{H}}\right) \mathrm{f}_{\mathrm{H}}\left(\alpha_{\mathrm{H}}\right)\right)$ and $\alpha_{\mathrm{L}}\left(\alpha_{\mathrm{H}}\right)$ is the solution for (5), so that $\frac{\partial \alpha_{L}}{\partial \alpha_{H}}>0$. Differentiating V with respect to $\alpha_{H}$, we have

$$
\begin{aligned}
\frac{\partial \mathrm{V}}{\partial \alpha_{\mathrm{H}}}= & \theta \frac{\partial \mathrm{V}_{\mathrm{H}}}{\partial \alpha_{\mathrm{H}}}+(1-\theta) \frac{\partial \mathrm{V}_{\mathrm{L}}}{\partial \alpha_{\mathrm{H}}} \\
= & \theta \mathrm{U}^{\prime}\left(\mathrm{w}-\mathrm{d}+\alpha_{\mathrm{H}}^{*}\right) \\
& +(1-\theta)\left\{\mathrm{P}_{\mathrm{L}} \frac{\partial \alpha_{\mathrm{L}}}{\partial \alpha_{\mathrm{H}}}\left(\mathrm{U}^{\prime}\left(\mathrm{w}-\mathrm{d}+\alpha_{\mathrm{L}}\right)-\mathrm{U}^{\prime}\left(\mathrm{w}-\beta_{\mathrm{L}}\right)\right)-\frac{\theta}{1-\theta} \mathrm{P}_{\mathrm{H}} \mathrm{U}^{\prime}\left(\mathrm{w}-\beta_{\mathrm{L}}\right)\left(\mathrm{P}_{\mathrm{H}}+\left(1-\mathrm{P}_{\mathrm{H}}\right) \frac{\mathrm{U}^{\prime}\left(\mathrm{w}-\mathrm{d}+\alpha_{\mathrm{H}}\right)}{\mathrm{U}^{\prime}\left(\mathrm{w}-\mathrm{f}_{\mathrm{H}}\left(\alpha_{\mathrm{H}}\right)\right)}\right)\right. \\
& >0
\end{aligned}
$$

since $\mathrm{U}^{\prime}\left(\mathrm{w}-\mathrm{d}+\alpha_{\mathrm{L}}\right)>U^{\prime}\left(\mathrm{w}-\beta_{\mathrm{L}}\right)$ and $\mathrm{U}^{\prime}\left(\mathrm{w}-\beta_{\mathrm{L}}\right)<U^{\prime}\left(\mathrm{w}-\mathrm{f}_{\mathrm{H}}\left(\alpha_{\mathrm{H}}\right)\right)<\mathrm{U}^{\prime}\left(\mathrm{w}-\mathrm{d}+\alpha_{\mathrm{H}}\right)$. This implies that the optimal $\alpha_{\mathrm{H}}, \alpha_{\mathrm{H}}^{*}$, is the maximum value, $\bar{\alpha}$.

2) Note that for $\alpha_{\mathrm{H}}<\bar{\alpha}$ the constraint (5C) is not binding in Case I. Forming the Lagrange function for the problem (5) to get the necessary conditions for the solution, we have

$$
\begin{aligned}
& \left(1-\varphi^{*}\right)\left\{\mathrm{U}^{\prime}\left(\mathrm{w}-\mathrm{d}+\alpha_{\mathrm{L}}^{*}\right)-\mathrm{U}^{\prime}\left(\mathrm{w}-\mathrm{B}\left(\alpha_{\mathrm{L}}, \alpha_{\mathrm{H}}\right)\right)\right\}-\lambda^{*}\left\{\frac{\mathrm{P}_{\mathrm{H}}}{\mathrm{P}_{\mathrm{L}}} \mathrm{U}^{\prime}\left(\mathrm{w}-\mathrm{d}+\alpha_{\mathrm{L}}^{*}\right)+\frac{1-\mathrm{P}_{\mathrm{H}}}{1-\mathrm{P}_{\mathrm{L}}} \mathrm{U}^{\prime}\left(\mathrm{w}-\mathrm{B}\left(\alpha_{\mathrm{L}}, \alpha_{\mathrm{H}}\right)\right)\right\}=0 \\
& \lambda^{*}\left\{\mathrm{~V}_{\mathrm{H}}\left(\alpha_{\mathrm{H}}, \mathrm{f}_{\mathrm{H}}\left(\alpha_{\mathrm{H}}\right)\right)-\left(\mathrm{P}_{\mathrm{H}} \mathrm{U}\left(\mathrm{w}-\mathrm{d}+\alpha_{\mathrm{L}}^{*}\right)+\left(1-\mathrm{P}_{\mathrm{H}}\right) \mathrm{U}\left(\mathrm{w}-\mathrm{B}\left(\alpha_{\mathrm{L}}, \alpha_{\mathrm{H}}\right)\right)\right\}=0\right. \\
& \varphi^{*}\left\{\mathrm{~V}_{\mathrm{L}}\left(\alpha_{\mathrm{H}}, \mathrm{f}_{\mathrm{H}}\left(\alpha_{\mathrm{H}}\right)\right)-\left(\mathrm{P}_{\mathrm{L}} \mathrm{U}\left(\mathrm{w}-\mathrm{d}+\alpha_{\mathrm{L}}^{*}\right)+\left(1-\mathrm{P}_{\mathrm{L}}\right) \mathrm{U}\left(\mathrm{w}-\mathrm{B}\left(\alpha_{\mathrm{L}}, \alpha_{\mathrm{H}}\right)\right)\right\}=0\right.
\end{aligned}
$$

where $\lambda, \varphi$ refer to the multipliers associated with the constraints $(5 \mathrm{~A}),(5 \mathrm{~B})$, respectively. We can see from (5A), (5B) and (11) that it should not be the case that $\lambda^{*} \neq 0, \varphi^{*} \neq 0$ for $\alpha_{\mathrm{H}}<\bar{\alpha}$ and that $\lambda^{*}=\varphi^{*}=0$. We can then see from (11) that $\lambda^{*} \neq 0, \varphi^{*}=0$ because, if $\lambda^{*}=0, \varphi^{*} \neq 0, \varphi^{*}=1$, in which case the sufficient condition is not satisfied. From (11) we have

$$
\lambda^{*}=\frac{\mathrm{P}_{\mathrm{L}}}{\mathrm{P}_{\mathrm{H}}} \frac{\mathrm{U}^{\prime}\left(\mathrm{w}-\mathrm{d}+\alpha_{\mathrm{L}}^{*}\right)-\mathrm{U}^{\prime}\left(\mathrm{w}-\mathrm{B}\left(\alpha_{\mathrm{L}}, \alpha_{\mathrm{H}}\right)\right)}{\left.\mathrm{W}-\mathrm{d}+\alpha_{\mathrm{L}}^{*}\right)-\mathrm{PU} \mathrm{U}^{\prime}\left(\mathrm{w}-\mathrm{B}\left(\alpha_{\mathrm{L}}, \alpha_{\mathrm{H}}\right)\right)}>0,
$$

where $\mathrm{P} \equiv \frac{\mathrm{P}_{\mathrm{L}}}{\mathrm{P}_{\mathrm{H}}} \frac{1-\mathrm{P}_{\mathrm{H}}}{1-\mathrm{P}_{\mathrm{L}}}<1$, since it is always the case that $\mathrm{U}^{\prime}\left(\mathrm{w}-\mathrm{d}+\alpha_{\mathrm{L}}^{*}\right)>U^{\prime}\left(\mathrm{w}-\mathrm{B}\left(\alpha_{\mathrm{L}}, \alpha_{\mathrm{H}}\right)\right)$ because the contract $\left(\alpha_{\mathrm{L}}, \alpha_{\mathrm{H}}\right)$ entails incomplete insurance.

The maximized utility for L-type, $\mathrm{V}_{\mathrm{L}}^{*}\left(\alpha_{\mathrm{H}}\right)$, can then be written as

$$
\begin{aligned}
\mathrm{V}_{\mathrm{L}}^{*}\left(\alpha_{\mathrm{H}}\right)= & \mathrm{V}_{\mathrm{L}}\left(\alpha_{\mathrm{L}}^{*}, \beta_{\mathrm{L}}^{*}\right) \\
= & \mathrm{P}_{\mathrm{L}} \mathrm{U}\left(\mathrm{w}-\mathrm{d}+\alpha_{\mathrm{L}}^{*}\right)+\left(1-\mathrm{P}_{\mathrm{L}}\right) \mathrm{U}\left(\mathrm{w}-\mathrm{B}\left(\alpha_{\mathrm{L}}, \alpha_{\mathrm{H}}\right)\right) \\
& \quad+\lambda^{*}\left(\mathrm{~V}_{\mathrm{H}}\left(\alpha_{\mathrm{H}}, \mathrm{f}_{\mathrm{H}}\left(\alpha_{\mathrm{H}}\right)\right)-\mathrm{P}_{\mathrm{H}} \mathrm{U}\left(\mathrm{w}-\mathrm{d}+\alpha_{\mathrm{L}}^{*}\right)-\left(1-\mathrm{P}_{\mathrm{H}}\right) \mathrm{U}\left(\mathrm{w}-\mathrm{B}\left(\alpha_{\mathrm{L}}, \alpha_{\mathrm{H}}\right)\right)\right)
\end{aligned}
$$

Thus, we have

$$
\frac{\partial v_{\mathrm{L}}^{*}}{\partial \alpha_{\mathrm{H}}}=\lambda^{*} \mathrm{U}^{\prime}\left(\mathrm{w}-\mathrm{d}+\alpha_{\mathrm{H}}^{*}\right)
$$




$$
-\frac{\theta}{1-\theta}\left(1-\lambda^{*} \frac{1-\mathrm{P}_{\mathrm{H}}}{1-\mathrm{P}_{\mathrm{L}}}\right) \mathrm{U}^{\prime}\left(\mathrm{w}-\mathrm{B}\left(\alpha_{\mathrm{L}}, \alpha_{\mathrm{H}}\right)\right)\left(\mathrm{P}_{\mathrm{H}}+\left(1-\mathrm{P}_{\mathrm{H}}\right) \frac{\mathrm{U} /\left(\mathrm{w}-\mathrm{d}+\alpha_{\mathrm{H}}\right)}{\mathrm{U} \prime\left(\mathrm{w}-\mathrm{f}_{\mathrm{H}}\left(\alpha_{\mathrm{H}}\right)\right)}\right.
$$

the sign of which is ambiguous as $\lambda^{*}<1$. If $\theta \approx 0$, however, $\frac{\partial V_{L}^{*}}{\partial \alpha_{H}}>0$ for $\alpha_{H} \leq \bar{\alpha}$, because $\lambda^{*}$ is always positive regardless of $\theta$. This, together with Theorem 31 ), suggests that there exists $\tilde{\theta}$, which is not greater than $\bar{\theta}$ such that for $\theta<\tilde{\theta}$ a PO allocation entails shirking for H-type.

Note that for $\theta<\tilde{\theta}$ a PO contract for $\mathrm{H}$ entails full-insurance while a PO contract for L entails incomplete insurance under A1 by Proposition 1. This suggests that a pooling contract cannot be PO for $\theta<\tilde{\theta}$ under A1 for $\mathrm{L}$.

\section{Theorem 4}

For a pooling contract $(\alpha, \beta)$ to be PO, it should be the case by Proposition 1 that $\beta \leq f_{L}(\alpha)$ and $\beta=f_{H}(\alpha)$, which is not feasible in Case II. Suppose that A1 holds for H. It should then be the case that a PO contract $\left(\alpha_{H}, \beta_{H}\right)$ for $H$ is on the NSH locus. Suppose not, i.e., suppose that $\alpha_{H}+\beta_{H}=d$. We can then think of a contract $\left(\alpha_{\mathrm{H}}{ }^{\prime}, \beta_{\mathrm{H}}{ }^{\prime}\right)$ such that $\beta_{\mathrm{H}}^{\prime}=\mathrm{f}_{\mathrm{H}}\left(\alpha_{\mathrm{H}}^{\prime}\right)$ and $\mathrm{V}_{\mathrm{H}}\left(\alpha_{\mathrm{H}}, \beta_{\mathrm{H}}\right)=\mathrm{V}_{\mathrm{H}}\left(\alpha_{\mathrm{H}}{ }^{\prime}, \beta_{\mathrm{H}}{ }^{\prime}\right)$, which satisfies the self-selection constraints. Since $\pi_{H}\left(\alpha_{H}{ }^{\prime}, \beta_{H}{ }^{\prime}\right)>\pi_{H}\left(\alpha_{H}, \beta_{H}\right)$ by A1, $\left(\alpha_{H}, \beta_{H}\right)$ will not be a PO contract for $H$. In other words, a PO contract does not entail shirking by any type under A1.

\section{Lemma 3}

i) PO-R $(1, \mathrm{H})$ should entail full-insurance for H-type, because otherwise there would always exist a contract involving more insurance that can attract H-type only since $P_{H}^{S}>P_{L}^{S}$. Suppose that $\mathrm{S}(1, \mathrm{H})\left\{\left(\alpha_{\mathrm{H}}, \beta_{\mathrm{H}}\right),\left(\alpha_{\mathrm{L}}, \beta_{\mathrm{L}}\right)\right\}$ is a PO-R $(1, \mathrm{H})$, where $\beta_{\mathrm{H}}=d-\alpha_{\mathrm{H}}=\frac{p_{H}^{S}}{1-p_{H}^{S}} \alpha_{\mathrm{H}}$. Since $\frac{p_{H}^{S}}{1-p_{H}^{S}} \frac{U^{\prime}\left(w-d+\alpha_{\mathrm{H}}\right.}{U^{\prime}\left(w-\beta_{\mathrm{H}}\right)}>\frac{p_{L}^{S}}{1-p_{L}^{S}} \frac{U^{\prime}\left(w-d+\alpha_{\mathrm{H}}\right.}{U^{\prime}\left(w-\beta_{\mathrm{H}}\right)}$, there must be a contract $\left(\alpha^{\prime}, \beta^{\prime}\right)\left(\alpha^{\prime}<\alpha_{H}, \beta^{\prime}<\beta_{H}\right)$ that attracts L-type only (given $\left.\left\{\left(\alpha_{H}, \beta_{H}\right),\left(\alpha_{L}, \beta_{L}\right)\right\}\right)$ to make profits, implying that the $\mathrm{S}(\mathrm{I}, \mathrm{H})$ is not $\mathrm{PO}-\mathrm{R}(\mathrm{l}, \mathrm{H})$.

ii) Suppose that, over the contracts between $\left(\alpha_{1}, \beta_{1}\right)$ and $\left(\alpha_{2}, \beta_{2}\right)$, i-type's probability of accident remains to be $p_{i}$, while j-type's probability is either $p_{j}$ or $p_{j}{ }^{\prime}$ depending upon his choice of efforts. Let us assume just for convenience that $p_{j}<p_{i}<p_{j}{ }^{\prime}$. Also, let $\beta_{1}=b_{1} \alpha_{1}$ and $\beta_{2}=b_{2} \alpha_{2}$. Suppose that $b_{1}=\frac{p_{j}}{1-p_{j}}$ and $b_{2}=\frac{p_{i}}{1-p_{i}}$ initially so that each contract initially yields zero profit. We will then increase $\alpha_{1}$ (or $\alpha_{2}$ ) while maintaining $b_{1}$ (or $b_{2}$ ) to examine how the change in $\alpha_{1}$ (or $\alpha_{2}$ ) affects $\alpha_{2}$ and $b_{2}$ (or $\alpha_{1}$ and $b_{1}$ ), as the two self-selection constraints are simultaneously strictly satisfied. As for the self-selection constraint for i-type, the following should hold:

$$
\left(1-p_{i}\right) U\left(w-b_{2} \alpha_{2}\right)+p_{i} U\left(w-d+\alpha_{2}\right)=\left(1-p_{i}\right) U\left(w-b_{1} \alpha_{1}\right)+p_{i} U\left(w-d+\alpha_{1}\right)
$$

And, as for the self-selection constraint for $\mathrm{j}$-type, the following should hold:

$$
\left(1-p_{j}^{\prime}\right) U\left(w-b_{2} \alpha_{2}\right)+p_{j}^{\prime} U\left(w-d+\alpha_{2}\right)=\left(1-p_{j}\right) U\left(w-b_{1} \alpha_{1}\right)+p_{j} U\left(w-d+\alpha_{1}\right)
$$

The above set of the two equations has four unknowns, $\alpha_{1}, \alpha_{2}, b_{1}, b_{2}$. Taking derivatives of each equation with respect to $\alpha_{1}, \alpha_{2}, b_{1}$, keeping $b_{2}=\frac{p_{i}}{1-p_{i}}$, we have

where

$$
\begin{aligned}
& \mathrm{Ad} \alpha_{2}=\mathrm{Cd} \alpha_{1}-\mathrm{Edb}_{1} \\
& \mathrm{Bd} \alpha_{2}=\mathrm{Dd} \alpha_{1}-\mathrm{Fdb}_{1} \mathrm{~A}
\end{aligned}
$$

$$
\begin{gathered}
\mathrm{A} \equiv-\mathrm{p}_{\mathrm{i}} \mathrm{U}^{\prime}\left(\mathrm{w}-\mathrm{b}_{2} \alpha_{2}\right)+\mathrm{p}_{\mathrm{i}} \mathrm{U}^{\prime}\left(\mathrm{w}-\mathrm{d}+\alpha_{2}\right)>0 \\
\mathrm{~B} \equiv-\mathrm{p}_{\mathrm{j}} \mathrm{U}^{\prime}\left(\mathrm{w}-\mathrm{b}_{2} \alpha_{2}\right)+\mathrm{p}_{\mathrm{j}} \mathrm{U}^{\prime}\left(\mathrm{w}-\mathrm{d}+\alpha_{2}\right)>A \\
\mathrm{C} \equiv-\left(1-\mathrm{p}_{\mathrm{i}}\right) \mathrm{U}^{\prime}\left(\mathrm{w}-\mathrm{b}_{1} \alpha_{1}\right)+\mathrm{p}_{\mathrm{i}} \mathrm{U}^{\prime}\left(\mathrm{w}-\mathrm{d}+\alpha_{1}\right) \\
\mathrm{D} \equiv-\left(1-\mathrm{p}_{\mathrm{j}}\right) \mathrm{U}^{\prime}\left(\mathrm{w}-\mathrm{b}_{1} \alpha_{1}\right)+\mathrm{p}_{\mathrm{j}} \mathrm{U}^{\prime}\left(\mathrm{w}-\mathrm{d}+\alpha_{1}\right)<C \\
E \equiv-\left(1-\mathrm{p}_{\mathrm{i}}\right) \alpha_{1} \mathrm{U}^{\prime}\left(\mathrm{w}-\mathrm{b}_{1} \alpha_{1}\right) \\
\mathrm{E} \equiv-\left(1-\mathrm{p}_{\mathrm{j}}\right) \alpha_{1} \mathrm{U}^{\prime}\left(\mathrm{w}-\mathrm{b}_{1} \alpha_{1}\right)>E
\end{gathered}
$$


We also know that $\frac{\mathrm{d} \alpha_{2}}{\mathrm{~d} \alpha_{1}}>0$, which implies by the above inequalities that $\frac{\mathrm{db}}{\mathrm{d} \alpha_{1}}<0$. This suggests that as $\alpha_{1}$ (or $\left.\alpha_{2}\right)$ decreases while keeping the self-selection constraints strictly satisfied, the contract $\left(\alpha_{1}, \beta_{1}\right)$ becomes profitable if the profit for $\left(\alpha_{2}, \beta_{2}\right)$ remains to be zero. Similarly we can examine how the change in $\alpha_{1}$ (or $\alpha_{2}$ ) affects $b_{2}$ when we keep $b_{1}=\frac{p_{j}}{1-p_{j}}$. By taking derivatives of each of the above two equations with respect to $\alpha_{1}, \alpha_{2}, b_{2}$, keeping $b_{1}=\frac{p_{j}}{1-p_{j}}$, we can get the result that $\frac{d_{b}}{d \alpha_{1}}<0$, implying that as $\alpha_{1}\left(\right.$ or $\left.\alpha_{2}\right)$ decreases while keeping the self-selection constraints strictly satisfied, the contract $\left(\alpha_{2}, \beta_{2}\right)$ becomes profitable if the profit for $\left(\alpha_{1}, \beta_{1}\right)$ remains to be zero.

iii) As Figure 8 illustrates, we can always think of an $\mathrm{S}(0,0),(\mathrm{A}, \mathrm{B})$, such that $\mathrm{V}_{\mathrm{H}}$ indifference curve passing $\mathrm{B}$ crosses $\mathrm{X}$, the intersection of NSL locus and zero-profit line for H-type, implying that $(\mathrm{A}, \mathrm{B})$ satisfies the desired property.

\section{Proposition 2}

Suppose that $\mathrm{S}(1, \mathrm{~h})$ yielding zero profit for each type, denoted by $(A, B)$, exists. Suppose that a set $\left(A^{\prime}, B^{\prime}\right)(\neq$ $(A, B)$ ) of contracts (A' for $\mathrm{L}_{\text {and }} \mathrm{B}^{\prime}$ for H-type) that yields zero profit for each type is PO-R $(1, \mathrm{~h})$. Since $(A, B)$ strictly satisfies the SS constraint for $k$-type $(k=H, L),\left(A^{\prime}, B^{\prime}\right)$ should be the one that does not strictly satisfy SSL

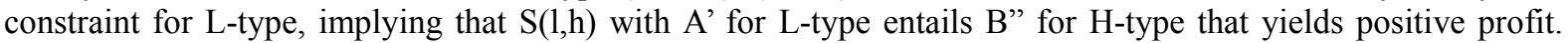
This suggests by Lemma 3 ii) that (A',B') should be pareto-dominated by $(A, B)$, suggesting that $\left(A^{\prime}, B^{\prime}\right)$ is not PO-R $(1, h)$. Suppose that $(A, B)$ does not exist. Since a PO-R $(1, h)$ has to strictly satisfy the SS constraint for ktype $(\mathrm{k}=\mathrm{H}, \mathrm{L})$, the amount of insurance for k-type has to be at its maximum, which is either full insurance (when $\mathrm{h}=\mathrm{H}$ ) or maximum non-shirking level (when $\mathrm{h}=0$ ). Finally, Lemma 3 iii) implies that there always exists a separating PO-R $(0,0)$ contract.

(2) Consider a pooling contract $(\alpha, \beta)$ such that $\alpha+\beta<d$ and $\beta>f_{\mathrm{H}}(\alpha)$. We can then think of a contract $\left(\alpha^{\prime}, \beta^{\prime}\right)$ such that $\mathrm{V}_{\mathrm{H}}(\alpha, \beta)=\mathrm{V}_{\mathrm{H}}\left(\alpha^{\prime}, \beta^{\prime}\right), \quad \alpha^{\prime}>\alpha, \beta>\beta^{\prime}, \quad$ so that a separating contract $\left\{\left(\alpha^{\prime}, \beta^{\prime}\right),(\alpha, \beta)\right\}$ dominates the pooling contract $(\alpha, \beta)$ because $\pi_{H}(\alpha, \beta)<\pi_{H}\left(\alpha^{\prime}, \beta^{\prime}\right)$. The same argument can be applied to any other pooling contract that does not strictly satisfy any non-shirking condition.

\section{Proposition 3}

To see if a PO-R(1,h) is a PO-G, we first need to make sure that it is not pareto-dominated by another regional $\mathrm{PO}$ or that there is no other contract that can profitably attracts one type given the PO-R $(1, \mathrm{~h})$. We can first see that PO-R(L,H) and PO-R $(0, \mathrm{H})$ are pareto-ranked to each other and that so are PO-R(L,0) and PO-R $(0,0)$. We can also see that PO-R $(\mathrm{L}, \mathrm{H})$ and $\mathrm{PO}-\mathrm{R}(\mathrm{L}, 0)$ are pareto-ranked to each other and that so are $\mathrm{PO}-\mathrm{R}(0, \mathrm{H})$ and $\mathrm{PO}-$ $\mathrm{R}(0,0)$. The remaining pairs will be PO-R(L,0) \& PO-R $(0, \mathrm{H})$ and PO-R(L,H) \& PO-R $(0,0)$. Consider be PO$\mathrm{R}(\mathrm{L}, 0) \& \mathrm{PO}-\mathrm{R}(0, \mathrm{H})$. Whenever $V_{H}$ associated with PO-R(L,0) is lower than that associated with $\mathrm{PO}-\mathrm{R}(0, \mathrm{H})$, there should be a contract that can profitably attract $\mathrm{H}$-type only, so that $\mathrm{PO}-\mathrm{R}(0, \mathrm{H})$ is $\mathrm{PO}-\mathrm{G}$. When $V_{H}$ associated with PO-R $(\mathrm{L}, 0)$ is higher than that associated with PO-R $(0, \mathrm{H}), V_{L}$ associated with PO-R(L,0) should also be higher than that associated with PO-R $(0, \mathrm{H})$, implying that PO-R(L,0) is PO-G. Consider PO-R(L,H) \& PO-R $(0,0)$. Whenever $V_{H}$ associated with PO-R $(0,0)$ is lower than that associated with PO-R(L,H), there should be a contract that can profitably attract H-type only, so that PO-R $(0,0)$ is PO-G. If not, PO-R(L,H) should be PO-G, because then, given PO-R $(0,0)$, by Lemma 3 ii), there should be a contract that can profitably attract L-type only.

\section{Theorem 5}

i) Proposition 2 suggests that a PO-R(1,h) may not be on the NS locus nor on the full-insurance locus. This suggests that a PO-G contract, whether it may be separating one or pooling one, may not be on the NS locus nor on the full-insurance locus. Note that a pooling contract $Z$ in Figure 9a may be PO-G.

ii) From Figure $9 \mathrm{a}$ we can see by $A 1$ that when $\theta \approx 0$ the pooling contract $X$ dominates any separating contract that involves no subsidy. When $\theta \approx 1$, the pooling contract $Y$ dominates any separating contract involving no subsidy except for some special cases such as $(\mathrm{A}, \mathrm{Y})$ in Figure $9 \mathrm{~b}$. 


\section{Proposition 4}

Suppose that a global PO contract A that yields zero profit for each type is not an RS equilibrium. A deviant contract that can make positive profits if offered would imply that the contract A is not PO, leading to the contradiction. Suppose, on the other hand, that an RS equilibrium is not global PO, i.e., that it is paretodominated. Then, by Lemma 3 ii), there exists a contract that will be chosen by one type to make positive profits, implying that it is not an RS equilibrium, i.e., leading to the contradiction.

\section{Theorem 7}

i) This is trivial by Theorem 6 i).

ii) For a pooling allocation to be an RS equilibrium it needs to be PO by i). See Theorem 10 on the condition for the existence of a pooling equilibrium.

iii) For the condition ii) to be satisfied, the single-crossing property should not hold.

\section{Theorem 8}

If a PO separating contract exists, it is unique in the case of single-crossing preference. It is also unique in the case of multi-crossing preferences by Proposition 3. Thus, an RS equilibrium is unique, if it exists, by Proposition 4.

In the case of single-crossing preferences, a PO contract entailing shirking involves cross-subsidy as is shown by Theorem 3, implying that an RS equilibrium should not entail shirking in this case. In the case of multi-crossing preferences, Theorem 5 and Proposition 4 suggest that an RS equilibrium may involve shirking or amount of insurance that is insufficient relative to NS or full-insurance constraint.

\section{Theorem 9}

i) As for the existence of $\tilde{\theta}$ :

In the case of multi-crossing preferences, $\tilde{\theta}$ always exists by Theorem 5 ii).

In the case of single-crossing preferences: Let us denote by $\mathrm{A}$ and $\mathrm{B}$ a contract $(\alpha, \beta)$ and $\left(\alpha^{\prime}, \beta^{\prime}\right)$, respectively, such that $\beta=\frac{\mathrm{P}_{\mathrm{H}}}{1-\mathrm{P}_{\mathrm{H}}} \alpha$ while $\beta=f_{H}(\alpha)$ and that $\beta^{\prime}=\frac{\mathrm{P}_{\mathrm{L}}}{1-\mathrm{P}_{\mathrm{L}}} \alpha^{\prime}$ while $\beta^{\prime}=f_{L}\left(\alpha^{\prime}\right)$, as is illustrated by $\mathrm{A}$ and $\mathrm{B}$ in Figure 10c. As a best possible case for equilibrium existence, we will consider a case where $\beta=f_{H}(\alpha) \approx \mathrm{d}-\alpha$, so that A may go to $\mathrm{A}^{\prime}$ in Figure 10c. Consider first the case where $\mathrm{P}_{\mathrm{L}}^{\mathrm{S}}=\mathrm{P}_{\mathrm{H}}$. Denoting by $\mathrm{B}$ ' a contract $\left(\alpha^{\prime \prime}, \beta^{\prime \prime}\right)$ such that $V_{H}\left(A^{\prime}\right)=V_{H}\left(B^{\prime \prime}\right)$ and $\beta^{\prime \prime}=\frac{P_{L}}{1-P_{L}} \alpha^{\prime \prime}$, we can see from A1 that $\alpha^{\prime \prime}<\alpha^{\prime}$, implying that $\tilde{\theta}>0$. Now, by increasing $\mathrm{P}_{\mathrm{H}}$ from $\mathrm{P}_{\mathrm{L}}^{\mathrm{S}}$, we will examine how $\alpha$ " will change to see if a new $\alpha$ " is still lower than $\alpha^{\prime}$. Restating the condition that $\mathrm{V}_{\mathrm{H}}\left(\mathrm{A}^{\prime}\right)=\mathrm{V}_{\mathrm{H}}\left(\mathrm{B}^{\prime \prime}\right)$ (taking into account zero-profit conditions), we have

$$
\mathrm{U}\left(\mathrm{w}-\mathrm{d} p_{H}\right)=p_{H} U\left(w-d+\alpha^{\prime \prime}\right)+\left(1-p_{H}\right) U\left(w-\frac{\mathrm{P}_{\mathrm{L}}}{1-\mathrm{P}_{\mathrm{L}}} \alpha^{\prime \prime}\right)
$$

Taking derivatives both sides of the above condition with respect to $p_{H}$ and $\alpha$, we have

where

$$
\frac{d \alpha^{\prime \prime}}{d p_{H}}=\frac{X}{Y}
$$

$$
\begin{aligned}
& \mathrm{X} \equiv U\left(w-\frac{\mathrm{P}_{\mathrm{L}}}{1-\mathrm{P}_{\mathrm{L}}} \alpha^{\prime \prime}\right)-U\left(w-d+\alpha^{\prime \prime}\right)-\mathrm{U}\left(\mathrm{w}-\mathrm{d} p_{H}\right) \\
& \mathrm{Y} \equiv\left(1-p_{H}\right)\left\{\frac{\mathrm{P}_{\mathrm{H}}}{1-\mathrm{P}_{\mathrm{H}}} U^{\prime}\left(w-d+\alpha^{\prime \prime}\right)-\frac{\mathrm{P}_{\mathrm{L}}}{1-\mathrm{P}_{\mathrm{L}}} U^{\prime}\left(w-\frac{\mathrm{P}_{\mathrm{L}}}{1-\mathrm{P}_{\mathrm{L}}} \alpha^{\prime \prime}\right)\right\}
\end{aligned}
$$

Note that $\mathrm{Y}>0$ because $w-\frac{\mathrm{P}_{\mathrm{L}}}{1-\mathrm{P}_{\mathrm{L}}} \alpha^{\prime \prime}>w-d+\alpha^{\prime \prime}$. Since $U\left(w-\frac{\mathrm{P}_{\mathrm{L}}}{1-\mathrm{P}_{\mathrm{L}}} \alpha^{\prime \prime}\right)-U\left(w-d+\alpha^{\prime \prime}\right)=\frac{1}{p_{H}}\{U(w-$ $\left.\left.\frac{\mathrm{P}_{\mathrm{L}}}{1-\mathrm{P}_{\mathrm{L}}} \alpha^{\prime \prime}\right)-\mathrm{U}\left(\mathrm{w}-\mathrm{d} p_{H}\right)\right\}$ by $(9-1)$ and since $\mathrm{dU}^{\prime}\left(\mathrm{w}-\mathrm{d} p_{H}\right)>\frac{1}{p_{H}}\left\{U(w)-\mathrm{U}\left(\mathrm{w}-\mathrm{d} p_{H}\right)\right\}$, we have

$$
\begin{aligned}
\mathrm{X} & <\frac{1}{p_{H}}\left\{U\left(w-\frac{\mathrm{P}_{\mathrm{L}}}{1-\mathrm{P}_{\mathrm{L}}} \alpha^{\prime \prime}\right)-\mathrm{U}\left(\mathrm{w}-\mathrm{d} p_{H}\right)\right\}-\frac{1}{p_{H}}\left\{U(w)-\mathrm{U}\left(\mathrm{w}-\mathrm{d} p_{H}\right)\right\} \\
& <0 .
\end{aligned}
$$

This implies that $\frac{d \alpha^{\prime \prime}}{d p_{H}}=\frac{X}{Y}<0$, suggesting that $\alpha^{\prime \prime}<\alpha^{\prime}$ for $\mathrm{P}_{\mathrm{H}}>\mathrm{P}_{\mathrm{L}}^{\mathrm{S}}$, i.e., that $\tilde{\theta}>0$ in Case II with singlecrossing preferences. 
As for the property of $\tilde{\theta}$ :

Figure 10a shows that as NSL constraint becomes stricter, $\tilde{\theta}$ decreases, while Figure 10b shows that as NSH becomes stricter, $\tilde{\theta}$ decreases.

ii) When $\theta \approx 1$, the pooling contract $\mathrm{Y}$ in Figure $9 \mathrm{~b}$ dominates any separating contract involving no subsidy, except for a separating allocation $(\mathrm{A}, \mathrm{Y})$ as shown in Figure $9 \mathrm{~b}$.

\section{Theorem 10}

Note first that at any $(\alpha, \beta)$ satisfying $\beta \leq f(\alpha), \frac{P_{L}}{1-P_{L}} \frac{U_{L}^{\prime}(w-d+\alpha)}{U_{L}^{\prime}(w-\beta)}>\frac{P_{H}}{1-P_{H}} \frac{U_{H}^{\prime}(w-d+\alpha)}{U_{H}^{\prime}(w-\beta)}$. Here we will choose to present as a proof a figure (Figure 11). In Figure 11, given a pooling contract A, a deviant contract B will attract H-type only to make losses, while a deviant contract $\mathrm{C}$ will attract $\mathrm{L}$-type only who would shirk, making losses. Note that there exists $\theta^{*}(>0)$ such that any contract outside the non-shirking locus will make loss if $\theta<\theta^{*}$.

\section{Lemma 4}

We will first identify the case when the solution $\left(\alpha^{*}, \beta^{*}\right)$ for $(10)$ is on the NS locus, i.e., when $\beta^{*}=f\left(\alpha^{*}\right)$. A necessary condition for that will be $\frac{\mathrm{P}_{\mathrm{L}}}{1-\mathrm{P}_{\mathrm{L}}} \frac{\mathrm{U}_{\mathrm{L}}^{\prime}\left(\mathrm{w}-\mathrm{d}+\alpha^{*}\right)}{\mathrm{U}_{\mathrm{L}}^{\prime}\left(\mathrm{w}-\mathrm{f}\left(\alpha^{*}\right)\right)} \geq \frac{\overline{\mathrm{P}}}{1-\overline{\mathrm{P}}}=\frac{f\left(\alpha^{*}\right)}{\alpha^{*}}$. When $\theta \approx 0, \frac{\mathrm{P}_{\mathrm{L}}}{1-\mathrm{P}_{\mathrm{L}}} \frac{\mathrm{U}_{\mathrm{L}}^{\prime}\left(\mathrm{w}-\mathrm{d}+\alpha^{*}\right)}{\mathrm{U}_{\mathrm{L}}^{\prime}\left(\mathrm{w}-\mathrm{f}\left(\alpha^{*}\right)\right)}>\frac{\overline{\mathrm{P}}}{1-\overline{\mathrm{P}}} \approx$ $\frac{\mathrm{P}_{\mathrm{L}}}{1-\mathrm{P}_{\mathrm{L}}}$ since $\frac{\mathrm{U}_{\mathrm{L}}^{\prime}\left(\mathrm{w}-\mathrm{d}+\alpha^{*}\right)}{\mathrm{U}_{\mathrm{L}}^{\prime}\left(\mathrm{w}-\mathrm{f}\left(\alpha^{*}\right)\right)}>1$, proving the first part of Lemma 4. For any given $\theta$ both $\alpha^{*}$ and $f\left(\alpha^{*}\right)$ are increasing in $\Delta \mathrm{P}$, implying that $\frac{\mathrm{U}_{\mathrm{L}}^{\prime}\left(\mathrm{w}-\mathrm{d}+\alpha^{*}\right)}{\mathrm{U}_{\mathrm{L}}^{\prime}\left(\mathrm{w}-\mathrm{f}\left(\alpha^{*}\right)\right)}$ is decreasing in $\Delta \mathrm{P}$ and thus that $\theta^{\prime}(\Delta \mathrm{P})<0$.

\section{Theorem 11}

Given the government revelation of information, by the assumption (A1), there would be no contract that profitably offers additional insurance. Suppose $\frac{\mathrm{P}_{\mathrm{L}}}{1-\mathrm{P}_{\mathrm{L}}} \frac{\mathrm{U}_{\mathrm{L}}^{\prime}\left(\mathrm{w}-\mathrm{d}+\alpha^{*}\right)}{\mathrm{U}_{\mathrm{L}}^{\prime}\left(\mathrm{w}-\mathrm{f}\left(\alpha^{*}\right)\right)} \geq \frac{\overline{\mathrm{P}}}{1-\overline{\mathrm{P}}}$ (as in Figure 12a). This suggests that at any contract entailing the amount of insurance smaller than $\alpha^{*}$ each type of individual would like to purchase more insurance at the price $\frac{\overline{\mathrm{P}}}{1-\overline{\mathrm{P}}}$ and can be made better-off compared to the contract $\left(\alpha^{*}, \beta^{*}\right)$. This implies that there would be no contract offering insurance smaller than $\alpha^{*}$ that can profitably attract L-type only when insurance provision is non-exclusive.

\section{Theorem 12}

Under the strategy of selling insurance up to $\alpha^{*}$ at the price $\frac{\overline{\mathrm{P}}}{1-\overline{\mathrm{P}}}$ while selling additional insurance up to $\alpha^{\prime}$ at the price $\frac{P_{H}}{1-P_{H}}$ for those purchasing more than $\alpha^{*}$, the resulting allocation would be $\left(\alpha^{*}, \beta^{*}\right)$ for both types and supplemental contract $\left(\alpha^{\prime}-\alpha^{*}, \beta^{\prime}-\beta^{*}\right)$ for H-type (Figure 12b). Given this outcome, no contract offering insurance smaller than $\alpha^{*}$ would not be able to profitably attract L-type only under non-exclusive provision as in the case of Theorem 11. Any contract offering insurance more than $\alpha^{*}$ at the price lower than $\frac{P_{H}}{1-P_{H}}$ but higher than $\frac{\overline{\mathrm{P}}}{1-\overline{\mathrm{P}}}$ would attract H-type only, yielding negative profits. Also, note that the pure pooling allocation $\left(\alpha^{*}, \beta^{*}\right)$ cannot be sustained as an equilibrium under PAS is because, at that point, H-type individuals have incentive to increase amount of insurances at the price $\frac{P_{H}}{1-P_{H}}$.

\section{Theorem 13}

For any PO allocation $\left\{\left(\alpha_{\mathrm{H}}, \beta_{\mathrm{H}}\right),\left(\alpha_{\mathrm{L}}, \beta_{\mathrm{L}}\right)\right\}$, let us consider $(\bar{\alpha}, \bar{\beta})$ such that $\bar{\beta}=\frac{\bar{P}}{1-\overline{\mathrm{P}}} \bar{\alpha}, \beta_{\mathrm{H}}-\bar{\beta}=\frac{\mathrm{P}_{\mathrm{H}}}{1-\mathrm{P}_{\mathrm{H}}}\left(\alpha_{\mathrm{H}}-\right.$ $\bar{\alpha}) \leq 0$. Since $\theta\left\{\left(1-\mathrm{P}_{\mathrm{H}}\right) \bar{\beta}-\mathrm{P}_{\mathrm{H}} \bar{\alpha}\right\}+(1-\theta)\left\{\left(1-\mathrm{P}_{\mathrm{L}}\right) \bar{\beta}-\mathrm{P}_{\mathrm{L}} \bar{\alpha}\right\}=(1-\overline{\mathrm{P}}) \bar{\beta}-\overline{\mathrm{P}} \bar{\alpha}=0$, we can see from the zero profit condition that $\beta_{\mathrm{L}}-\bar{\beta}=\frac{\mathrm{P}_{\mathrm{L}}}{1-\mathrm{P}_{\mathrm{L}}}\left(\alpha_{\mathrm{L}}-\bar{\alpha}\right)$. Also, since $\left\{\left(\alpha_{\mathrm{i}}-\bar{\alpha}\right),\left(\beta_{\mathrm{i}}-\bar{\beta}\right)\right\}$ is PO given $(\bar{\alpha}, \bar{\beta})$ and does not involve any subsidy, it should be sustained as a R-S equilibrium given $(\bar{\alpha}, \bar{\beta})$. Finally, when a PO allocation does not entail subsidy, $\beta_{i}=\frac{P_{i}}{1-P_{i}} \alpha_{i}(i=H, L)$ so that $\bar{\beta}=\bar{\alpha}=0$, while when it is a pooling one, 
$\beta_{\mathrm{L}}=\beta_{\mathrm{H}}$ and $\alpha_{\mathrm{L}}=\alpha_{\mathrm{H}}$, so that $\beta_{\mathrm{i}}=\bar{\beta}$ and $\alpha_{\mathrm{i}}=\bar{\alpha}$.

\section{Theorem 14}

The first part of the theorem, the decomposition of a separating contract into a pooling and a separating ones (with no subsidy), is already proved in Theorem 13. It suffices to prove the remaining part. We will show that, without the government tax, a firm can make positive profit by deviating from the separating contract $\left\{\left(\alpha_{\mathrm{i}}-\bar{\alpha}\right),\left(\beta_{\mathrm{i}}-\bar{\beta}\right)\right\}_{\mathrm{i}=\mathrm{H}, \mathrm{L}}$. Consider, for example, $\left\{\left(\alpha_{\mathrm{H}}-\bar{\alpha}\right),\left(\beta_{\mathrm{H}}-\bar{\beta}\right)\right.$ that yields zero profit for a firm offering it given the pooling and separating contracts. There then exists a contract $\left(\alpha^{\prime}, \beta^{\prime}\right)$ that a firm can offer H-type, such that $\alpha^{\prime}>\alpha_{\mathrm{H}}, \beta^{\prime}>\beta_{\mathrm{H}}$ and that $\frac{\mathrm{P}_{\mathrm{H}}^{\mathrm{S}}}{1-\mathrm{P}_{\mathrm{H}}^{\mathrm{S}}}<\frac{\beta^{\prime}}{\alpha \prime}<\frac{\mathrm{P}_{\mathrm{H}}^{\mathrm{S}}}{1-\mathrm{P}_{\mathrm{H}}^{\mathrm{S}}} \frac{\mathrm{U}^{\prime}\left(\mathrm{w}-\mathrm{d}+\alpha^{\prime}\right)}{\mathrm{U}^{\prime}\left(\mathrm{w}-\beta^{\prime}\right)}$, which attracts H-type and makes positive profit, while it yields negative profit for the government (offering a pooling contract $(\bar{\alpha}, \bar{\beta})$ ) because the accident probability increases from $\mathrm{P}_{\mathrm{H}}$ to $\mathrm{P}_{\mathrm{H}}^{\mathrm{S}}$ as the deviant firm offers H-type $\left(\alpha^{\prime}, \beta^{\prime}\right)$.

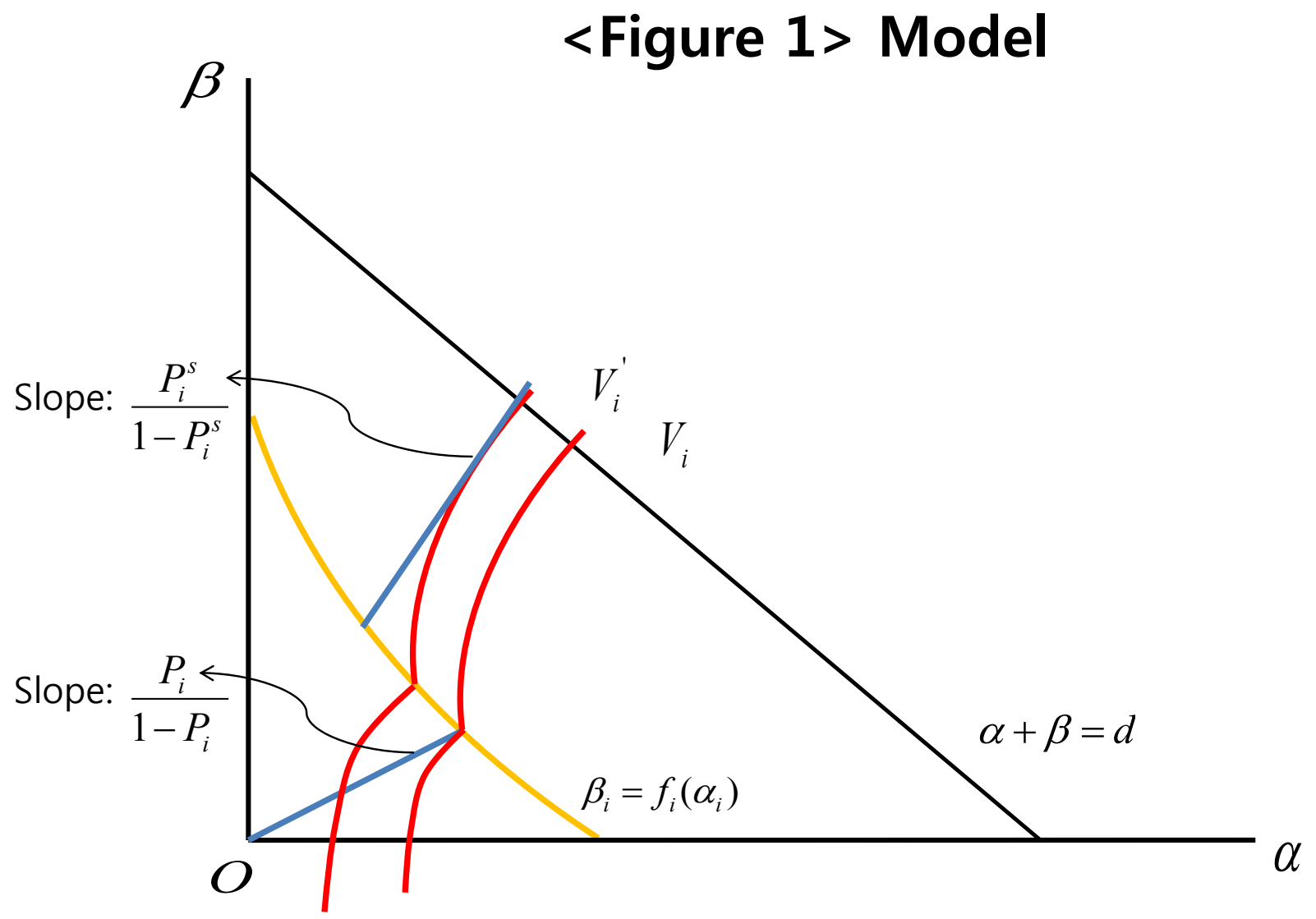


<Figure 2> Model with Multi-crossing Preferences

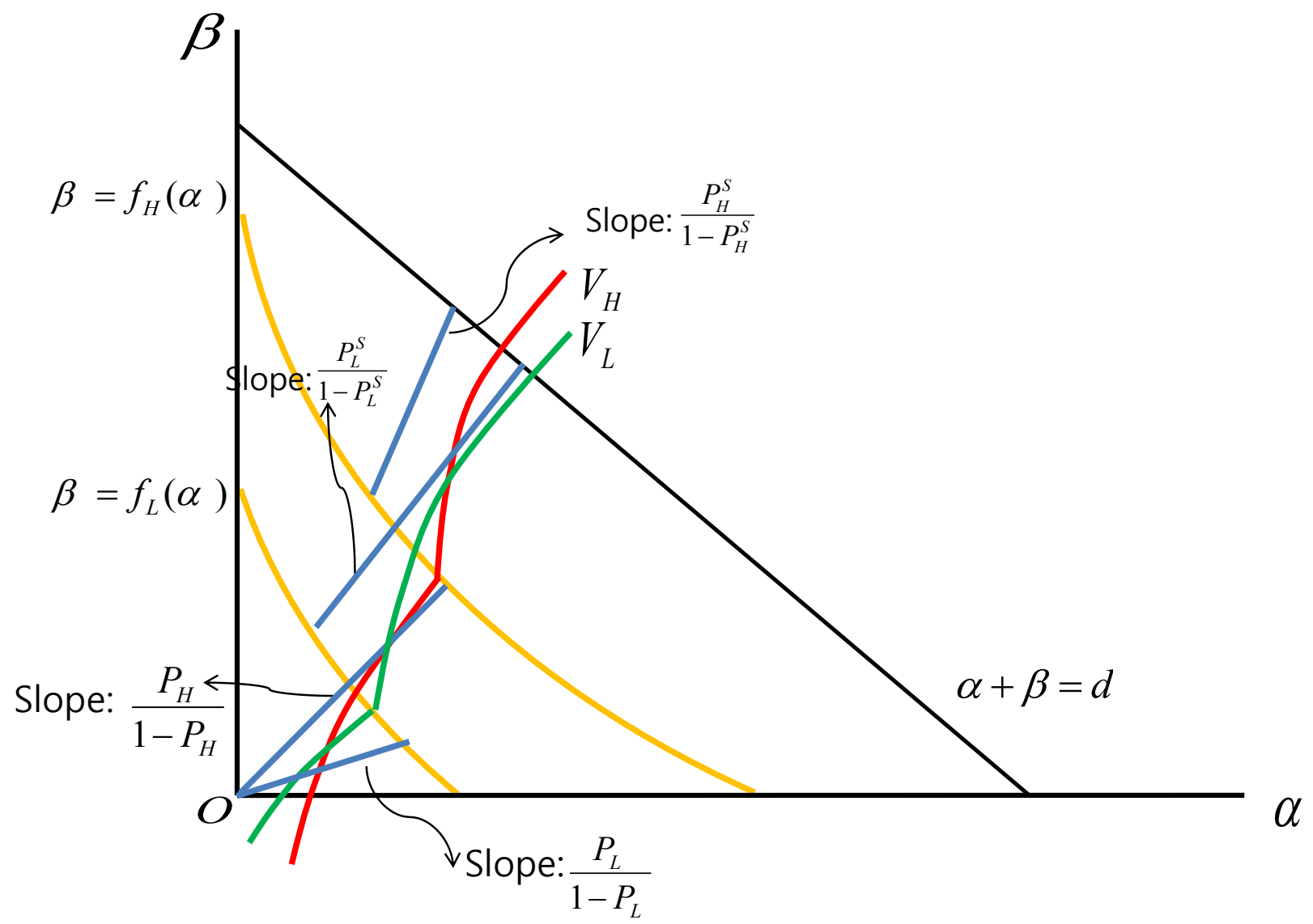




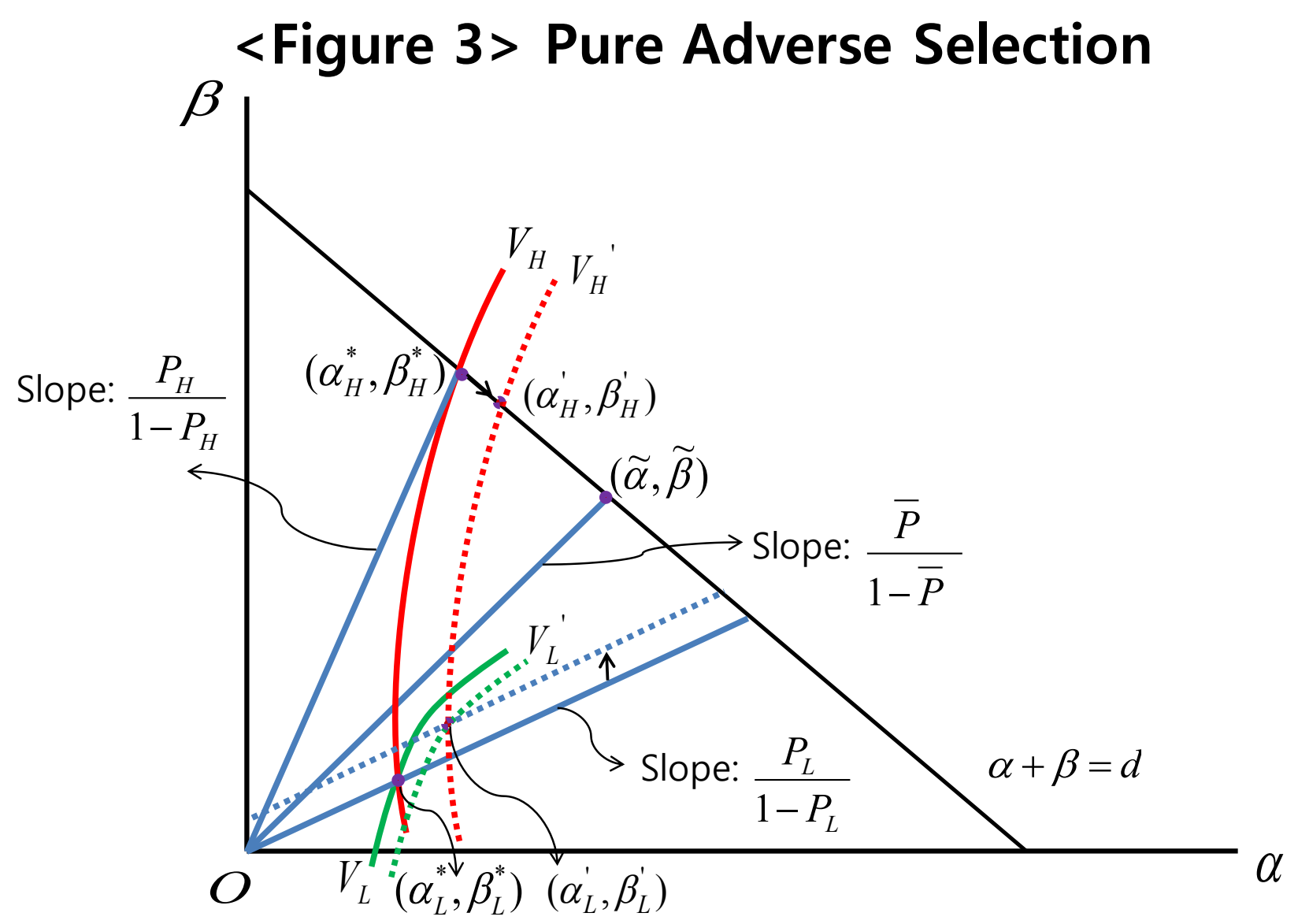




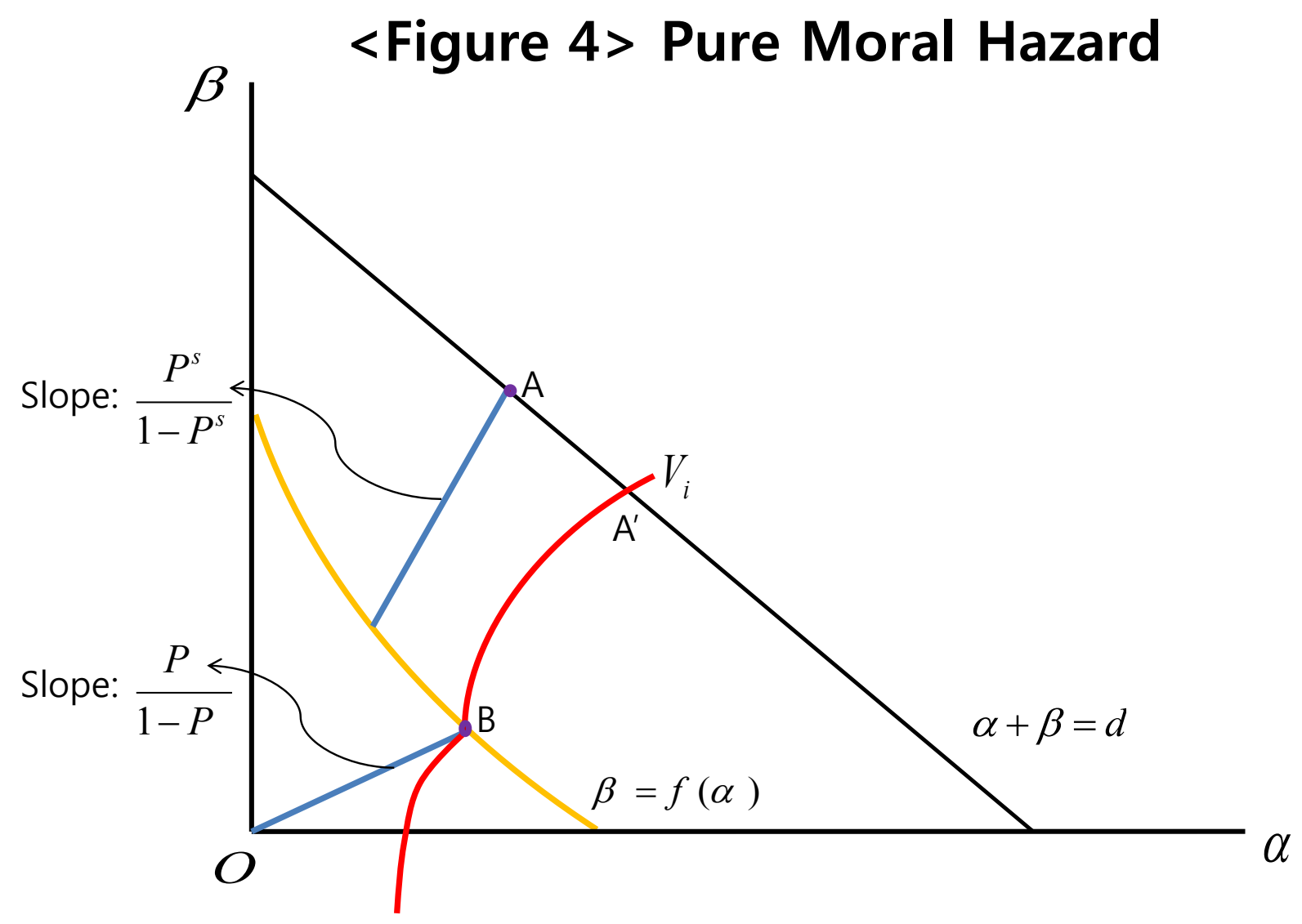


$<$ Figure 5a $>$ Constraints for PO $\left(\Delta \mathrm{P}_{H}<\Delta \mathrm{P}_{L}\right)$

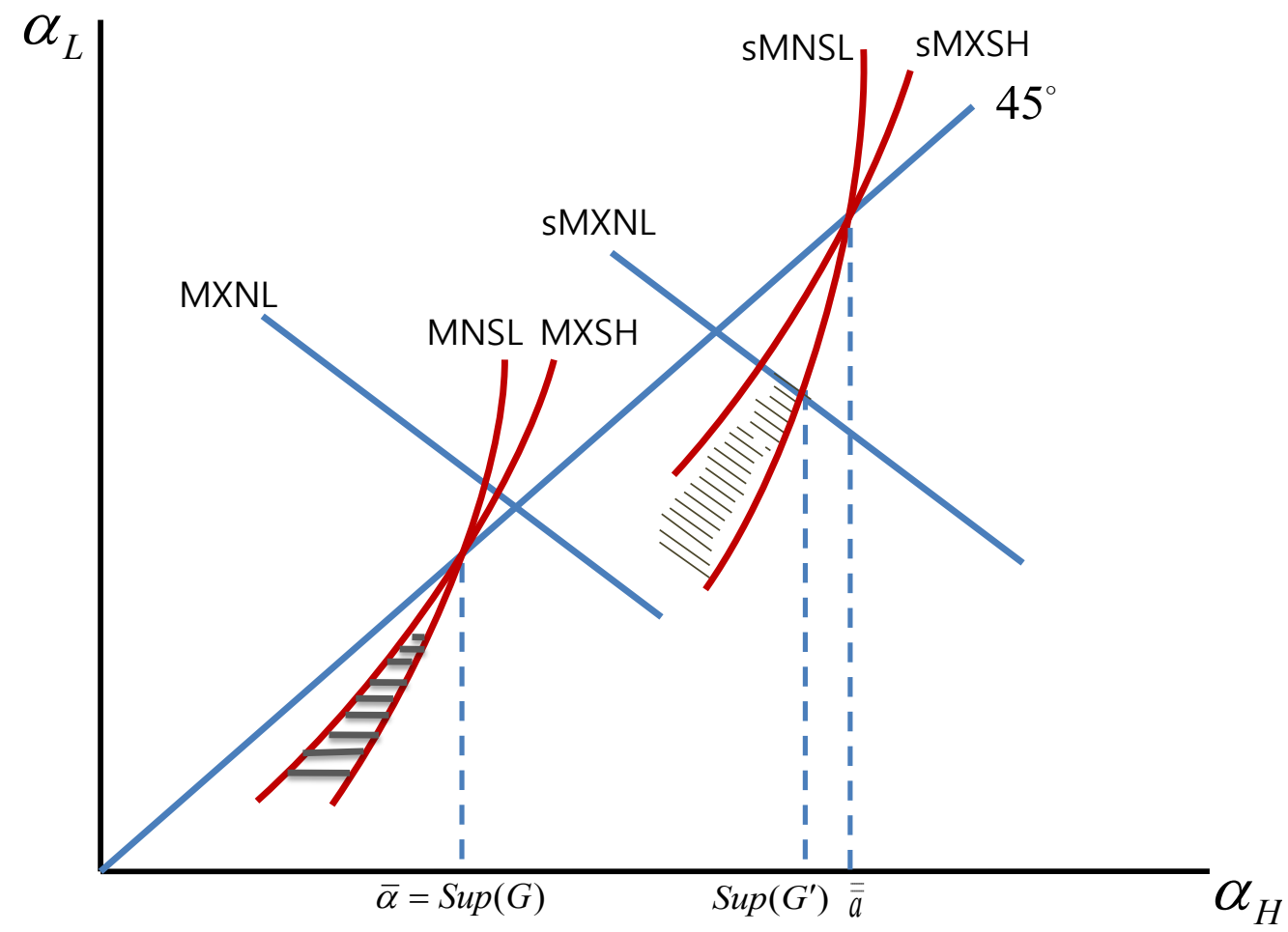


$<$ Figure $5 \mathrm{~b}>$ Constraints for $\mathrm{PO}\left(\Delta \mathrm{P}_{\mathrm{H}}>\Delta \mathrm{P}_{\mathrm{L}}\right)$

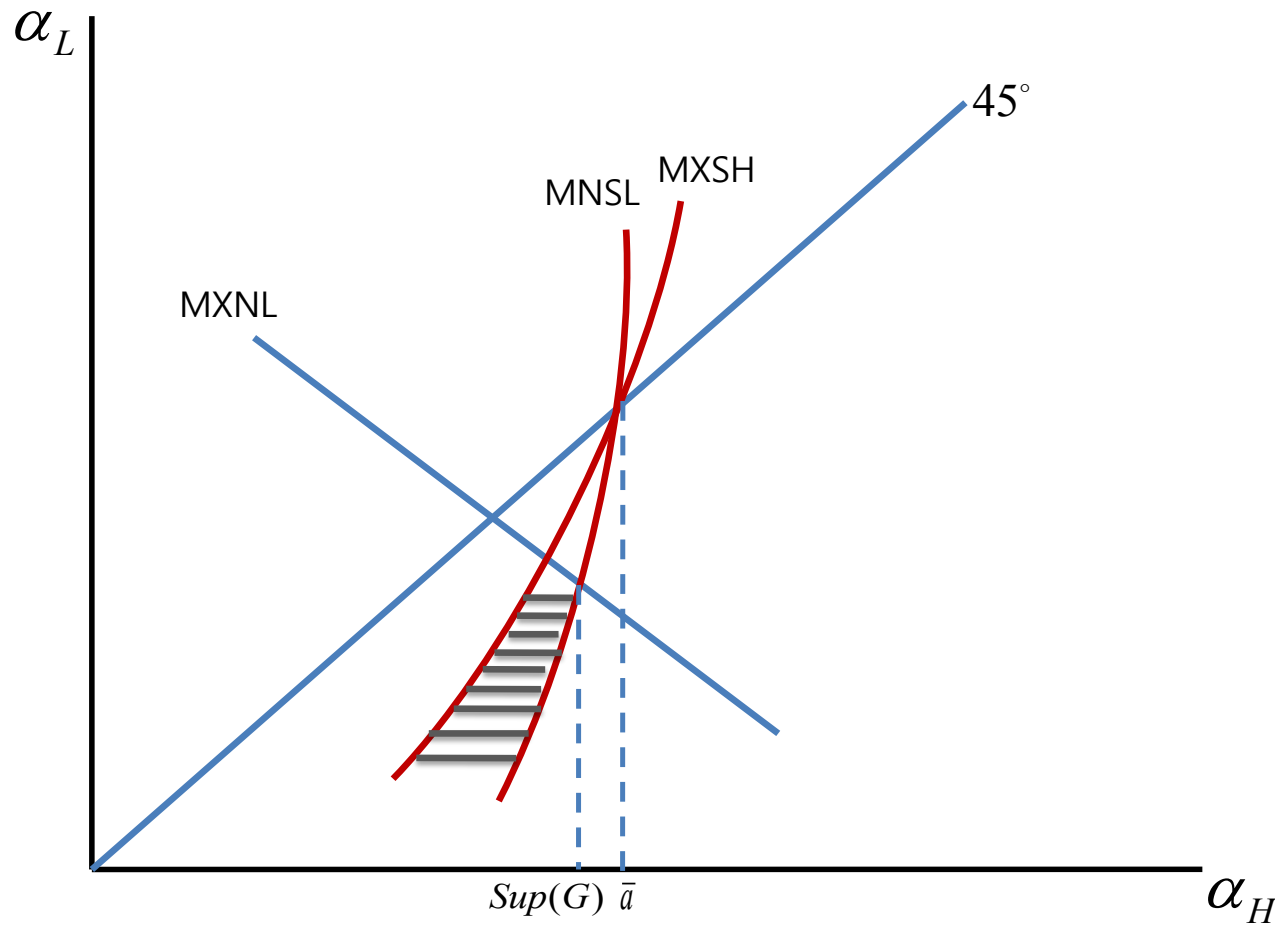



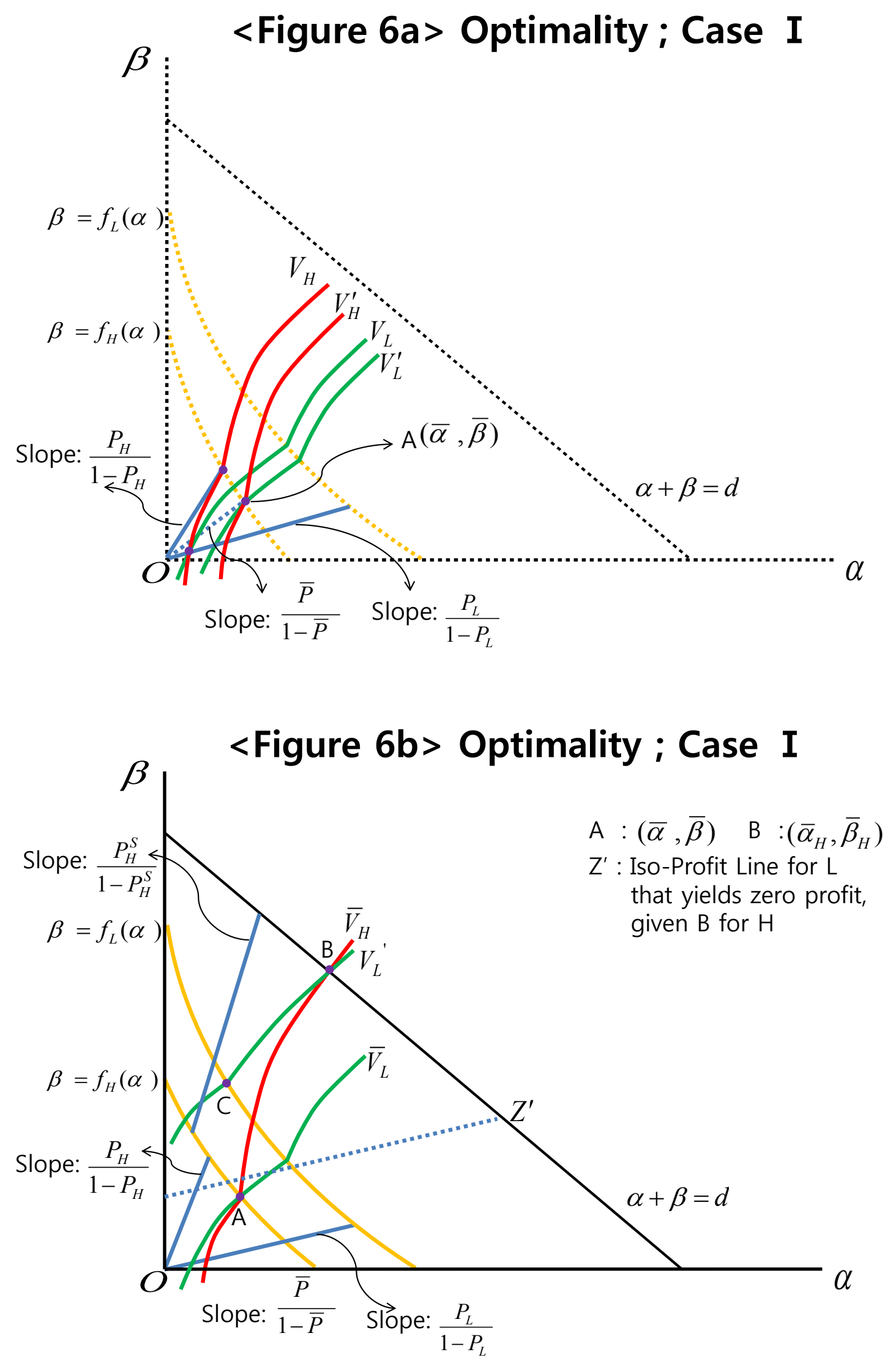


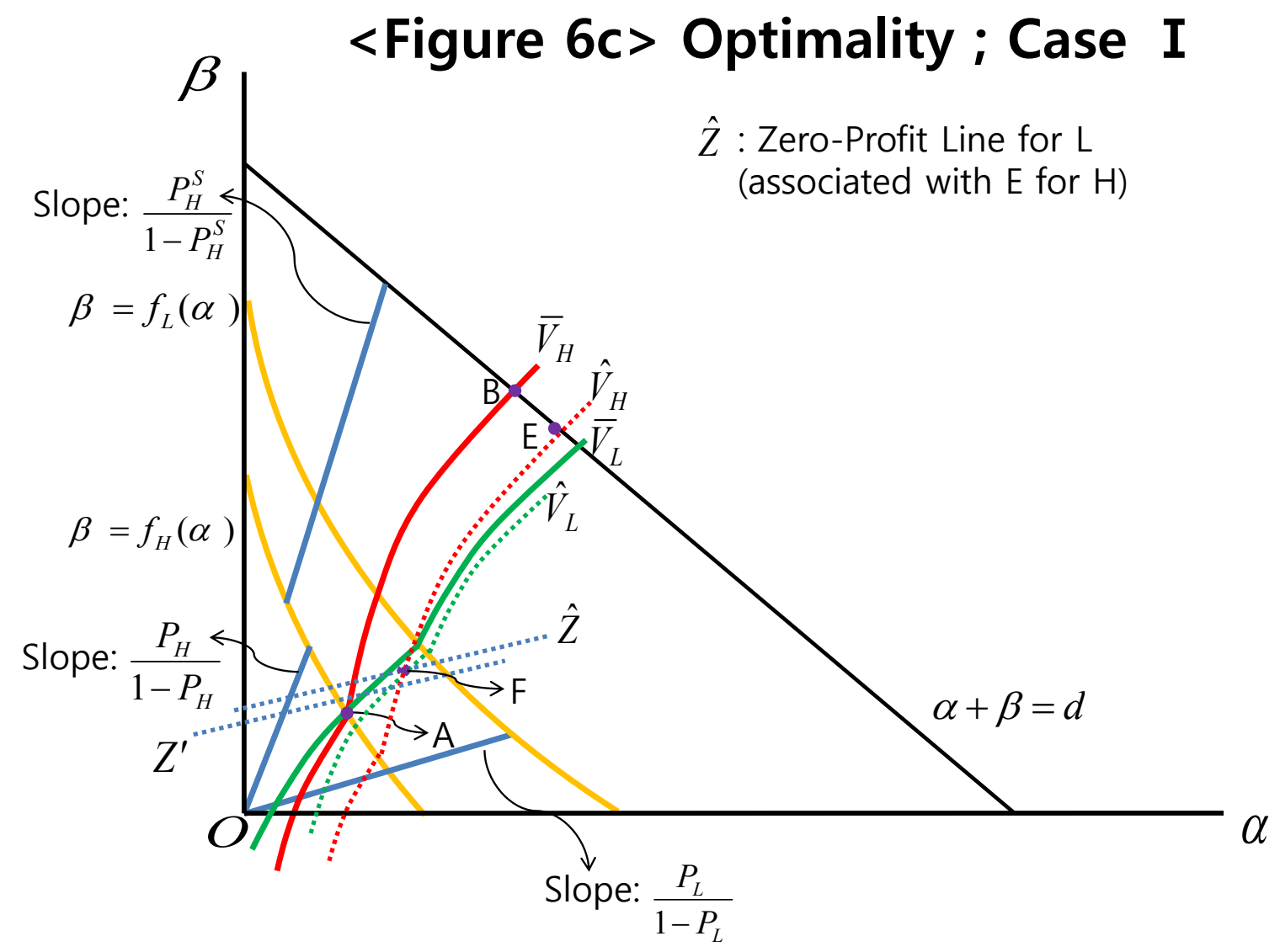




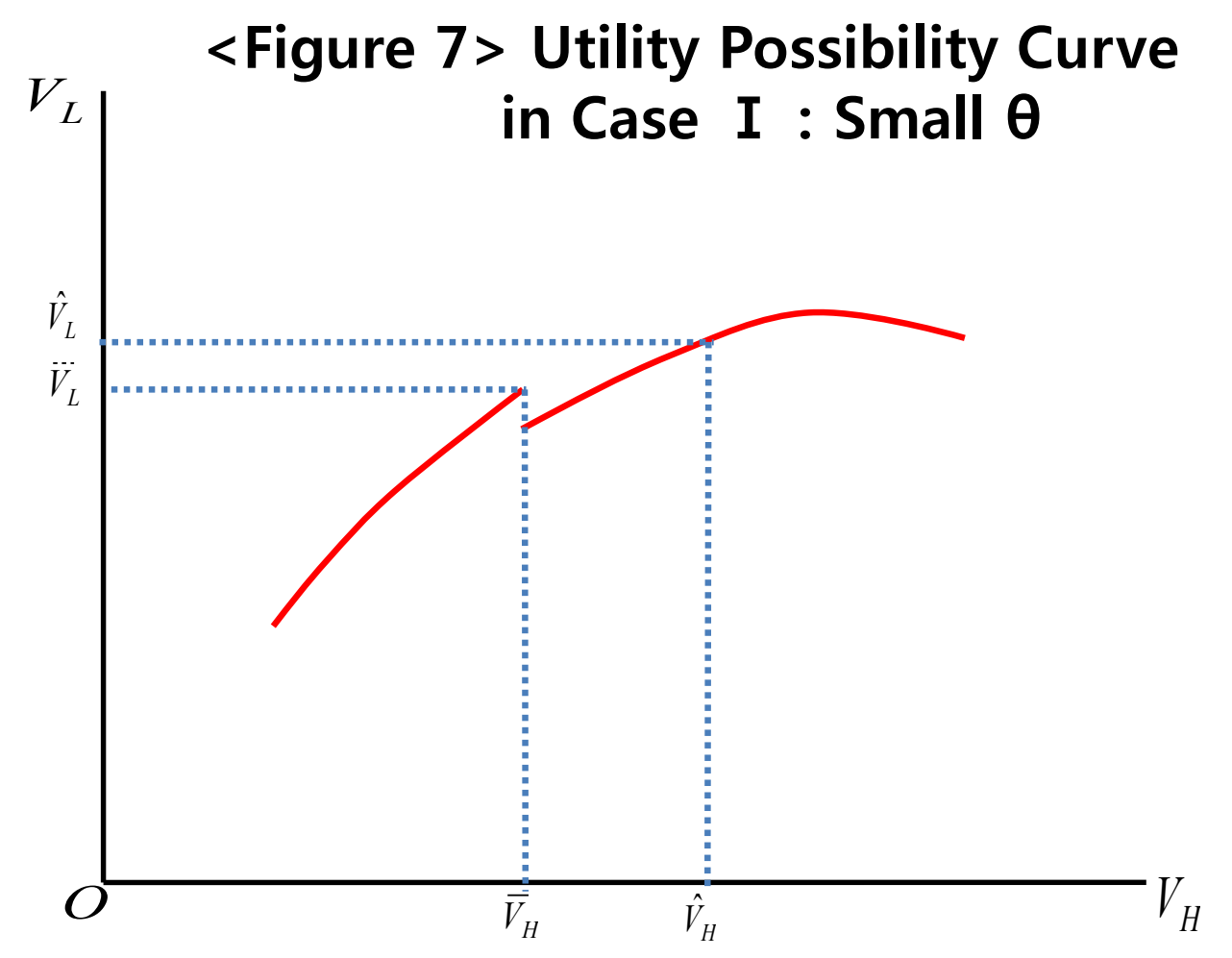


< Figure 8>

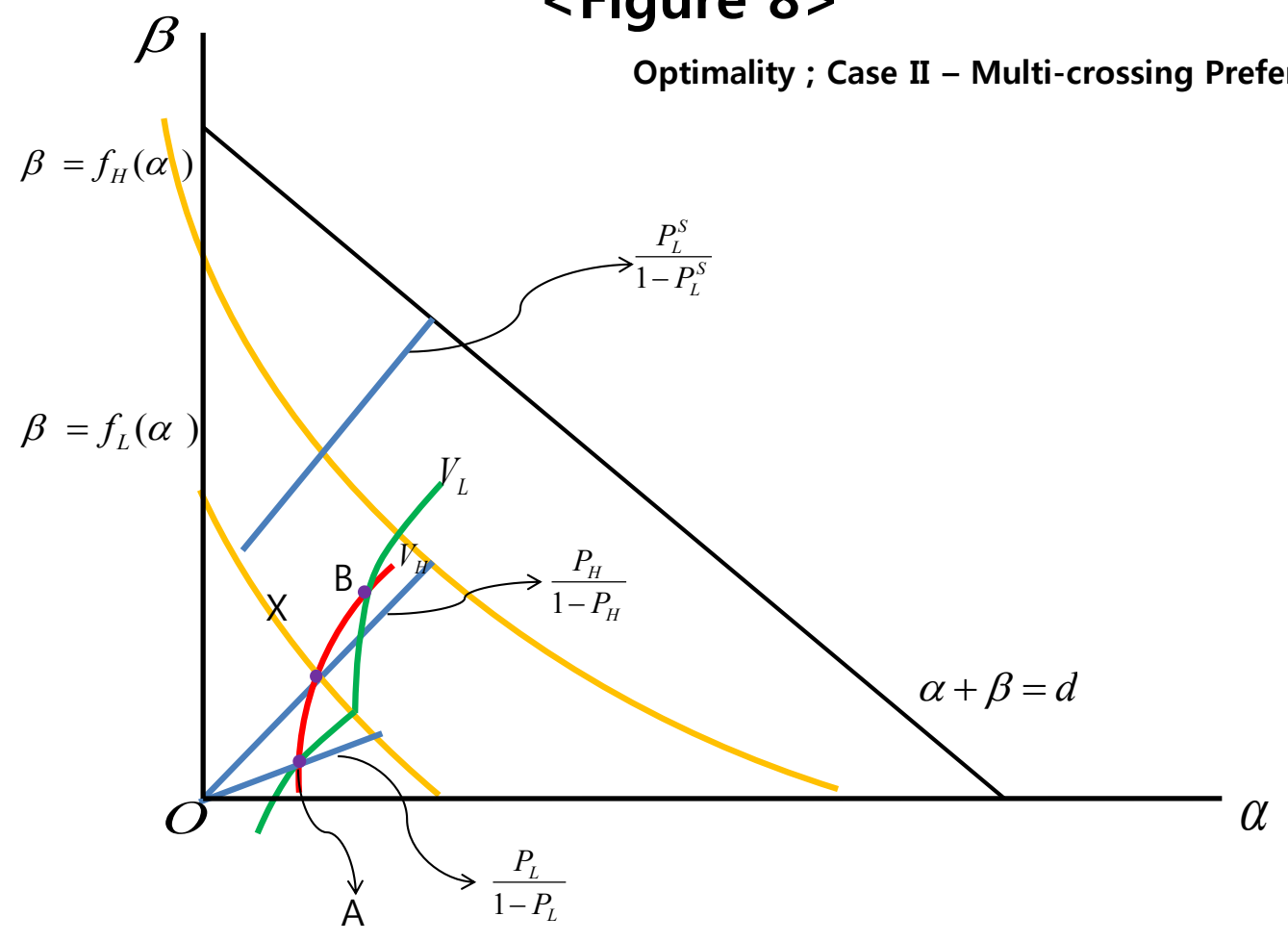

48 

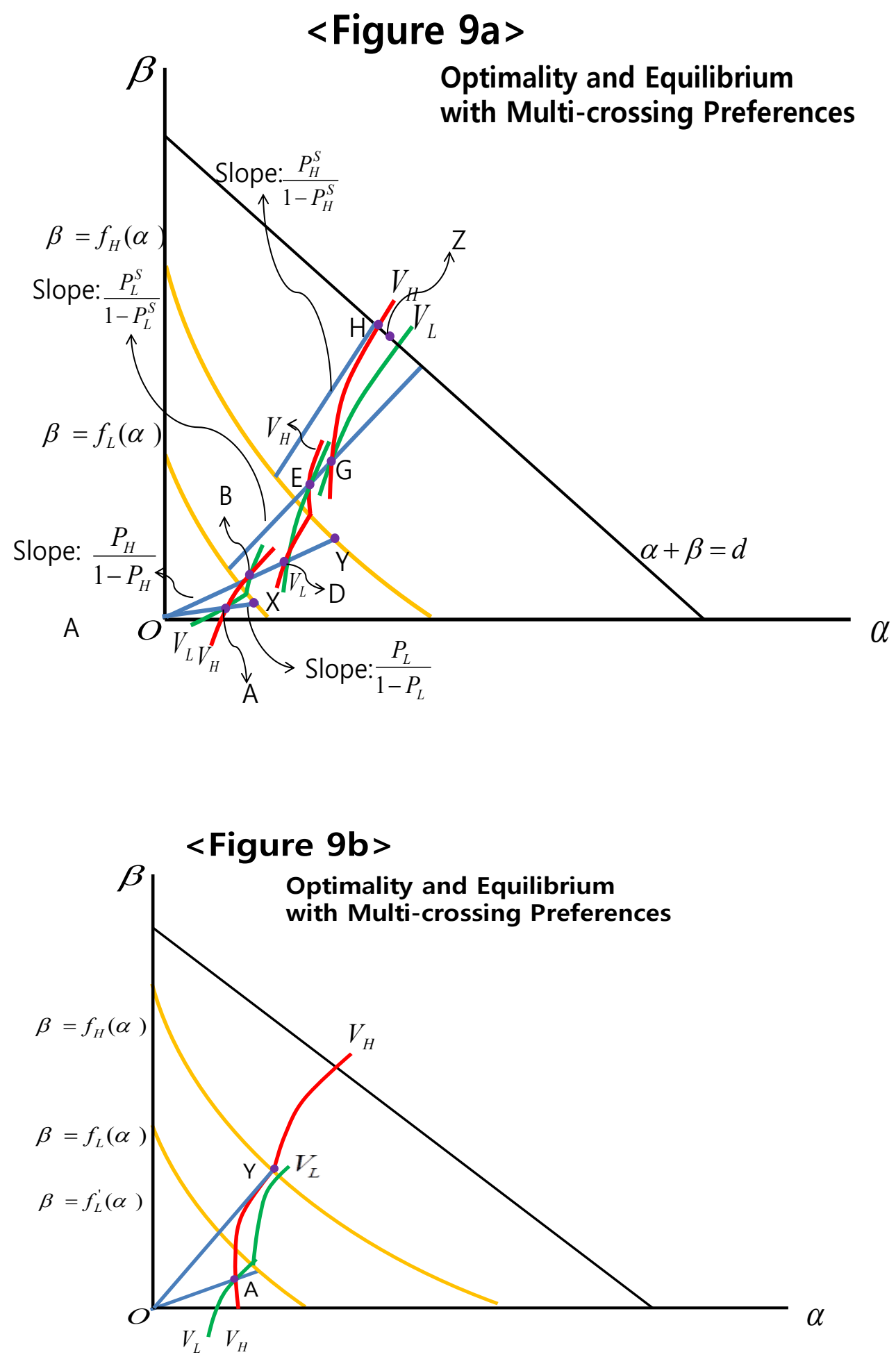

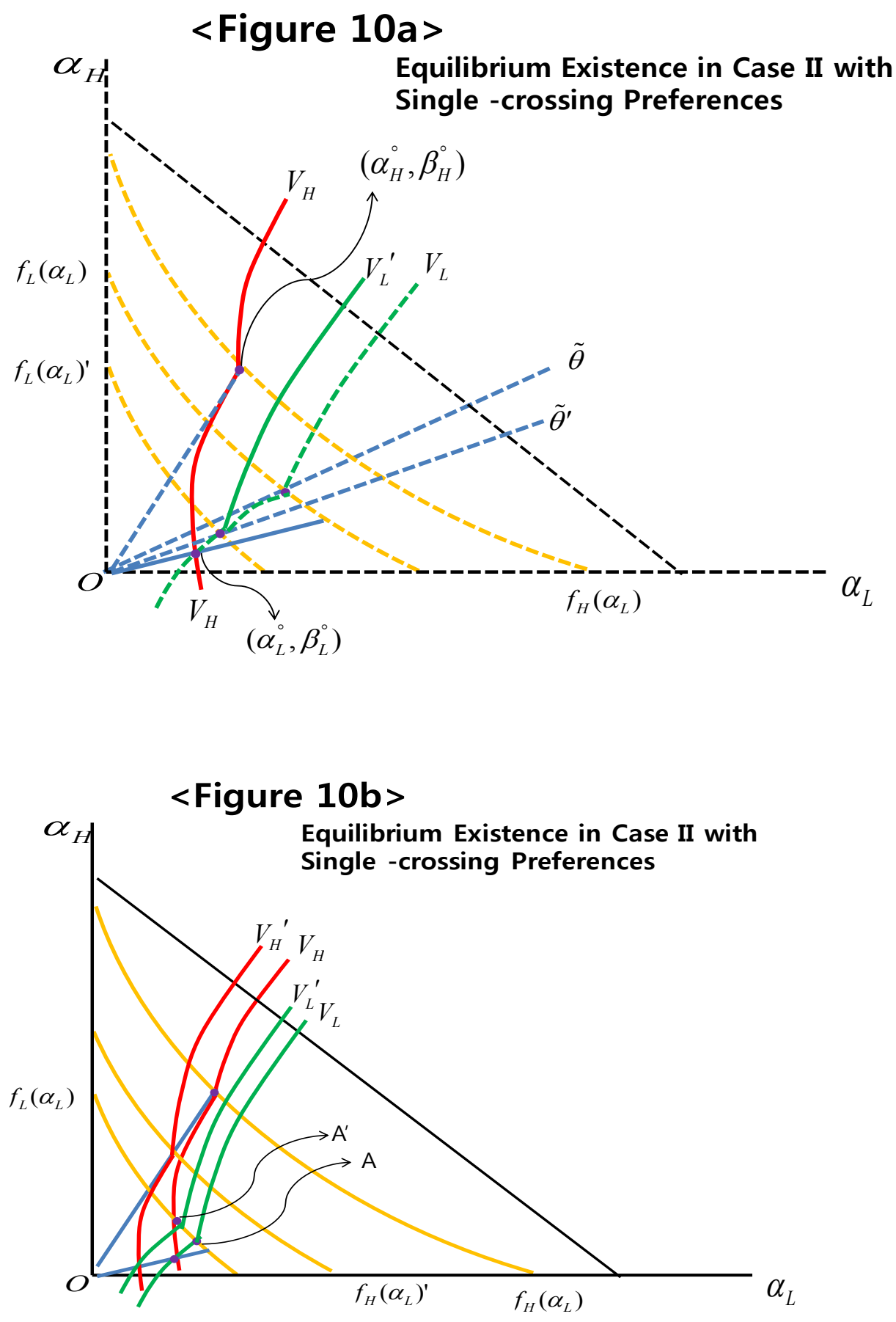


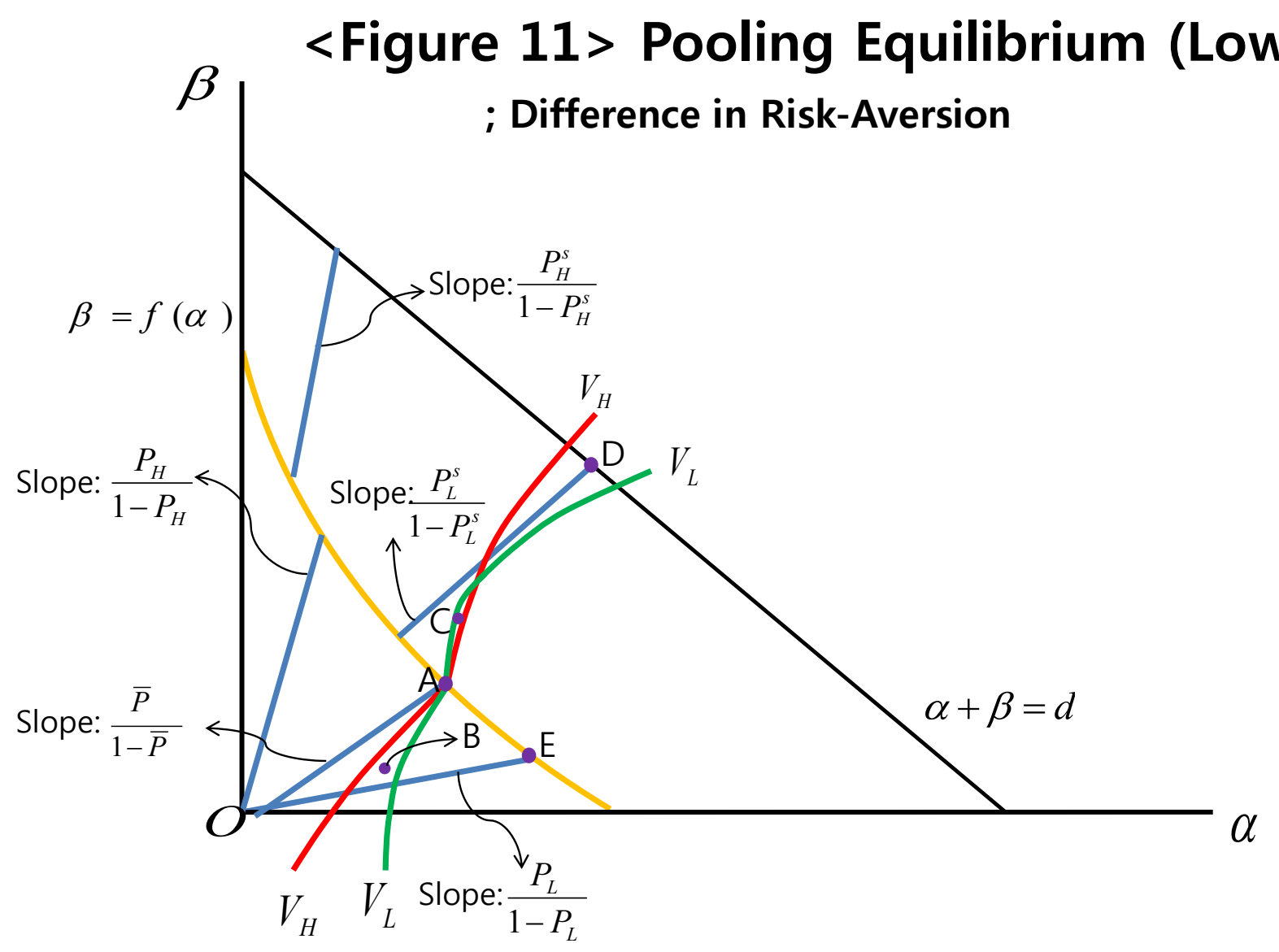




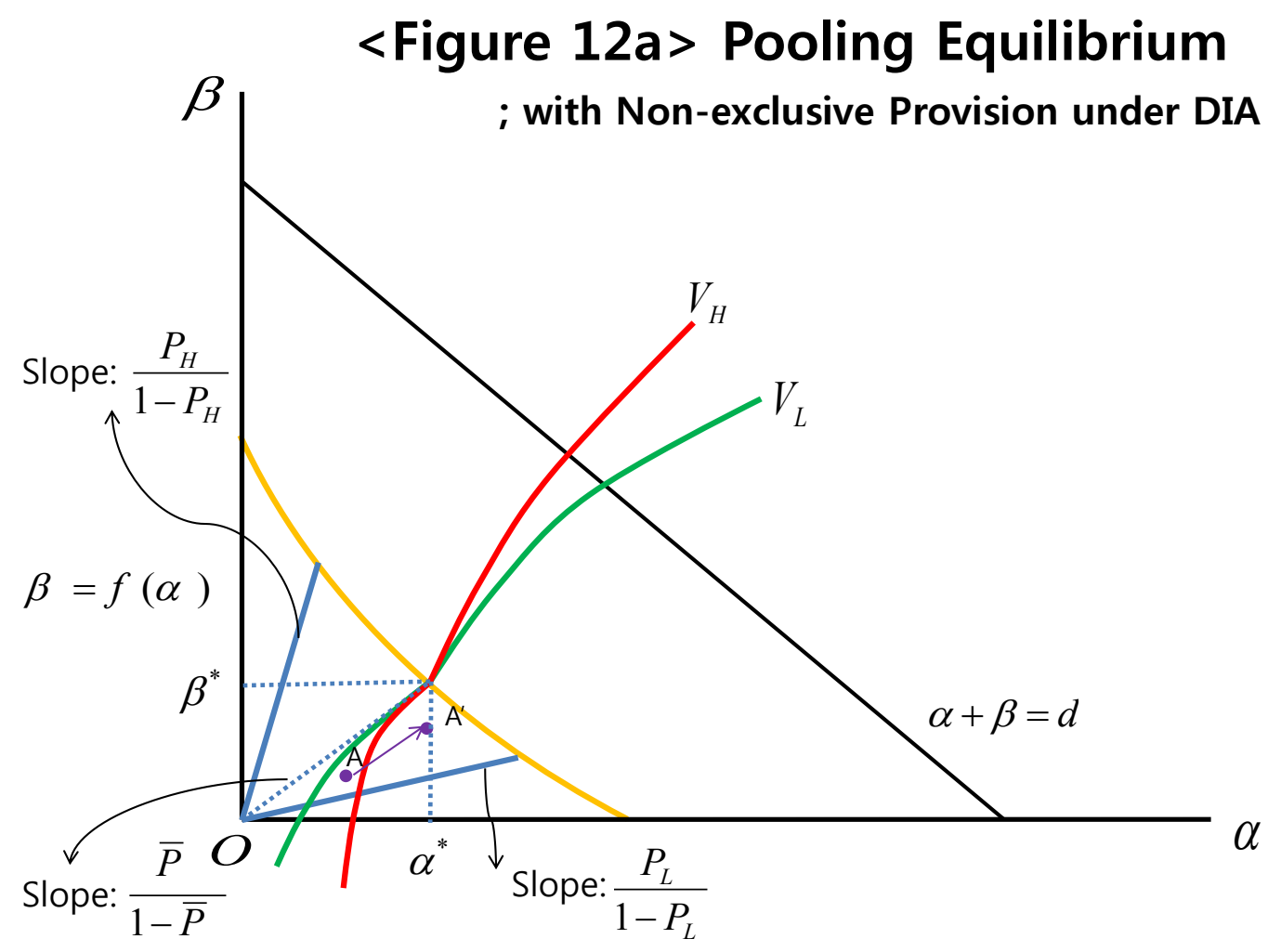




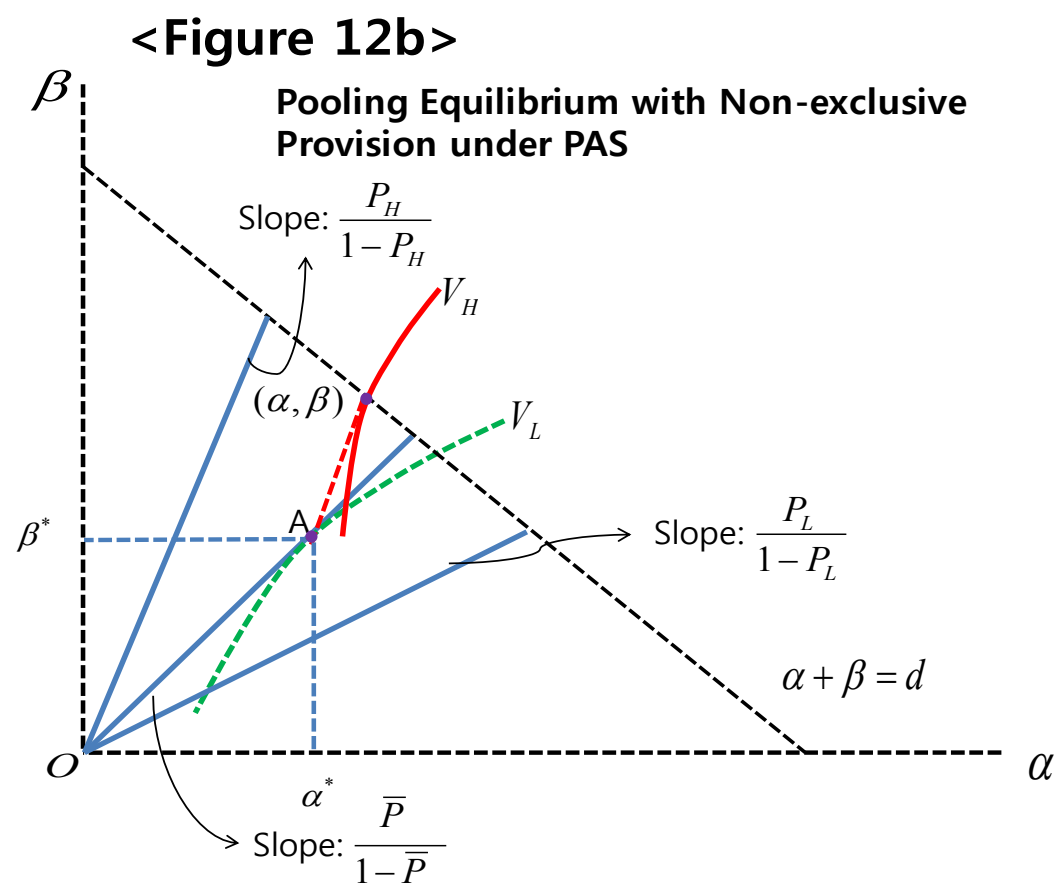

53 


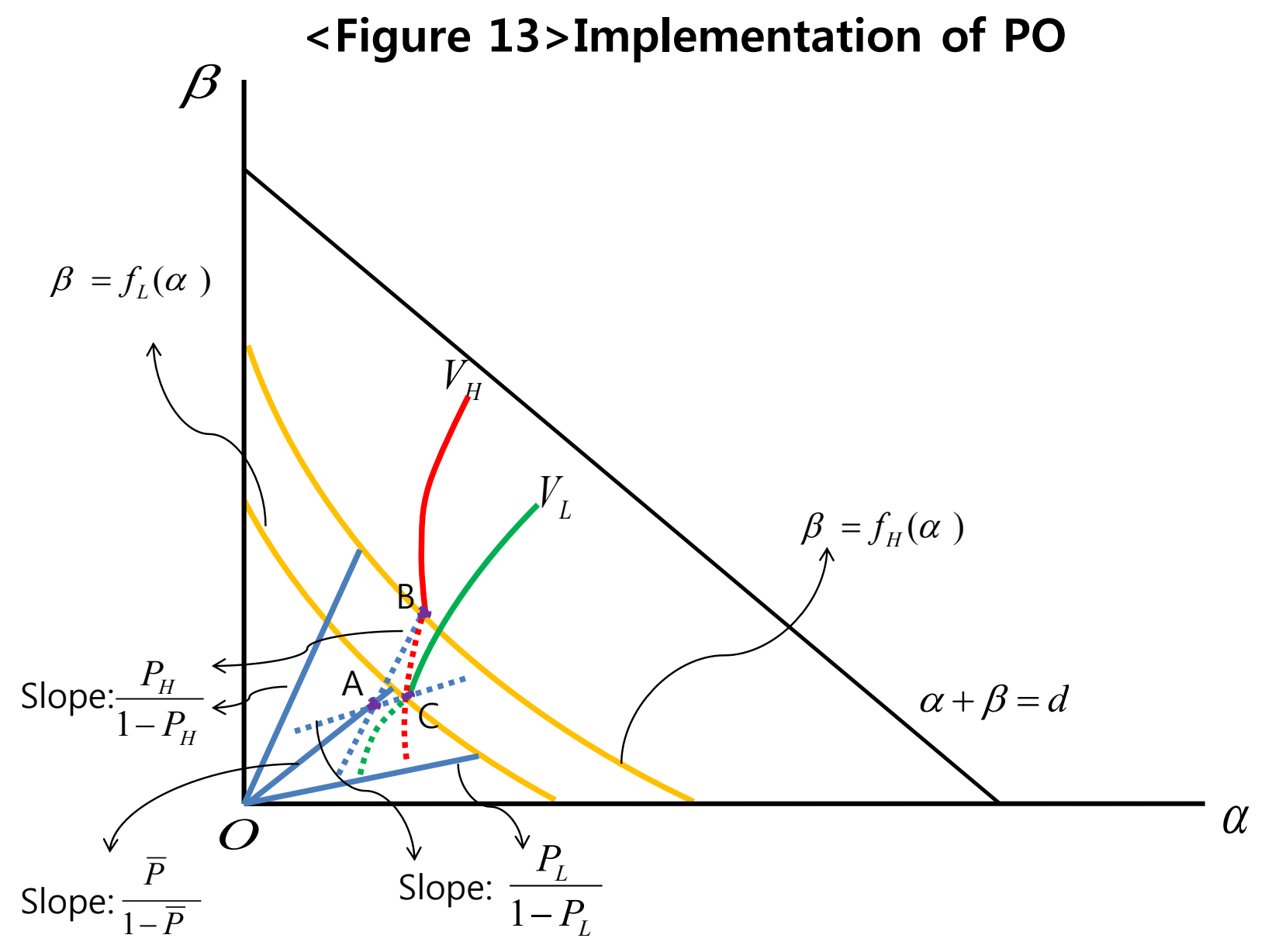

